Annuaire suisse de politique de développement

13 | 1994

Annuaire Suisse - Tiers Monde 1994

\title{
II. Négociations internationales
}

\section{René Longet}

\section{OpenEdition}

\section{Journals}

Édition électronique

URL : http://journals.openedition.org/aspd/1025

DOI : $10.4000 /$ aspd. 1025

ISSN : 1663-9669

\section{Éditeur}

Institut de hautes études internationales et du développement

\section{Édition imprimée}

Date de publication : 1 janvier 1994

Pagination : $13-94$

ISSN : 1660-5934

\section{Référence électronique}

René Longet, « II. Négociations internationales », Annuaire suisse de politique de développement [En ligne], 13 | 1994, mis en ligne le 03 décembre 2012, consulté le 10 décembre 2020. URL : http:// journals.openedition.org/aspd/1025; DOI : https://doi.org/10.4000/aspd.1025

Ce document a été généré automatiquement le 10 décembre 2020.

(C) The Graduate Institute | Geneva 


\title{
II. Négociations internationales
}

\author{
René Longet
}

\section{Relations financières internationales}

\subsection{Dette extérieure des pays en développement}

1 Pour certains milieux, la crise de l'endettement serait quasiment résolue. Ainsi Lewis Preston, président de la Banque mondiale, déclarait en septembre 1992 devant ses gouverneurs d'Amérique latine et des Caraïbes: "Dix ans après le début de la crise de l'endettement, nous pouvons à bon droit en célébrer la fin". L'endettement ne bloquait plus la croissance et le développement de l'Amérique latine ${ }^{(1)}$. Il est vrai que, à la suite des réformes entreprises au cours des années 80 , certains pays d'Amérique latine ont commencé à consolider leur situation économique. Le flux net des capitaux dans la région est à nouveau positif. Une partie des capitaux en fuite regagnent la région. En 1992, après une longue abstention, les banques privées ont octroyé de nouveaux crédits. On ne saurait en dire autant des pays africains. Au sud du Sahara, le niveau de la dette et le poids de son service opposent une résistance considérable au développement. Si ces pays honoraient toutes leurs obligations, $75 \%$ des revenus à l'exportation retourneraient au Nord au titre de service de la dette.

D'une manière générale, il convient de relativiser "la fin de la crise de l'endettement : la dette extérieure a été transférée des bailleurs privés à des institutions financières internationales (FMI, Banque mondiale, banques régionales de développement) ainsi qu'à des créanciers publics. Les dettes envers les institutions financières multilatérales ne sont pas négociables, ce qui signifie qu'elles ne seront ni remises, ni rééchelonnées. En 1991, un quart du service de la dette totale des pays en développement auprès de créanciers multilatéraux a été honoré.

L'OCDE ne considère pas pour autant que la crise soit résolue. Le volume cumulé de la dette extérieure de tous les pays en développement a, selon ses analyses, augmenté de 3 \% en 1992 pour passer à 1534 milliards de dollars, à 1664 milliards de dollars selon la Banque mondiale (voir tableau $n^{\circ} 4$ ). L'octroi de crédits bancaires privés qui s'élèvent 
en 1992 à 40 milliards de dollars se limite à quelques pays, avant tout le Mexique, le Brésil, l'Argentine, l'Inde, la Chine, l'Indonésie, le Koweït et l'Arabie Saoudite, et il s'agit en général de crédits à court terme. La majorité des pays en développement, en particulier les plus pauvres d'entre eux, n'avaient pas accès en 1992 à cette source de financement. Lors du sommet des sept principaux pays industrialisés à Tokyo, en juillet 1993, un projet de réduction de la dette des pays les plus pauvres soumis par la France et l'Angleterre, et qui proposait d'élargir les "conditions de Trinidad" a été rejeté, notamment par les Etats-Unis et le Japon. Pour résoudre la crise, ces deux pays misent avant tout sur la politique du Fonds monétaire international (FMI) et proposent d'améliorer les possibilités d'accès de pays en développement aux différentes "facilités" du FMI.

4 La Banque mondiale publie chaque année dans les "World Debt Tables" les statistiques de l'endettement extérieur des pays en développement. Les indications de la Banque mondiale et de l'OCDE concordent mal parce qu'elles reposent sur une classification des pays et sur des critères statistiques différents. Au cours de ces dernières années, les pays d'Europe de l'Est et de l'ex-Union soviétique ont été repris dans les différentes listes de ces institutions, si bien que, selon la Banque mondiale, l'endettement total s'en est trouvé augmenté d'environ 250 milliards de dollars

Tableau $N^{\circ}$ 4. L'endettement extérieur ${ }^{1}$

(en milliards de \$)

\begin{tabular}{|l|r|r|r|}
\hline & 1990 & 1991 & 1992 \\
\hline Endettement à long terme & 1213 & 1273 & 1309 \\
de source publique & 601 & 653 & 667 \\
de source privée & 612 & 620 & 642 \\
Endettement à court terme & 275 & 300 & 317 \\
Crédits du FMI & 35 & 38 & 38 \\
\hline Endettement cumulé & 1523 & 1611 & 1664 \\
\hline
\end{tabular}

Source :Word Debt Tables 1993-94

L'évolution de la crise de l'endettement

6 L'endettement international des pays en développement a crû de manière débridée au cours des années 70 pour atteindre son point critique en 1982, lorsque le Mexique s'est déclaré incapable d'en honorer le service, ce qui a déclenché la crise de la dette.

7 Ce n'est pas tant le montant de la dette extérieure des pays en développement qui était préoccupante que le poids croissant de son service, c'est-à-dire du règlement des intérêts et de son remboursement, ainsi que l'évolution négative des transferts nets de capitaux. Le rapport du service consenti de la dette aux revenus à l'exportation - le quota du service de la dette - a atteint son point culminant en 1986 avec une moyenne de $30 \%$ sur l'ensemble des pays en développement. Mais, dans certaines régions, le montant théoriquement dû était considérablement plus élevé, particulièrement en Afrique noire et dans certains pays d'Amérique latine. Ainsi, en 1992, le quota moyen du service de la dette des pays africains atteignait $31 \%$. Ce sont les pays en développement d'Asie qui, avec un record de $15 \%$ en 1986, puis de $8 \%$ en 
1991 et 1992, ont connu les quotas les plus faibles. L'Amérique latine et les Caraïbes se sont trouvées confrontées en 1986 à un quota de $46 \%$, lequel atteignit son point bas de 27 \% en 1990 pour remonter à 34 \% en 1992.

8 Pour de nombreux pays, en particulier les plus pauvres, le quota du service de la dette n'est qu'un chiffre théorique puisqu'ils sont économiquement incapables d'honorer leurs obligations. La Banque mondiale estime qu'un quota de $25 \%$ est économiquement supportable. L'incapacité momentanée ou durable de payer dans laquelle de nombreux pays en développement se sont trouvés a conduit au rééchelonnement régulier de la dette dans le cadre du Club de Paris pour les créanciers publics, et du Club de Londres pour les banques privées. Souhaitant redresser la situation, le secrétaire américain des finances Brady a proposé à la fin des années 80 un projet de réduction de la dette visant à obtenir que les 15 pays les plus endettés (en chiffres absolus) puissent "normaliser" leurs rapports avec les banques, c'est-à-dire, en particulier, avoir à nouveau accès au marché du crédit privé. On a prévu pour les pays les plus pauvres des "conditions de Toronto élargies" dégageant ces pays d'une partie de leur dette exigible.

\subsection{La dette extérieure des pays de l'Est}

9 Pour l'analyse de la dette extérieure des pays de l'Est, nous nous fondons sur les chiffres et la classification des pays utilisés par l'OCDE ${ }^{(2)}$. L'endettement brut des pays de l'Est s'élevait en 1992 à 195 milliards de dollars en devises convertibles. En 1991, il s'élevait à 183 milliards de dollars (voir tableau $n^{\circ}$ 5). Les engagements nets (dette brute moins avoirs auprès des banques occidentales) s'élevaient à 172 (162) milliards de dollars. Mais il faut signaler de grandes différences régionales dans ce groupe de pays. Ainsi, grâce à une généreuse remise que le Club de Paris lui a accordée pour des raisons politiques, la Pologne a pu réduire sa dette. Dans tous les autres pays, la dette a augmenté. La Hongrie, la Pologne et l'ex-Tchécoslovaquie ont réussi à abaisser leur quota du service de la dette en accroissant leurs exportations vers l'Ouest. Dans les autres pays de l'Est, les statistiques de la dette se sont dégradées. La Bulgarie a décrété en 1990 un moratoire sur le service de sa dette, ce qui a entrâné la capitalisation de ses arriérés et donc l'accroissement de sa dette sans apport de capitaux frais. La Roumanie est relativement peu endettée. On manque de données fiables sur la répartition de la dette de l'ex-Yougoslavie entre les Etats qui lui succèdent. Quant aux pays de l'exUnion soviétique, leur dette extérieure s'accroît considérablement, mais la situation légale doit encore être éclaircie. A quoi il faut ajouter une importante fuite des capitaux difficile à chiffrer.

Le flux des capitaux vers les pays de l'Est a atteint en 1992 de 8 à 9 milliards de dollars et a été financé pour plus de moitié par le FMI et la Banque mondiale. Seconde source en importance, les investissements étrangers directs ( $30 \%)$ se sont principalement concentrés sur la Hongrie et la Tchécoslovaquie. La contribution nette des banques d'affaires reste modeste. La Banque européenne de la reconstruction et du développement (BERD) a été fondée en 1991 pour soutenir le processus de reconversion et amorcer la nouvelle économie des pays de l'Est. Installée à Londres, cette banque est soutenue par 56 pays (dont la Suisse) qui ont réuni un capital de 18 milliards de francs. (La participation suisse est de 2,28\% du capital total, soit environ 410 millions de francs). 
Durant ses deux premières années de fonctionnement, on a reproché à la BERD la timidité avec laquelle elle soutenait les projets proposés par les pays de l'Est; on a également vivement critiqué la politique du personnel et les notes de frais somptuaires de son premier président, Jacques Attali. Au cours de ces deux années, la banque a consacré 440 millions de francs à sa propre installation et n'a investi que 220 millions de francs dans les pays de l'Est. Jacques Attali a dû démissionner. En août 1993, Jacques de Larosière, ancien directeur du FMI, lui succédait à la tête de la BERD. Lors de sa seconde assemblée annuelle, en avril 1993, la banque a reçu des pays membres le mandat explicite de consacrer à l'avenir une part significative de ses investissements au soutien des petites et moyennes entreprises des pays de l'Est. Elle doit en particulier travailler de manière plus décentralisée pour gagner en efficacité et accélérer ses procédures. La BERD doit donc agrandir ses bureaux dans les pays de l'Est. Elle a l'intention de consacrer au moins $60 \%$ du total de ses prêts à des projets privés.

\begin{tabular}{|l|r|r|}
\hline \multirow{2}{*}{} & \multicolumn{2}{|c|}{$\begin{array}{c}\text { Dette } \\
\text { milliards de \$ }\end{array}$} \\
\cline { 2 - 3 } & \multicolumn{1}{|c|}{$\mathbf{1 9 9 1}$} & \multicolumn{1}{|c|}{$\mathbf{1 9 9 2}^{\mathbf{1}}$} \\
\hline Albanie & 0,6 & 0,6 \\
Bulgarie 11,4 & 12,9 & \\
Ex-Tchécoslovaquie & 9,4 & 10,0 \\
Ex-Yougoslavie & 18,0 & 20,5 \\
Pologne & 48,4 & 45,5 \\
Roumanie & 1,6 & 2,9 \\
Ex-Union soviétique & 70,8 & 80,0 \\
Hongrie & 22,7 & 22,4 \\
\hline Pays de l'Est au total & 182,9 & 194,8 \\
\hline
\end{tabular}

Tableau $\mathrm{N}^{\circ}$ 5. Endettement des pays de l'Est

Note1 $^{2}$

Sources: Wifo/NZZ, 12.2.1993.

\subsection{Fonds monétaire international}

13 A la fin 1992, et après des années de négociation, le Fonds monétaire international a pu obtenir sa neuvième augmentation de capital. Cette augmentation est allée de pair avec une nouvelle répartition des quotas nationaux. Au cours de son dernier exercice, le Fonds a été très occupé par le montage des premiers crédits accordés aux pays de l'Est, dont étaient encore exclus la majorité des Etats de l'ex-Union soviétique pour lesquels seul un soutien technique pouvait être envisagé. Les premiers pays à recevoir une aide financière furent la Russie et le Kirghizistan. La Suisse est devenue membre du FMI en 1992 et dispose d'un siège à son Conseil d'administration. Elle dirige un groupe de pays composé de la Pologne et de cinq Etats d'Asie centrale: I'Azerbaïdjan, le Turkménistan, l'Ouzbékistan, le Tadjikistan et le Kirghizistan.

\subsubsection{La politique du FMI}

14 Augmentation du capital 

pays en cours de réforme ne satisfont pas encore les conditions "normales" que le FMI pose à son aide financière, et pourtant les besoins en capitaux sont importants et urgents. Le FMI soutient le processus de réforme en accordant tout d'abord son aide technique sous forme de conseils. Pour l'aide financière, le FMI s'est doté en avril 1993 d'un nouvel instrument, l'aide à la transition systémique (Systemic transformation facility, STF) qui tient 6 milliards de dollars à la disposition des pays de l'Est, à des conditions simplifiées. En mai 1993, le FMI octroyait un premier crédit de ce type au Kirghizistan. Le principal client de la STF devrait cependant être la Russie qui, en raison de ses quotas, s'est vu accorder un droit de tirage de 3 milliards de dollars. En 1992, la Russie avait obtenu du FMI une première tranche de crédit d'un montant de 1 milliard de dollars. En raison de la lenteur des réformes, le FMI n'a pas accordé de nouvelles tranches à ce pays

21 Les besoins en capitaux dépassent de loin les moyens immédiats de la STF. C'est pourquoi le FMI envisage, comme solution à long terme, une nouvelle allocation de droits de tirages spéciaux (DTS). Ce serait la première création de nouveaux DTS depuis la fin des années 70 , alors que les pays en développement en ont vainement réclamés tout au long de cette période. Il s'agit d'une décision politique très contestée. Les nouveaux droits de tirage doivent être accessibles à tous les pays, y compris aux pays en développement. 

réforme économique, le FMI a créé en 1987 la Facilité d'ajustement structurel renforcée (FASR) permettant aux pays les plus pauvres d'obtenir des crédits à des conditions avantageuses comparables à celle de l'AID, soit à un taux de 0,5\% et une échéance de dix années dont cinq exemptées de remboursement. Sans ce dispositif, bien des pays d'Afrique noire ne pourraient plus obtenir de crédits du FMI. Les moyens mis à la disposition de la FASR (en gros 7 milliards de dollars) ne filtrent que lentement car les gouvernements des pays les plus pauvres ne sont souvent pas à même de satisfaire les conditions posées par le FMI. Lors de la session annuelle de 1992, la FASR a été prolongée d'une année. Certains pays industrialisés se sont opposés à cette prolongation, arguant que les FASR concurrençaient inutilement l'AID. dans une lettre d'intention signée par le pays bénéficiaire et le FMI. Depuis quelques temps, le souci du développement social et, avec lui, des droits de l'homme, est venu s'ajouter aux critères purement économiques du modèle de développement naguère dominant. L'octroi de crédits par le FMI n'est pas encore directement lié au respect des droits de l'homme, mais le cas du Pérou illustre l'évolution en cours. En 1986, ce pays a perdu droit aux crédits du FMI pour avoir décrété unilatéralement un moratoire sur le service de sa dette. En 1990, le gouvernement a révoqué ce moratoire et a participé à un programme de réforme économique du FMI. Les arriérés accumulés pendant le moratoire ont été réglés par une communauté internationale de donateurs (dont le Japon, les Etats-Unis et la Suisse). Mais ces donateurs ont fait pression sur le gouvernement de Lima pour qu'il respecte les droits de l'homme et ouvre ses prisons aux visites du CICR. Ecrasé par une dette de 22 milliards de dollars, le Pérou a partiellement cédé à cette pression politique pour avoir de nouveau accès au FMI et aux marchés internationaux des capitaux.

\subsubsection{Position de la Suisse ${ }^{(3)}$}

La Suisse est représentée depuis novembre 1992 au Conseil d'administration du FMI, par Daniel Kaeser, du Département des finances. Quant au Conseil des gouverneurs, le plus important des organes directeurs, qui définit lors de la session annuelle les grandes orientations du FMI, c'est le conseiller fédéral Otto Stich qui y représente la Suisse. L'application pratique des décisions du Conseil des gouverneurs et les décisions en matière d'aide financière échoient aux 24 membres du Conseil d'administration qui 
représentent chacun un pays ou un groupe de pays : 12 pour les pays industrialisés, 11 pour les pays en développement et 1 pour l'Europe de l'Est. La Suisse représente un groupe de pays comprenant la Pologne, ('Azerbaïdjan, le Turkménistan, l'Ouzbékistan, le Tadjikistan et le Kirghizistan. En avril 1993, une délégation dirigée par le conseiller fédéral Otto Stich se rendait dans les pays d'Asie centrale membres du même groupe que la Suisse "pour y renforcer les liens de confiance". C'est au Kirghizistan que le processus de réforme est le plus avancé ; son programme économique a su convaincre le FMI. Ce pays a été le premier à recevoir une aide financière de la nouvelle aide à "la transition systémique". A l'issue de ce voyage, la Suisse a conclu avec l'Ouzbékistan un accord de protection des Investissements. Il est probable que ces républiques d'Asie centrale jouent un rôle important dans l'octroi de l'aide au développement pour les pays de l'Est prévue par le second crédit-cadre.

La Suisse soutient en principe la politique du FMI dans les pays en développement. Elle considère que les programmes de réforme structurelle posés par le FMI comme condition à toute aide financière constituent bien la base d'une croissance économique de longue durée dans le Tiers Monde. Cependant, lors de la session annuelle de 1992, Otto Stich a insisté pour que tous les pays fassent preuve de discipline budgétaire, les pays industrialisés compris, et réduisent leur propre endettement.

La Commission mixte consultative sur la coopération au développement et l'aide humanitaire, qui conseille le Conseil fédéral en matière de politique du développement, a reçu le mandat supplémentaire de le conseiller sur les questions relatives à la politique du FMI et de la Banque mondiale. Elle s'est dotée à cette fin d'un comité présidé par Lilian Uchtenhagen (Comité Uchtenhagen).

31 La Communauté de travail des œuvres d'entraide et la Déclaration de Berne suivent de près la politique de la Suisse dans les organes directeurs du FMI et de la Banque mondiale. Elle a ouvert un bureau à Washington et entretient des liens étroits avec les organisations non gouvernementales qui suivent la politique de ces institutions. La Déclaration de Berne et Greenpeace informent régulièrement les lecteurs de leur bulletin Inside Out de la politique et de la conduite du FMI et commentent la position de la Suisse de manière critique. Elles présentent également des propositions sur certaines questions concrètes et veillent, avec les œuvres d'entraide, au respect des promesses faites au cours de la campagne ayant précédé la votation sur l'adhésion de la Suisse au FMI et à la Banque mondiale : la Suisse doit respecter au FMI les principes qui servent de base à sa propre politique du développement. Les œuvres privées d'entraide attendent en particulier des représentants de la Suisse qu'ils encouragent au sein du FMI et de la Banque mondiale les réformes permettant aux pays en développement d'accroître leur influence sur ces institutions. La nouvelle répartition des DTS devrait, entre autres choses, permettre aux pays africains endettés de se désendetter.

Proposition de la Communauté de travail pour la révision du droit de vote

Depuis sa création, le FMI n'a jamais modifié les principes régissant le droit de vote. Chaque pays dispose de 250 voix de base plus un nombre de voix correspondant à sa quote-part au capital. Ensemble, elles constituent sa part de voix. En revanche, le poids des voix a changé. L'influence relative des pays en développement a diminué et leur marginalisation se poursuit. En 1970, ils étaient 93 et disposaient de $37 \%$ des voix. En 1993, ils étaient 135 et disposaient de $34 \%$ des voix. C'est ce que souligne Richard Gerster, directeur de la Communauté de travail Swissaid/Action de Carême/Pain pour le Prochain/Helvetas/Caritas ${ }^{(4)}$. Il demande une réforme du droit de vote revalorisant 
les voix de base d'un facteur vingt, par analogie avec la multiplication par vingt du capital depuis 1944. Les pays en développement disposeraient alors de $49 \%$ des voix (voix de base plus voix de quote-part). Regroupant $80 \%$ de la population mondiale, ils seraient mieux représentés et pourraient mieux se faire entendre lors de l'élaboration des programmes d'ajustement structurel dont leurs populations portent le poids, et qui devraient conduire à un développement durable au sens économique, social, politique et écologique du terme.

Consultations du FMI sur la politique économique suisse

Conformément à l'article 4 de ses statuts, le Fonds monétaire examine chaque année la politique monétaire et économique de ses pays membres. La Suisse a été l'objet d'un premier examen en octobre 1993. Les rapports sont ensuite examinés par le Conseil d'administration du FMI. A l'occasion de ces consultations, la Communauté des œuvres suisses d'entraide a pu présenter aux représentants du FMI les mesures de politique du développement qu'elle préconise pour soutenir les efforts de réforme des pays en développement, soit, entre autres, l'élargissement de l'aide juridique internationale, la réduction des subventions aux exportations et autres obstacles commerciaux, une politique étrangère non discriminatoire ainsi que le renforcement de l'aide au développement.

\subsection{Groupe de la Banque mondiale 1.4.1. Politique de la Banque mondiale}

\subsubsection{Politique de la Banque mondiale}

Le groupe de la Banque mondiale, qui comprend la Banque mondiale et l'AID, a accordé au cours de son exercice 1992/93 des crédits pour un montant record. Une part importante de ces crédits sont allés à des pays de 'Est dont certains ont ainsi profité pour la première fois de cette source de financement. Par contre, les pays africains ont obtenu sensiblement moins que l'année précédente. Il ressort d'un rapport interne sur la qualité des crédits qu'un tiers de tous les projets doivent être considérés comme des échecs. Diverses propositions de réévaluation des critères d'octroi ont donc été présentées. La Banque mondiale a été notamment critiquée pour sa participation au gigantesque projet de barrage dans la vallée du Narmada, en Inde, projet dont elle s'est retirée au cours de cet exercice. La Suisse est membre de la Banque mondiale depuis 1992 et a obtenu, tout comme au FMI, un siège à son Conseil d'administration. Les œuvres suisses d'entraide et les organisations de développement suivent avec une attention particulière le travail de la Suisse dans le groupe de la Banque mondiale.

Le groupe de la Banque mondiale comprend, au sens strict, la Banque mondiale (Banque internationale de la reconstruction et du développement, BIRD) et l'AID (Association internationale de développement), institutions qui accordent des crédits aux gouvernements des pays en développement. Souhaitant également soutenir le secteur privé, la Banque mondiale a créé en 1956 la Société financière internationale SFI (International Finance Corporation, IFC) et, au cours des années 80, l'Agence multilatérale de garantie des investissements AMGI (Multilatéral Investment Guarantee Association, MIGA) qui accordent des crédits au secteur privé ou garantissent des investissements privés.

Montant record des crédits 

1993 des crédits pour un montant record de 23,7 milliards de dollars, contre 21,7 l'année précédente. La Banque entre dans ce chiffre pour 16,9 milliards, l'AID pour 6,8. En ventilant les chiffres par région, on constate que cette augmentation est due avant tout l'octroi de crédits aux pays de l'Est, lesquels ont obtenu en tout 3,9 milliards de dollars (2,1 l'année précédente). Les républiques d'Asie centrale classées pays en développement que sont l'Ouzbékistan, le Kazakhstan, le Kirghizistan et $\Gamma$ Azerbaïdjan ont droit aux prêts de l'AID.

L'Afrique a reçu, avec 2,8 milliards de dollars de nouveaux prêts, 1,2 milliards de moins que l'année précédente (4 milliards). La Banque justifie cette réduction par le recul des crédits à la balance des paiements (crédits rapidement disponibles). Elle favorise actuellement les crédits de projet s'étendant sur de plus longues périodes. La politique d'ajustement structurel poursuivie en Afrique par la Banque mondiale et le FMI ne serait pas, selon plusieurs critiques, adaptée aux données locales. L'organisation britannique d'entraide Oxfam va jusqu'à exiger le retrait de la Banque mondiale et du FMI de ce continent. Les réformes économiques auraient échoué dans la majeure partie des pays africains, et leur coût social y serait considérable ${ }^{(5)}$. La Communauté de travail des œuvres suisses d'entraide exige pour sa part que la Banque mondiale renforce son engagement en Afrique.

41 Retrait du projet de barrage sur le Narmada

L'Inde a commencé en 1987 la construction d'un gigantesque projet d'irrigation dans la vallée du Narmada. La Banque mondiale s'y était associée en promettant une participation de 450 millions de dollars (le coût total est estimé à 3 milliards de dollars). Ce projet a été vivement controversé dès le début en raison de son coût social et écologique. Soumise à de nombreuses pressions, la Banque mondiale exigeade l'Inde qu'elle revoie sa politique en matière de déplacement des populations et de protection de l'environnement. En avril 1993, incapable de respecter ces directives dans les délais impartis, l'Inde renonçait à l'appoint de la Banque mondiale.

Plusieurs organisations suisses de développement ont instamment prié le Conseil fédéral de plaider au Conseil d'administration le retrait de la Banque mondiale du projet de barrage sur le Narmada. La Commission consultative sur la coopération au développement et l'aide humanitaire (Commission Nebiker), qui conseille le Conseil fédéral en matière de politique de développement, s'est également occupée de ce dossier. Elle avait proposé que la Suisse ne soutienne le projet que si les conditions de protection de l'environnement et des populations locales posées par la Banque mondiale étaient effectivement respectées.

\section{Rapport Wapenhans}

45

La Banque mondiale fait périodiquement la une des journaux en finançant des projets controversés. Pour mieux pouvoir répondre aux critiques, elle a confié une étude interne de sa pratique du crédit à son ancien vice-président, Willi Wapenhans. Le Rapport Wapenhans conclut qu'une grande part des crédits de la Banque mondiale ont abouti à des échecs. La part des projets jugés satisfaisants est tombée de 85 à $63 \%$ entre 1981 et 1991. Il recommande une série de réformes dont, en particulier, le renforcement de la surveillance du déroulement des projets. D'autre part, les projets ne doivent plus être poursuivis de manière isolée, mais dans le cadre d'une stratégie nationale globale. Cette analyse a provoqué l'interruption de plusieurs projets au Brésil,

Annuaire suisse de politique de développement, 13 | 1994 
en Inde, au Nigeria et en Turquie. Par ailleurs, les associations privées telles que les organisations de développement ou de protection de l'environnement doivent pouvoir faire opposition aux projets envisagés.

La Communauté de travail des œuvres d'entraide a déclaré, dans une prise de position sur les propositions de réforme de la Banque mondiale, que le Rapport Wapenhans devrait également servir de base à une analyse fouillée et à un travail de relations publiques au sein des organisations non gouvernementales, lesquelles devraient soumettre à leurs délégués au Conseil d'administration des propositions de réforme plus poussées. Il faudrait de surcroît envisager une participation de la Banque mondiale aux risques associés aux projets qu'elle finance.

Rapport sur le développement dans le monde : la santé

Le rapport de la Banque mondiale sur le développement dans le monde met chaque année l'accent sur un thème particulier. Le rapport 1992 traite de manière critique- en étroite collaboration avec l'Organisation mondiale de la santé - des conquêtes et des lacunes de la santé publique dans le Tiers Monde. Quelques succès décisifs ont été enregistrés en la matière au cours des quatre dernières décennies. La mortalité infantile a décru de deux tiers ; l'espérance de vie dans les pays en développement est passée de 40 ans en 1950 à 63 ans aujourd'hui ; diverses maladies, comme la variole, ont été pratiquement éradiquées par des campagnes mondiales de vaccination. Le bilan sanitaire présenté par les auteurs de ce rapport sur le développement dans le monde n'en reste pas moins critique. Une grande part de l'argent alloué est gaspillé ou consacré à des projets de prestige profitant aux classes privilégiées.

La Banque mondiale préconise quelques mesures simples pour améliorer la santé publique dans les pays en développement. Les gouvernements doivent avant tout garantir les soins de base destinés à toutes les couches de la population, créer des structures décentralisées (cliniques régionales, dispensaires...) et soutenir la formation des femmes et des jeunes filles, lesquelles, en dernière analyse, se chargent des soins au sein des familles. Les principaux problèmes qui se posent à la santé publique des années à venir sont: le vieillissement de la population, le sida, la résistance croissante de nombreux agents infectieux et, de manière systématique, la persistance de la pauvreté.

La Banque mondiale encourage les gouvernements à favoriser la concurrence dans le domaine de la santé; elle y voit une garantie d'efficacité et d'économie. Le rapport précise toutefois que le secteur privé de la santé doit être réglementé par l'Etat de manière à assurer les soins de base pour toute la population. Cela soulèvera bien des problèmes, la couverture par les assurances dans les pays en développement étant notoirement insuffisante et les gouvernements n'étant généralement pas en mesure de contrôler efficacement l'offre privée dans ce secteur.

La dixième augmentation du capital de l'AID

52 En décembre 1992, les pays donateurs de l'AID ont convenu d'augmenter le capital de leur association à 13 milliards de DTS(18,5 milliards de dollars). Participation de la Suisse : 470 millions de francs. Cette augmentation élargit la marge d'action de l'AID qui accorde des crédits concessionnels aux pays les plus pauvres, mais la liste des pays preneurs de crédits auprès de l'AID s'est également rallongée (pays en développement d'Asie centrale). Les "pays mixtes" (pouvant prétendre à des crédits de la Banque mondiale et de l'AID) que sont l'Inde et la Chine, devront probablement renoncer à épuiser "leurs" crédits AID. 

Daniel Gerber, de l'office fédéral des affaires économiques extérieures. Les organisations suisses de développement suivent avec attention la politique de la Suisse au sein de cette institution (comme au sein du FMI). Elles essaient de l'infléchir dans un sens favorable aux préoccupations des pays en développement et de lui faire respecter les grands principes de la politique suisse du développement. Banque mondiale Dans leur publication Inside-Out IWF, Weltbank und die Schweiz (le FMI, la Banque mondiale et la Suisse), la Déclaration de Berne et Greenpeace Suisse lui demandent de faire preuve de plus de transparence et de présenter les plans de projets plus tôt. Le fait de pouvoir accéder très tôt et de manière complète aux informations est l'une des conditions importantes de participation locale aux projets de développement, et donc à leur succès, comme le mentionne d'ailleurs la Banque mondiale dans son projet de réforme. Les organisations suisses de développement exigent que les études d'impact social et écologique soient systématiquement publiées. D'autre part, la Confédération est priée de défendre fermement les réformes proposées par le rapport Wapenhans. Elle doit en particulier soutenir la création d'une instance de recours indépendante et de mécanismes indépendants d'évaluation des projets présentant certains risques. Réunis en septembre 1993, les directeurs exécutifs ont discuté et accepté ces propositions d'initiatives de la Suisse.

Le Fonds international de protection de l'environnement de la Banque mondiale a également fait l'objet de critiques. On en abuserait pour réparer les dégâts écologiques 
provoqués par les projets de la Banque mondiale. La Déclaration de Berne et la Communauté de travail des œuvres d'entraide exigent que la Suisse fasse le nécessaire pour que ce fonds dispose d'un secrétariat indépendant de celui de la Banque mondiale.

\subsection{Session annuelle 1993 du FMl et de la Banque mondiale}

59 C'est en automne que le Fonds monétaire international et la Banque mondiale tiennent conjointement leur session annuelle. La session 1993 s'est déroulée du 27 au 30 septembre 1993 à Washington. Thème principal: la relance de la conjoncture mondiale. Sujets abordés: la récession dans les pays industrialisés, l'effort de réforme dans les pays de l'Est ainsi que le succès économique de certains pays en développement d'Asie et d'Amérique latine. En ce qui concerne les pays subsahariens, le FMI et la Banque mondiale ont demandé à leurs pays créanciers de renoncer à une partie de leurs créances.

Lors de leurs deux précédentes sessions annuelles, le Fonds monétaire international et la Banque mondiale s'étaient surtout concentrés sur les problèmes des pays de l'Est. La session de 1993 a de nouveau été l'occasion de rappeler l'importance cruciale du financement du processus de réforme en cours dans ces pays ; et de reconnaître que les "difficultés institutionnelles" y opposent bien des obstacles. Le débat sur la relance de l'économie mondiale a beaucoup occupé les participants. Il a débouché sur une série d'appels aux gouvernements pour qu'ils concluent positivement les négociations du GATT de l'Uruguay Round. La récession des pays industrialisés augmenterait la menace du protectionnisme, lequel désavantage les pays en développement qui s'efforcent de libéraliser leurs marchés. Les gouvernements doivent tirer le meilleur parti de leur marge de manœuvre pour adopter des mesures d'impulsion économique et, en particulier, procéder à une nouvelle réduction des taux d'intérêt.

La session du FMI et de la Banque mondiale est un événement important pour les ministres des finances et du développement des pays membres. Si l'on y inclut les réunions de préparation des groupes de pays (Groupe des Dix, Groupe des 24) et des comités (Comité intérimaire, Comité de développement), elle dure en gros une semaine. En 1993, la Suisse y était représentée par le conseiller fédéral Otto Stich (Département fédéral des finances), le président de la Banque nationale Markus Lusser (FMI) et le secrétaire d'Etat Franz Blankart, directeur de l'office fédéral des affaires économiques extérieures.

\section{Aucune nouvelle attribution de droits de tirage spéciaux}

Les droits de tirage spéciaux (DTS) sont des octrois de crédit par le FMI. Ils peuvent être utilisés comme moyen de paiement entre membres. Les DTS sont créés et attribués "gratuitement", c'est-à-dire sans paiement préalable, au prorata de la quote-part des pays. Leur fonction est d'augmenter les réserves de devises. Ils présentent une importance particulière pour les pays aux réserves de devises limitées. La création de DTS relève du Conseil des gouverneurs, lequel, en cette matière, doit décider à la majorité de $85 \%$. De nombreux pays en développement, soutenus par le directeur du FMI Camdessus, ont revendiqué la création de nouveaux DTS. La question a été débattue pour la première fols lors de la session de printemps 1993, sans qu'une majorité n'ait pu être dégagée. Ce sont certains pays africains et certains pays de l'Est qui souhaitent le plus une nouvelle attribution de DTS. La Suisse a appuyé la demande 
d'une nouvelle allocation générale de DTS. Les voix nécessaires à la création de nouveaux DTS n'ont cependant pas pu être réunies.

\section{Le problème de la dette des pays africains}

Pour les pays endettés sub-sahariens, la crise de la dette est loin d'être surmontée ; on ne saurait comparer leur situation à celle des pays lourdement endettés d'Amérique latine qui, eux, peuvent faire état d'une certaine croissance économique. Les pays d'Afrique noire n'ont pratiquement de dettes qu'auprès d'autres gouvernements, du FMI et de la Banque mondiale. La solution de leur problème semble donc passer par de grosses remises de dettes (accordées par les gouvernements créanciers), par l'octroi de nouveaux prêts concessionnels par la Banque mondiale et l'AID, ainsi que par une aide au développement à des conditions particulièrement favorables. Cette opinion est largement partagée par les membres du FMI et de la Banque mondiale. Les pays industrialisés réunis dans le Club des Dix ont à ce sujet proposé leurs conditions de Toronto élargies qui prévoient de passer l'éponge sur les deux tiers de la dette de ce groupe de pays.

\section{Le Comité de développement de la Banque mondiale}

La prochaine conclusion de l'Uruguay Round (négociations du GATT) pourrait constituer un événement heureux pour les pays africains dans la mesure où les nouveaux accords leur ouvriraient le marché mondial. Telle est la position du Comité de développement de la Banque mondiale et de la Suisse. Suisse qui, par ailleurs, a prié la Banque mondiale de s'unir à d'autres institutions internationales pour défendre plus énergiquement l'amélioration de la politique des matières premières. La Suisse a demandé aux autres pays membres d'accorder la priorité à la question du désendettement et de créer à cette fin des instruments analogues à ceux dont ellemême s'est dotée (facilité de désendettement). Autre thème important abordé lors de cette session : le financement du processus de privatisation. La Banque mondiale et le FMI financent le secteur public et ne jouent qu'un rôle de catalyseur dans les flux de capitaux privés. Le représentant suisse au Comité de développement a demandé si la Banque mondiale ne pouvait pas renforcer son soutien à la privatisation dans les pays en développement et les pays de l'Est.

\section{Autres sujets}

- Prolongation des facilités d'ajustement structurel élargies (FASE II) du FMI : les pays membres du FMI se sont accordés sur la prolongation des FASE échéant à la fin novembre 1993. Une prolongation qui serait nécessaire pour garantir la poursuite des réformes structurelles dans les pays en développement. La nature exacte des FASE II et leur mode de financement n'ont pas encore été fixés.

- Nouvelles tâches au Proche-Orient et en Afrique du Sud : Le FMI et la Banque mondiale se préparent à renouer avec l'Afrique du Sud et le Proche-Orient. Deux régions qui auront besoin de moyens financiers considérables.

- Le rôle positif de la Su/sse.selon la Communauté de travail des œuvres d'entraide, la Suisse joue un rôle actif et positif au sein du FMI et de la Banque mondiale. C'est le jugement exprimé par ses représentants lors d'une conférence de presse convoquée à la veille de la session annuelle. Ils ont lancé à cette occasion un appel aux représentants de la Suisse leur demandant de soutenir activement une généreuse remise de la dette des pays en développement les plus pauvres, en particulier des pays africains. 


\subsection{Rééchelonnements dans le cadre du Club de Paris}

68 développement ayant des problèmes de paiement. Ils y négocient non pas les accords multilatéraux de rééchelonnement proprement dits, mais le cadre dans lequel les futurs accords de rééchelonnements seront définis. Participent à ces négociations les pays créanciers concernés par ces rééchelonnement, les représentants des pays débiteurs ainsi que des conseillers des institutions internationales et de la CNUCED. La Suisse y participe au même titre que les autres pays créanciers lorsque sa part dans un paquet de dettes en cours de rééchelonnement dépasse un certain seuil (clause de minimis). Les dettes $d e \mathrm{~m} / \mathrm{n} / \mathrm{m} /$ sdoivent continuer d'être honorées. arré 1956 déjà. Sa mission : rééchelonner à court terme les arriérés des pays débiteurs. A l'époque, il s'agissait surtout de quelques pays d'Amérique latine à cours de liquidité. Les pays créanciers s'en sont tenus plusieurs décennies à ces rééchelonnements à court terme. Les frais ont toutefois progressivement atteint des niveaux extravagants, certains pays ayant obtenu plusieurs rééchelonnements successifs. Si bien que, au plus haut de la crise de l'endettement des années 80 , les paquets de dettes furent rééchelonnés à plus long terme. Jusqu'en 1987, on appliqua à ces arriérés le taux d'intérêt du marché et tous les pays furent pratiquement logés à la même enseigne. Les préoccupations financières des Etats créanciers l'emportaient sur toute autre considération. Le Club de Paris avait la réputation d'être l'agent de recouvrement des pays industrialisés.

Cette politique n'a pas sensiblement allégé le fardeau des pays endettés. C'est pourquoi le ministre américain des finances d'alors, James Brady, a proposé un plan de remise de dettes prévoyant également des remises sur les dettes contractées auprès de banques d'affaires. En 1988, à Toronto, les créanciers se mirent d'accord sur la définition des catégories de pays pouvant bénéficier des conditions de Toronto, lesquelles ont été aménagées en 1991 en conditions de Toronto élargies (également connues sous le nom de conditions de Trinidad). Ce plan ne se limitait donc pas au rééchelonnement de la dette mais prévoyait des remises. Les premiers pays à en profiter - et qui bénéficièrent d'un traitement exceptionnel - furent la Pologne et l'Egypte dont les dettes respectives furent réduites à la moitié de leur valeur actuelle (net présent value réduction). Les autres pays ont obtenu une réduction de $50 \%$ du service de leur dette (debt service réduction). Les pays bénéficiant d'une remise de dette de ce type doivent appliquer un programme d'ajustement économique défini par le FMI et la Banque mondiale. A la suggestion du premier ministre anglais John Major, les conditions de Trinidad devaient permettre d'accorder aux pays en développement les plus pauvres une réduction de leur dette de deux tiers, ce qui n'a pas (encore) été pratiqué. (Le dispositif de gestion des dettes du Club de Paris est présenté en détail dans l'édition 1993 de l'annuaire, pp. 34 et ss). 
Tableau $\mathrm{N}^{\circ} 6$. Accords multilatéraux d'aménagement des dettes

\begin{tabular}{|c|c|c|}
\hline Pays & Conditions & Montant (mio \$) \\
\hline & \multicolumn{2}{|c|}{1992} \\
\hline Philippines & LMIC & 215 \\
\hline Equateur V & LMIC & 339 \\
\hline Tanzanie IV & Trinidad & 691 \\
\hline Cameroun III & LMIC & 960 \\
\hline Bolivie IV & Trinidad & 65 \\
\hline Brésil IV & habituelles & $10^{\prime} 500$ \\
\hline Maroc & LMIC & $1 ' 250$ \\
\hline Jordanie II & LMIC & 771 \\
\hline Guinée Equatoriale & Trinidad & - \\
\hline Ouganda V & Trinidad & 38 \\
\hline Togo IX & Trinidad & 100 \\
\hline Argentine V & habituelles & $2 ' 700$ \\
\hline Zambie V & Trinidad & 918 \\
\hline Honduras II & Trinidad & 180 \\
\hline Mali III & Trinidad & 20 \\
\hline Guinée-Conackry III & Trinidad & 203 \\
\hline Sierra-Leone V & Trinidad & 190 \\
\hline Bulgarie II & habituelles & 251 \\
\hline Ethiopie & Trinidad & 441 \\
\hline \multirow[t]{2}{*}{ Total des montants rééchelonnés 1992} & & $19 ' 832$ \\
\hline & \multicolumn{2}{|c|}{ Premier semestre 1993} \\
\hline Jamaïque & LMIC & 291 \\
\hline Mauritanie & Trinidad & 218 \\
\hline Mozambique & Trinidad & 440 \\
\hline Guatemala & - & 440 \\
\hline Russie & habituelles & $1 ' 700$ \\
\hline Pérou & LMIC & $1 ' 884$ \\
\hline Guyanne & Trinidad & 39 \\
\hline Burkina Faso & Trinidad & 36 \\
\hline Bénin & Trinidad & 24 \\
\hline Costa Rica & habituelles & 56 \\
\hline
\end{tabular}

Source :BAWI

Tableau $\mathrm{N}^{\circ}$ 7. Accords bilatéraux de rééchelonnement des dettes

\begin{tabular}{|c|c|c|c|}
\hline Pays & $\begin{array}{l}\text { Montant } \\
\text { (mio. fr.) }\end{array}$ & $\begin{array}{l}\text { Intérêt } \\
(\%)\end{array}$ & Condition \\
\hline & \multicolumn{3}{|c|}{1992} \\
\hline Egypte & $1^{\prime} 000,0$ & 7,625 & réduction $50 \%$ \\
\hline Gabon IV & 1,6 & 7,625 & habituelle \\
\hline Côte d'Ivoire & 87,0 & 7,625 & LMIC \\
\hline Cameroun II & 9,5 & 7,625 & LMIC \\
\hline Bulgarie I & 70,0 & 7,625 & habituelle \\
\hline Argentine & 95,0 & 7,625 & habituelle \\
\hline Equateur V & 7,5 & $7,625 / 2,75$ & LMIC \\
\hline Jordanie II & 17,5 & 7,625 & LMIC \\
\hline Pologne & 672,0 & 8,000 & réduction $50 \%$ \\
\hline Togo & 36,0 & réduction & Trinidad \\
\hline Zambie V & 11,0 & réduction & Trinidad \\
\hline Bolivie IV & 12,1 & réduction & Trinidad \\
\hline Tanzanie IV & 14,0 & réduction & Trinidad \\
\hline \multirow[t]{2}{*}{$\begin{array}{l}\text { Total des montants } \\
\text { rééchelonnés } 1992\end{array}$} & $2 ' 033,0$ & & \\
\hline & \multicolumn{3}{|c|}{ Premier semestre 1993} \\
\hline Guinée & 2,7 & 5,950 & Trinidad \\
\hline Argentine & 261,0 & 7,000 & habituelle \\
\hline Sierra Leone & 25,7 & 5,950 & Trinidad \\
\hline Mali & 1,05 & 5,950 & Trinidad \\
\hline Bulgarie & 16,1 & 6,625 & habituelle \\
\hline Brésil & 348,5 & 6,625 & habituelle \\
\hline
\end{tabular}

Source : BAWI 
71 Accords multilatéraux : En 1992, de nouveaux accords sur le rééchelonnement des dettes auprès d'institutions publiques ou garanties par des institutions publiques ont été négociés dans le cadre du Club de Paris avec 19 pays, pour un montant total de 19,8 milliards de dollars. Comme le montre le tableau 6, douze pays africains, cinq pays d'Amérique latine, un pays asiatique et un pays d'Europe de l'Est ont profité de ces mesures. Principal bénéficiaire: le Brésil (un gros débiteur) avec 10,5 milliards de dollars. La Suisse a participé aux négociations qui ont réuni 14 pays. Dans le premier semestre 1993, dix pays ont conclu des accords multilatéraux de rééchelonnement. Ce sont la Russie et le Pérou qui ont négocié les montants les plus importants. La Suisse n'était concernée que par le cas de la Russie.

Accords bilatéraux de rééchelonnement : de l'accord de principe du Club de Paris à la conclusion d'un accord bilatéral formel de rééchelonnement, il faut en général compter quelques mois de travail. En 1992, la Suisse a signé 13 accords bilatéraux de rééchelonnement pour un total de 2 milliards de francs. Cas les plus importants: l'Egypte et la Pologne ; conformément à l'accord du Club de Paris, la Suisse leur a remis la moitié de leur dette actuelle et a rééchelonnée le solde. Au cours du premier semestre 1993, la Suisse a conclu un accord de rééchelonnement avec 6 pays. Leurs conditions sont présentées dans le tableau 7.

\subsection{Mesures de désendettement prises par la Suisse}

73 A la mi-93, la Confédération avait acquis auprès de privés des titres de créance d'une valeur nominale totale de l'ordre de 1,4 milliards de francs envers 28 pays en développement. L'achat de ces créances lui a coûté en tout 78 millions de francs. La Suisse les utilisera dans les négociations bilatérales de désendettement avec les divers pays concernés. En 1993, elle a signé des accords de ce type avec la Bolivie et le Nicaragua; d'autres pays suivront. En général, la Suisse demande en contrepartie de la remise de la dette la mise sur pied d'un fonds de contre-valeur. En avril 1993, la Bolivie a créé un tel fonds.

S’inspirant de la pétition des œuvres suisses d'entraide intitulée "Le développement implique le désendettement", la Confédération a créé en 1991 un dispositif permettant de financer des opérations de désendettement des pays en développement. Il s'applique lorsque les conditions suivantes sont réunies ${ }^{(6)}$ :

- Le pays est un pays pauvre lourdement endetté. Les efforts de la Suisse se concentrent sur les pays les plus pauvres (LLDC) ainsi que sur les pays avec lesquels elle entretient déjà des rapports d'aide au développement.

- Le pays doit avoir engagé un programme de réforme économique à moyen terme faisant participer de larges secteurs de la population au processus de développement local.

- Le pays doit présenter un plan de gestion de la dette, lequel doit faire état des accords d'allégement déjà négociés sur une base multi ou bilatérale.

- La remise de dette prévue par des actions internationales doit être suffisamment importante pour qu'on puisse en attendre un effet significatif à moyen terme.

- Les créanciers privés touchés par les remises de dette doivent participer à l'action au prorata des risques encourus, lesquels sont en général mesurés par la perte réelle de valeur des titres de créance rachetés sur le marché secondaire.

Pour financer ces opérations de remise de dette, la Suisse dispose en tout de 500 millions de francs : 100 millions de crédit-cadre pour la poursuite du financement des mesure de politique économique et commerciale, y compris les mesures de 
désendettement (message du 21.2.1990) et 400 millions du crédit-cadre pour des mesures de désendettement des pays en développement les plus pauvres, votés à l'occasion du 700ème anniversaire de la Confédération (message du 30.1.1991). Les opérations de désendettement ont été confiées à l'office fédéral des affaires commerciales extérieures en collaboration avec la Direction de la coopération au développement et de l'aide humanitaire et du Bureau de désendettement de la Communauté de travail des œuvres d'entraide. La commission mixte pour la coopération au développement et l'aide humanitaire (commission Nebiker) a reçu pour mandat d'accompagner les mesures de désendettement et a créé à cet effet le Souscomité des mesures de désendettement.

Les dépenses effectives liées aux mesures de désendettement se sont élevées à 84,1 millions de francs en 1991 et à 59,5 millions de francs en 1992.

Conduire à terme de telles opérations bilatérales de désendettement est une activité coûteuse qui peut durer des mois ou des années selon la situation politique et économique des pays concernés. D'autre part, les restrictions budgétaires de la Confédération retardent l'utilisation rapide des moyens à disposition. La Communauté de travail des œuvres d'entraide craint que, au rythme auquel les opérations de désendettement se poursuivent, les capitaux à disposition ne soient épuisés qu'après l'an 2000. Lors de l'annonce du crédit extraordinaire du 700ème, en 1991, on avait parlé de 5 ans.

Remises internationales de dettes

La Suisse participe à des actions internationales coordonnées par l'AID. Les premières opérations de rachat de créances ont été conduites en faveur du Niger et du Mozambique (rachat de dettes commerciales par la "facilité" de désendettement de l'AID). D'autres actions ont ensuite été entreprises en faveur du Nicaragua et du Pérou (aide au remboursement des arriérés auprès d'institutions de financement internationales). La Suisse a participé à trois opérations internationales de rachat de créances commerciales sur la Bolivie $(1988,1990,1993)$. Elle a, de plus, versé 20 millions de francs au dispositif de désendettement de l'AID. Le Ghana, qui avait évité le surendettement, a reçu dans le cadre des mesures complémentaires une aide à la balance des paiements de 15 millions de francs. En 1993, la Suisse a participé à la mise au point de rachats internationaux de créances en faveur des pays suivants: Ouganda, Togo, Zambie, Nicaragua et Tanzanie.

Opérations bilatérales de désendettement

81 Entre 1991 et 1993, la Confédération a mené des opérations bilatérales de désendettement avec 28 pays, pour un montant total de 1370 millions de francs (valeur nominale des titres de créance). Le rachat des ces créances lui a coûté en tout 78 millions de francs (voir tableau 8) :

- Le rachat à des exportateurs et banques de crédits et franchises garantis par

- la GRE a constitué le gros de ces opérations (valeur nominale des créances : 1320 millions de francs) intéressant en tout 27 pays. Ces opérations ont coûté 74 millions de francs à la Confédération. 130 exportateurs et 20 banques y ont largement participé ( $97 \%$ de leurs créances). Les exportateurs et les banques ont touché en moyenne de la Confédération $20 \%$ de la valeur nominale de leurs titres. Le plus gros bénéficiaire : la Côte d'Ivoire avec une dette nominale de 302 millions de francs rachetée 10 millions de francs. 
- La part des crédits commerciaux non garantis accordés par des banques et des maisons d'exportation a été moindre (7,9 millions de francs). Les banques se sont montrées très réticentes lors de l'opération de rachat de leurs créances organisée en décembre 1991 par l'office fédéral des affaires économiques extérieures. Cette opération n'a permis de récupérer que 4,3 millions de francs de créances nominales sur un seul pays, le Togo, créances rachetées par la Confédération au cours du marché de $22 \%$, soit 0,7 million de francs. Les exportateurs ont participé à l'opération conduite en septembre 1992 et portant sur une créance totale de 3,3 millions de francs rachetée au cours moyen du marché de $9 \%$, soit une dépense de 0,3 millions de francs pour la Confédération. Six pays africains ont profité de cette opération : le Congo, le Mozambique, la Zambie, le Soudan, la Tanzanie et le Zaïre.

- En 1992, la Confédération à racheté à des banques internationales des créances sur l'Equateur d'une valeur nominale de 22,9 millions de francs au prix de 6,2 millions de francs (valeur sur le marché secondaire : $27 \%$ ).

La Bolivie est pays de concentration de l'aide suisse au développement. Le revenu par habitant y était en 1990 de 630 dollars. En 1985, le gouvernement a lancé un programme de réforme économique. En 1984, le service de la dette y culminait avec 63 \% des recettes à l'exportation. En 1991, ce chiffre était toujours de 34 \%. Le rééchelonnement de la dette, les remises de dette et l'augmentation des exportations ont quelque peu allégé le service de la dette. La Suisse a participé à trois opérations internationales progressives de rachat de créances auprès de bailleurs privés, ce qui a permis à la Bolivie de réduire sa dette bancaire envers des institutions publiques. En 1988, les banques ont participé à cette opération avec $47 \%$ de leurs exigibilités, en 1990 avec 76 \% et en 1992 avec $100 \%$. Le prix de rachat est passé de $11 \%$ en 1988 et en 1990, à $16 \%$ en 1992. La dette extérieure totale de la Bolivie a ainsi diminué de $6 \%$. La Suisse à participé à cette opération pour un montant de 50 millions de francs.

En quatre cycles de négociations avec le Club de Paris, la Bolivie a ainsi pu obtenir de 1987 à 1992 des conditions toujours plus favorables. Dans son accord bilatéral de désendettement (signé en avril 1993), la Suisse a obtenu du gouvernement bolivien qu'il crée un fonds de contre-valeur d'un montant équivalent à 5,7 millions de francs (environ $11 \%$ de la dette remise). Cette somme en devises locales a été déposée sur un compte rémunéré dans une banque privée bolivienne. L'argent sera consacré à des projets de développement dans la protection de l'environnement et à des mesures d'encouragement pour petites entreprises choisies par un comité composé de représentants du gouvernement, du bureau de coordination de la DDA, des œuvres locales d'entraide, des organisations patronales et $\mathrm{du}$ fonds national pour la protection de l'environnement.

Ainsi, entre 1991 et 1993, la Confédération a pratiquement racheté tous les titres de créance suisses offerts sur le marché.

En 1993, des négociations bilatérales de désendettement ont été conduites avec plusieurs pays réunissant les conditions de remise nécessaires : l'Equateur, le Honduras, la Jordanie, le Mozambique, le Nicaragua, le Pérou, la Zambie, l’Egypte, le Sénégal et la Tanzanie. D'autres pays pourraient faire l'objet de telles négociations, entre autres les Philippines, la Côte d'Ivoire, la Guinée et la Guinée Bissau et Madagascar. Le premier 
accord bilatéral de désendettement a été signé en avril 1993 avec la Bolivie. Ce fut ensuite le tour du Nicaragua, avec la signature en juin 1993 d'un accord portant sur un montant de 2,65 millions de francs, puis, en septembre, le Honduras (63,3 millions de francs). A la demande de la Suisse, une conférence internationale des pays donateurs s'est tenue en juin à Berne pour étudier les mesures de réduction de la dette commerciale du Nicaragua et de la Zambie auprès de bailleurs privés.

Tableau $\mathrm{N}^{\circ}$ 8. Montant du désendettement ou titres de créance acquis par la Confédération sur la base de l'ensemble des opérations de rachat (Situation au 22.12.1993)

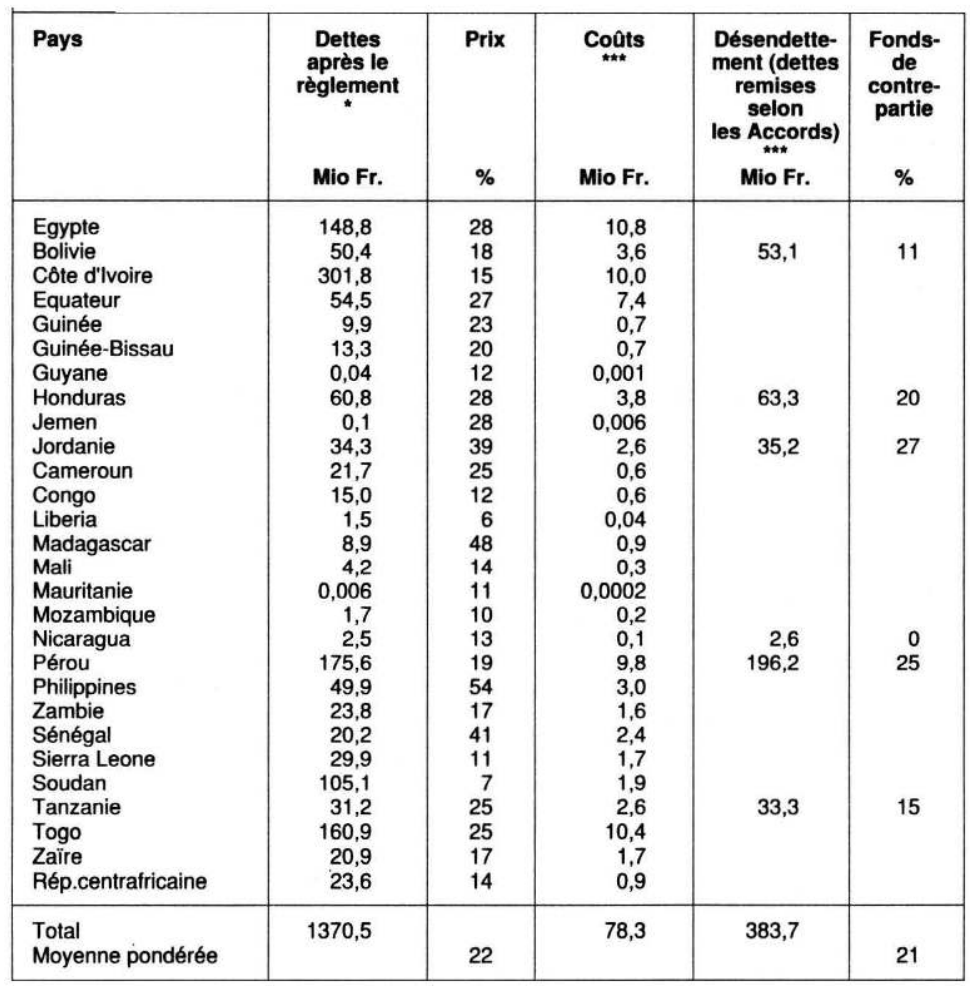

Source : OFAEE

Note $^{* 3}$

Note $^{* * 4}$

Note N**5 $^{* * 2}$

Il est probable que, pour certains pays, ces opérations de désendettement s'étaleront sur plusieurs années. Il faut, en effet, que les conditions-cadre politiques et économiques soient favorables à une remise de dette et que l'opération s'annonce prometteuse du point de vue du développement. Dans l'intervalle allant de l'achat de créances privées jusqu'à la remise effective de la dette du pays en développement, le service de la dette continue de courir, ce qui représente environ 20 millions de francs par année. La Communauté de travail des œuvres d'entraide précise à ce sujet : "Il faut trouver une solution claire à la question des intérêts et du remboursement dus au cours de la période aboutissant au désendettement, une solution en harmonie avec le sens et l'esprit de la pétition sur le désendettement ${ }^{(7)}$.

Désendettement créatif par la création de fonds de contre-valeur 
89 Le projet défendu par la pétition "Le développement implique le désendettement" repose sur le principe du "désendettement créatif" : la création de fonds de contrevaleur en devises du pays concerné doit permettre à la population de profiter directement de l'allégement négocié.

La Confédération a approuvé cette idée. La Communauté de travail des œuvres d'entraide a ouvert en octobre 1991 un "Bureau du désendettement" qui intervient comme consultant auprès de l'OFACE et de la DDA. Il élabore des projets de fonds de contre-valeur. A cet égard, les pays débiteurs peuvent être classés en trois catégories :

- Pays de concentration de l'aide publique suisse au développement (p. ex. la Bolivie)

- Pays de concentration de l'aide privée suisse au développement (p. ex. le Togo, les Philippines)

- Pays dans lesquels la Suisse n'est pas engagée de manière significative (p. ex. la Zambie, la Guinée)

91 La création de fonds de contre-valeur prend tout son sens dans les pays de concentrations d'aide au développement avec la Suisse, lorsque le montant de cette activité en devises locales justifie cette dépense. C'est le cas des pays ayant une dette importante envers la Suisse. Dans le cas idéal, des organisations non gouvernementales déjà en activité dans le pays se chargent de la gestion du fonds en partenariat avec un service du gouvernement. Dans les autres cas, il apparaît plus judicieux de soutenir directement des projets en cours plutôt que de créer un fonds de contre-valeur. Le Bureau du désendettement a tiré les conclusions suivantes de la création des fonds de contre-valeur ${ }^{(8)}$ :

- Les fonds de contre-valeur peuvent améliorer la durabilité du processus de développement.

- La constitution d'un fonds peut renforcer l'autonomie des ONG locales.

- Il existe certaines limites à ce type d'actions, à trois niveaux distincts :

1. Economique : il faut prendre garde à ne pas trop charger les finances de l'Etat. Cela pourrait être le cas dans les pays qui n'honorent pas leur dette extérieure ou ne l'honorent que partiellement. La suppression de la dette n'y libère pas d'argent utilisable à d'autres fins, à moins qu'on imprime de nouveaux billets (risque d'inflation) ou qu'on le soustraie aux dépenses de l'Etat.

2. Politique : certaines $\mathrm{ONG}$, en particulier les plus petites, renoncent à demander une aide financière par crainte de perdre leur autonomie face au gouvernement. Autre problème : l'instabilité politique qui, comme on l'a vu lors des troubles du Togo, peut retarder la mise en train du fonds.

3. 3.Institutionnel : bien des pays, surtout parmi les plus petits, n'ont pas d'ONG locales actives au niveau national et capables de gérer un tel fonds en partenariat avec le gouvernement.

\section{Procédure internationale de mise en faillite}

93 La Communauté de travail des œuvres d'entraide a proposé au Conseil fédéral d'initier au niveau international la création d'une procédure de droit international de cessation de paiement applicable aux pays en développement ouverts aux réformes économiques. Cette proposition a été présentée au Parlement par le conseiller aux Etats Ulrich Gadient (petite question du 19.6.1992 : droit de faillite pour le désendettement des pays en développement ouverts à la réforme). Dans sa réponse, le Conseil fédéral déplore que les efforts déjà entrepris dans ce sens n'aient soulevé que peu d'intérêt auprès des autres pays créanciers ${ }^{(9)}$.

Comptabilisation statistique des mesures de désendettement contestée 
L'OCDE a proposé de comptabiliser les mesures de désendettement à leur valeur nominale dans les statistiques d'aide au développement. La Suisse a insisté pour qu'on comptabilise les créances rachetées à leur valeur sur le marché ou à leur valeur de rachat, cela afin de ne pas fausser les statistiques.

\section{Commerce international}

\subsection{CNUCED}

La CNUCED, Conférence des Nations Unies pour le commerce et le développement, s'est occupée principalement de la mise en cuvre de la réforme institutionnelle et des nouvelles orientations adoptées en février 1992 lors de la CNUCED VIII. Le Conseil a examiné notamment les réformes économiques entreprises par les pays en développement et les problèmes d'environnement, ceci sous l'angle des politiques commerciales. La CNUCED s'inquiète de l'effritement du soutien au développement des Pays les moins avancés. Les nouvelles commissions et les nouveaux groupes ont entamé leurs travaux. Le Programme pilote de création de centres pour le commerce a été mis sur pied, pour atteindre une meilleure efficacité dans les opérations du commerce extérieur. La concertation internationale sur les matières premières reste dans une crise profonde, avec des difficultés dans la négociation de nouveaux accords sur les bois tropicaux, le café, le cacao et le caoutchouc naturel. Le commerce du bois tropical soulève beaucoup d'oppositions dans les milieux écologiques. Les moyens du nouvel Accord international sur le cacao pour stabiliser les cours semblent assez faibles car celui-ci ne possède plus de mécanisme d'intervention directe sur le marché, mais une politique de gestion de la production (sorte de cartel de pays producteurs). Les pays consommateurs ont jusqu'en été 1993 refusé de renégocier un nouvel accord sur le caoutchouc. La Suisse s'est engagée ces dernières années en faveur d'un renouveau de la CNUCED, en direction d'une meilleure prise en compte des lois du marché.

\section{Réformes institutionnelles de la CNUCED}

De nouvelles orientations de travail et une réforme des instances de l'organisation avaient été adoptées lors de la 8ème Conférence des Nations Unies pour le commerce et le développement, en février 1992 à Carthagène (Colombie). (Voir Annuaire 1993, point 3.1)

Les discussions au sein de la CNUCED se sont déroulées avec pour toile de fond un renouveau de la reconnaissance des valeurs du libéralisme économique, la fin de la bipolarité Est-Ouest, la prise de conscience plus large des problèmes de l'environnement, ainsi que la longue attente de la conclusion des négociations commerciales de l'Uruguay Round.

La forme des débats se modifie lentement à la CNUCED. L'ancienne tendance à vouloir à tout prix établir des traités internationaux contraignants ou adopter des résolutions politiques et recommandations fait peu à peu place à des discussions plus informelles. L'objectif de certains pays, industrialisés surtout, est de transformer la CNUCED en une organisation mondiale qui aurait un rôle semblable à celui de l'OCDE. L'accent serait ainsi mis sur la comparaison des expériences nationales, les analyses économiques globales, les études techniques, la formation, l'assistance technique, l'identification et la préparation de thèmes de négociations d'autres organisations internationales, l'appui aux délégations des pays en développement lors de négociations qui se 
déroulent ailleurs (au GATT par exemple). Certains pays en développement et certaines organisations non gouvernementales craignent pourtant une perte de l'importance de la CNUCED dans le dialogue Nord-Sud.

Autre nouveauté décidée par la CNUCED VIII: la participation d'acteurs non gouvernementaux et d'experts (surtout de l'économie privée) aux travaux du Conseil. En outre, les pays prennent de moins en moins position en tant que groupe de pays (industrialisés, en développement ou de l'Est). Seul le groupe des 77, groupe des pays en développement, prend quelquefois encore position en tant que groupe. L'avis des ÉtatsUnis et de la Communauté Européenne devient prédominant pour les pays industrialisés. Les pays nordiques s'expriment aussi souvent en tant que groupe. La Suisse fait partie des quelques pays industrialisés qui s'expriment isolément. Pour la Suisse, cette réforme de la CNUCED est nécessaire, car l'organisation n'était plus en mesure d'apporter une contribution substantielle sur les questions de développement. Les oppositions traditionnelles entre blocs de pays ne permettaient plus de tenir compte de la différenciation croissante entre pays en développement.

\subsubsection{Conseil de la CNUCED}

Le Conseil du commerce et du développement s'est réuni en sessions ordinaires au début octobre 1992, en mars et fin septembre 1993, avec une quinzaine de thèmes à l'ordre du jour. Les discussions sur l'endettement et sur l'Uruguay Round ne sont pas abordées ici, puisque ces thèmes sont développés aux points 1 et 2.2 de cette partie sur les négociations internationales.

Politiques commerciales, ajustement structurel et réformes économiques

Beaucoup de pays en développement ont entrepris ces dix dernières années une libéralisation de leur économie, avec notamment des mesures prises pour :

- déréglementer l'économie nationale ;

- libéraliser les secteurs financiers et bancaires ;

- attirer l'investissement direct étranger ;

- privatiser certaines entreprises ;

- réformer les politiques commerciales : libéralisation, réformes du régime de change et dévaluations de la monnaie nationale, réformes des incitations à l'exportation, adoption de normes internationales.

Ces mesures ont souvent entraîné un coût social élevé et seuls les pays en développement les plus avancés ont réussi à atteindre une croissance soutenue de leurs exportations. Selon le secrétariat de la CNUCED et beaucoup de pays en développement, ces efforts se sont heurtés à la récession économique mondiale et au protectionnisme des pays industrialisés face aux exportations vitales des pays en développement. Les investissements et transferts de technologies des pays industrialisés sont restés insuffisants et l'allégement de la dette devrait se poursuivre encore. Les pays industrialisés reconnaissent le rôle joué par ces facteurs, mais ils insistent sur la responsabilité des politiques de libéralisation insuffisantes ou incohérentes menées par certains pays en développement.

Le délégué suisse a mis l'accent sur la propre responsabilité politique des pays en développement pour "mettre leur maison en ordre", en améliorant la gestion des affaires publiques, en assurant la stabilité macro-économique et en mettant en valeur les ressources humaines. La Suisse reconnaît cependant que les pays en développement, 
en particulier les plus pauvres, ont besoin d'un appui extérieur pour amortir les coûts sociaux qui accompagnent les réformes entreprises ${ }^{(10)}$.

Le Rapport 1993 de la CNUCED sur le commerce et le développement proposait des mesures macro-économiques concertées pour relancer l'économie mondiale. Les pays industrialisés, dont la Suisse, ont exprimé de grandes réserves face à certaines mesures keynésiennes proposées dans le Rapport, surtout quand le Secrétariat de la CNUCED suggère que les pays industrialisés doivent prendre des mesures fiscales concertées pour relancer l'économie. L'idée serait de taxer le capital, par le biais d'un prélèvement unique, dans le but de réduire les dettes des gouvernements. résultats économiques souvent décevants. Ces pays représentent un dixième de la population mondiale. Leur PIB par habitant n'a cessé de baisser de 1989 à 1993. Certains PMA connaissent pourtant une forte croissance (Botswana, Maldives, Lesotho). D'autres subissent les conséquences des catastrophes naturelles ou des guerres civiles (conflits actuels ou passés en Afghanistan, au Cambodge, en Ethiopie, au Liberia, au Mozambique, en Somalie, au Soudan). La récession mondiale a aussi de lourdes 
conséquences sur ces économies. Les possibilités d'emploi de travailleurs migrants sont en baisse et provoquent une diminution des apports de devises pour les PMA. Les prix mondiaux des principales exportations des PMA reculent. La part des PMA dans le commerce mondial a diminué de 1980 à 1991, passant de 0,6 \% à 0,3\%. La part des PMA dans les importations de la Suisse s'élevait à 0,12 \% seulement en 1992.

Les PMA dépendent presque uniquement de l'Aide publique au développement (APD) pour leur financement extérieur, en raison d'un accès limité aux crédits et aux investissements directs étrangers. Le Programme d'action recommandait aux pays industrialisés de consacrer le 0,15\% de leur PNB à l'aide aux PMA. Cette aide moyenne a pourtant baissé de $0,09 \%$ en 1989 et 1990 à $0.08 \%$ en 1991. L'aide de la Suisse aux PMA s'est élevée à $0,06 \%$ de son PNB en 1992. Les pays en développement ont demandé au Conseil, sans succès, une révision à la hausse des objectifs d'aide au développement, compte tenu de l'augmentation du nombre de pays classés dans la liste des PMA de 41 en 1990 à 47.

115 Les PMA préparent l'examen à mi-parcours du Programme d'action qui aura lieu en 1995. Les pays industrialisés ont relevé les cas exemplaires des PMA qui ont connu une croissance économique, grâce à une politique économique efficace, à une bonne gestion des affaires publiques et à la stabilité interne. La mobilisation des ressources internes et la politique démographique doivent selon eux devenir prioritaires.

\subsubsection{Commissions et groupes de travail de la CNUCED}

Neuf nouveaux organes subsidiaires ont été chargés d'exécuter le programme de travail adopté lors de la CNUCED VIII. Il s'agit des 4 commissions permanentes suivantes: produits de base, atténuation de la pauvreté, coopération économique entre pays en développement, développement des secteurs de services. 5 groupes de travail spéciaux ont un mandat portant sur des questions plus spécifiques et techniques: investissements et apports financiers (financement du développement non générateur de dette), efficacité commerciale, comparaison de l'expérience des pays en matière de privatisation, expansion des débouchés commerciaux des pays en développement, interaction des investissements et du transfert de technologie. Deux anciens organes ont été maintenus : le Comité spécial des préférences et le Groupe intergouvernemental d'experts des pratiques commerciales restrictives (voir le point V.2. de la revue pour les préférences douanières accordées par la Suisse). La Suisse est membre de tous ces groupes et de toutes ces commissions. Le programme de travail des nouvelles commissions permanentes et des groupes ont été mis sur pied dès le printemps 1992.

Efficacité du commerce

118 L'Initiative pour l'efficacité commerciale avait été lancée lors de la CNUCED VIII à Carthagène. Ce programme a pour but, premièrement, d'améliorer le déroulement des opérations commerciales, par l'utilisation des techniques d'information modernes et par la création de réseaux entre tous les acteurs et services qui interviennent dans les transactions commerciales. Le coût des opérations commerciales devrait ainsi diminuer. L'autre but est d'accroître la participation au commerce international. De nouvelles opportunités d'exporter pourraient être découvertes et les petites et moyennes entreprises pourraient être intégrées aux échanges mondiaux. Toute une série de "centres pour le commerce" (Trade points) ont ainsi été créés ou sont en projet dans des pays en développement ou des pays industrialisés, pour réunir sous le même 
toit les bureaux des différents acteurs du commerce international (voir encadré). La Suisse a pour projet d'établir un premier centre de commerce à Lausanne et elle a octroyé pour les années 1993/94 un demi-million de dollars au programme d'efficacité commerciale (Trade points).

\section{Concept des centres pour le commerce (Trade points)}

Le principe est de réunir sous le même toit ou de mettre en réseau les bureaux des différents services qui interviennent dans les transactions du commerce international.

L'entreprise qui veut exporter un produit trouvera dans ce lieu :

des informations sur les débouchés commerciaux, sur les procédures administratives pour exporter, les tarifs douaniers, les restrictions du commerce et sur les contrôles de qualité ou sanitaires;

des bureaux pour régler les formalités administratives (transport, assurances, paiements...) ;

des contacts avec les aeteurs et services du commerce : services des douanes, ministère du commerce extérieur, chambres de commerce, banques, assurances, entreprises de transport, services de télécommunication, universités (études du marché, recherche...) ;

des moyens de télécommunication : fax, téléphones, vidéoconférence, courrier électronique...

Le financement est assuré par les utilisateurs, les firmes participantes, des apports gouvernementaux, la CNUCED (appui, logiciels, équipements). Les différents points de commerce sont reliés entre eux et sont membres de la Fédération internationale des associations pour l'efficacité commerciale, qui a son siège à Genève (associations à but non lucratifs).

Le Groupe de travail sur l'efficacité commerciale coordonne d'une part l'établissement du programme pilote des centres pour le commerce, et sur la base de cette expérience, il proposera des recommandations pour le Symposium mondial sur l'efficacité commerciale qui aura lieu en octobre 1994, à Colombus, Ohio (États-Unis). Le Symposium permettra de réviser les lignes directrices de la CNUCED pour l'établissement de futurs centres et d'adopter des directives et des modèles en matière d'efficacité commerciale.

Le groupe de travail étudiera d'autre part les moyens d'améliorer les flux d'information pour le renforcement de l'efficacité commerciale, ainsi que le rôle que pourraient jouer les gouvernements dans ce domaine (améliorer les conditions juridiques, réglementaires et administratives). De l'assistance technique est aussi prévue.

\subsubsection{Matières premières}

121 Le Programme intégré pour les produits de base élaboré en 1976 par la CNUCED avait pour objectifs l'atténuation des fluctuations de prix, l'accroissement des recettes d'exportations des pays en développement, la diversification de la production, ainsi que la promotion des systèmes de commercialisation, de distribution et de transport. Les efforts internationaux devaient se concrétiser par l'adoption d'accords internationaux sur les produits de base, le Fonds commun pour ces produits, le financement compensatoire des déficits de recettes d'exportation, ainsi que par l'assistance technique. 
Le nouvel Accord sur le sucre est entré en vigueur le 20 janvier 1993 (avec la participation de la Suisse). Les accords internationaux n'ont cependant pas réussi à stabiliser les prix à long terme. Seul l'accord sur le caoutchouc naturel possède un mécanisme d'intervention sur les marchés (stock régulateur). Les négociations de nouveaux accords sur les bois tropicaux, le café, le cacao et le caoutchouc naturel s'avèrent très laborieuses. Une majorité des pays consommateurs ne désirent en fait plus renégocier des accords qui seraient contraires au principe du libre-échange. L'offre structurellement excédentaire doit s'adapter à la demande. Les pays producteurs pensent pour leur part qu'un Accord sur un produit de base ne doit pas être un simple accord économique, mais qu'il a une composante politique, de par son importance pour le développement et par la création d'un partenariat entre producteurs et consommateurs. Le manque d'élasticité de la production par rapport aux variations des cours accentue la volatilité des prix. Certains craignent, qu'en l'absence de tout dispositif d'intervention, le marché ne s'adapte trop lentement ou de façon excessive à la demande. Une nouvelle politique internationale pour les produits de base reste encore à définir. La Colombie avait proposé lors de la CNUCED VIII l'organisation d'une conférence mondiale sur les produits de base. La plupart des pays consommateurs, y compris la Suisse, restent très sceptiques sur l'opportunité d'une telle conférence. La Suisse a souligné, devant la Commission sur les produits de base, les avantages d'un recours accru aux Instruments du marché de gestion des risques dans les transactions entre producteurs et consommateurs. Pour la Suisse, la politique internationale dans le domaine des matières premières est à un tournant. Les accords (qu'elle soutenait autrefois) fonctionnent mal et entravent la création de bourses de marchandises efficaces. La sécurité des transactions doit être accrue par le recours aux bourses et aux engagements contractuels à terme entre les entreprises productrices et celles qui interviennent au stade de la transformation et de la commercialisation ${ }^{(11)}$.

La Commission sur les produits de base se fixe comme but d'étudier les moyens d'améliorer le fonctionnement des marchés par de meilleures statistiques et des études. Un Rapport du Secrétariat étudie par exemple les moyens d'accroître l'efficacité et l'utilisation des mécanismes de gestion des risques liés aux fluctuations des prix des produits de base. Il présente les avantages et les inconvénients des instruments suivants : contrats à terme, "futures", options négociables, swaps, commodity bonds, prêts indexés sur les produits de base ${ }^{(12)}$.

\section{Accord international sur le cacao}

124 L'Accord de 1986 est arrivé à échéance fin septembre 1993. Les dispositions économiques (stock régulateur) ne fonctionnent plus depuis 1988 (voir Annuaires précédents). Le marché du cacao a connu une période d'excédent de l'offre pendant sept années consécutives, jusqu'à la saison 1990/91. Les importants stocks diminuent lentement depuis cette saison et les prix ont atteint des niveaux très bas.

Un nouvel Accord sur le cacao a été adopté le 16 juillet 1993 pour une durée de 5 ans, à l'issue de la 5ème session de la Conférence des Nations Unies sur le cacao. Il peut être prorogé deux fois pour des périodes n'excédant pas deux ans. Cet Accord renonce à créer un mécanisme de contingents à l'exportation et ne maintient pas de stock régulateur, négocié, géré et financé par l'ensemble des pays. Il n'engage en fait plus que les pays producteurs, en instituant une politique de gestion de la production. Il ne comprend plus d'objectif de prix à défendre. Les pays n'avaient pas réussi à s'entendre 
sur un montant maximal de retrait de la production exportable, ni sur un niveau de prix à défendre. Les pays consommateurs, dont la Suisse, ne voulaient plus participer financièrement au fonctionnement d'un accord tant que les pays ne règlent pas leurs arriérés (137 millions de dollars en janvier 1993, dus principalement par la Côte d'Ivoire, le Brésil et le Ghana). Les États-Unis, le Royaume-Uni, l'Allemagne et la Hollande voulaient même laisser libre cours aux forces du marché.

Selon les termes du nouvel Accord, le Comité des producteurs instauré par le Conseil international du cacao devra fixer un cadre indicatif sur les niveaux annuels de production globale, afin d'éviter une trop grande surproduction. Il pourra formuler des recommandations pour rétablir un équilibre entre l'offre et la demande. Les pays exportateurs de cacao devront sur cette base élaborer des programmes pour ajuster leur production et le Comité devra être informé sur la mise en œuvre de ces programmes.

Les pays importateurs, réunis dans un comité de la consommation, devraient s'efforcer d'annuler ou de réduire substantiellement les obstacles internes à l'expansion de la consommation de cacao. Ils devront aussi encourager de nouveaux usages du cacao et évaluer les tendances de la consommation cacaoyère. L'Accord permettra de rassembler des statistiques et d'entreprendre des études sur l'évolution du marché cacaoyer. Un nouvel article stipule que les pays doivent prendre en considération la gestion durable des ressources en cacao et la transformation du cacao.

Le Conseil fédéral a décidé l'adhésion de la Suisse à l'Accord. Les principaux producteurs de cacao sont les suivants : Côte d'Ivoire (31,3\% de la production mondiale en 1992/93, avec une production en baisse ces dernières années), le Brésil (12,7\%), le Ghana (12\%), l'Indonésie ( $9,2 \%$, avec une production en très forte hausse), la Malaisie $(9 \%)$ et le Nigeria (5,6 \%) (Chiffres : Marchés tropicaux 9.7.1993).

\section{Accord international sur le café}

129 Le fonctionnement de l'Accord de 1983 a connu de multiples difficultés qui avaient, en juillet 1989, entraîné la suspension du système des contingents à l'exportation. La baisse des prix mondiaux du café qui s'en est suivi a eu de graves conséquences sur des millions de producteurs. Les pays exportateurs auraient connu, selon l'Organisation internationale du café, des pertes de recettes d'exportation évaluées à 10 milliards de dollars de juillet 1989 jusqu'au début de l'année 1993. Les prix réels du café sont à leurs niveaux de 1929. La part des prix de détail du café qui revient au producteur se serait amenuisée, passant de $47 \%$ en 1985-86 à $22 \%$ en 1990-91 (Marchés tropicaux, 16.4.1993). Les importateurs, torréfacteurs et grossistes ont donc accru sensiblement leurs marges. La baisse du prix au producteur peut avoir pour conséquence une détérioration de la qualité du café vert (moins de soins aux cultures, moins de maind'œuvre).

130 Les négociations en vue d'un nouvel Accord sur le café sont très difficiles et les positions des pays restent inconciliables. Les travaux d'un comité de travail composé de 20 pays, dont la Suisse, ainsi que les réunions de l'Organisation internationale du café n'ont permis de régler que des points mineurs du futur Accord. Les négociations ont été suspendues le 31 mars 1993. Les dispositions administratives de l'ancien Accord sur le café ont été prolongées d'une année, jusqu'à fin septembre 1994. 
Les pays producteurs souhaitaient réinstaller un quota global d'exportation susceptible de faire remonter les prix mondiaux du café, soit un quota global nettement inférieur à la consommation actuelle. Mais aucun consensus n'a été trouvé sur le niveau exact de ce quota global. Celui-ci devrait ensuite être réparti entre les types de café (sélectivité) et entre les pays producteurs de café. La sélectivité permettrait de tenir compte de l'évolution des demandes pour les différents types de café, ce qui n'était pas possible autrefois. Les divergences se sont focalisées sur le nombre de sortes de café à prendre en considération. Les pays consommateurs en proposaient 3 (Robusta et deux types d'Arabica) et les producteurs quatre (Robusta et trois types d'Arabica). En outre, les pays producteurs souhaitaient une durée de l'Accord plus longue que les consommateurs ( 5 à 6 ans, contre 3 à 4 ans).

2 Puisqu'un nouvel Accord n'est pas en vue, les pays de l'Amérique centrale, la Colombie et le Brésil ont repris l'idée d'établir un "cartel" de pays producteurs. Ils ont été rejoints par les pays producteurs africains. Ces pays se sont engagés à retenir et stocker une partie de leur café exportable (20\% dès le 1er octobre 1993).

\section{Commerce plus équitable : café Max Havelaar en Suisse}

La Fondation Max Havelaar a été créée par des œuvres d'entraide suisses au printemps 1992. Elle est soutenue financièrement par l'OFAEE, qui a accordé 1650000 francs pour le lancement du label "Max Havelaar". La Fondation octroie des licences qui permettent l'utilisation du label aux torréfacteurs et revendeurs de café qui commercialisent du café acheté à des associations de petits producteurs de café (maximum 5 hectares), sur la base de contrats à terme. Les méthodes de cultures et de traitements doivent être respectueuses de l'environnement. Des crédits peuvent être accordés et des actions sociales peuvent être encouragées (assistance technique, santé, éducation...). Le prix de vente du café en Suisse est plus élevé, mais les producteurs reçoivent une rémunération supérieure à ce que le prix mondial leur aurait rapporté. En Hollande, ce type de café avait réussi à conquérir 2,5\% du marché en 4 ans. La Fondation suisse s'était fixée pour but d'atteindre $5 \%$ des ventes de café en trois ans. Or, une année après son introduction en Suisse, le café Max Havelaar représentait déjà cette part de $5 \%$. Le lancement sur le marché d'autres produits munis d'un label est envisagé (pour les bananes, le thé, le sucre, le cacao ou le chocolat). Le miel "Max Havelaar" était en vente en Suisse dès l'automne 1993.

\section{Accord international sur le caoutchouc naturel}

L'Accord de 1987 qui devait arriver à échéance en décembre 1993 a été prolongé d'une année. Cet Accord possédait un stock régulateur. Des achats de caoutchouc pouvaient intervenir si le prix indicateur du marché était de $15 \%$ inférieur à un prix de référence et des ventes permettaient de freiner la hausse des cours lorsque le prix indicateur dépassait de $15 \%$ le prix de référence. Des ventes ont eu lieu lors des hausses des prix, fin 1987, au premier semestre de 1988 et de 1989. La production a ensuite été largement excédentaire depuis 1991, avec pour conséquence une augmentation régulière des stocks. 180000 tonnes de caoutchouc ont été achetés par l'organisme stabilisateur. Malgré les prix très bas, le stock régulateur ne pouvait ensuite plus intervenir sur le marché pour les achats, car les pays consommateurs voulaient au préalable réajuster la fourchette des prix d'intervention de $5 \%$ à la baisse (Pautomaticité de la révision du prix de référence était d'ailleurs prévue dans l'Accord). Les pays producteurs refusaient cela, jugeant que les cours étaient déjà trop bas. Ce différend a bloqué la négociation en 
vue d'un nouvel Accord, jusqu'en automne 1993. Une première session de négociation est prévue pour avril 1994, sous les auspices des Nations Unies.

Le 30 mars 1993,16 pays consommateurs sur 20 ont rejeté la demande des pays producteurs de caoutchouc naturel de négocier un nouvel Accord (dont la Communauté européenne, les États-Unis, la Finlande, le Japon, la Norvège, la Suède et la Suisse). Le Maroc et la Russie se sont abstenus. Seule la Chine était en faveur de cette proposition.

\section{Accord international sur les bois tropicaux}

L'Accord international de 1983 arrive à échéance à fin mars 1994. Il cherchait à promouvoir une exploitation commerciale des bois tropicaux tout en maintenant l'équilibre écologique des forêts. Il ne comportait pas de mécanisme d'intervention directe sur le marché, mais cherchait à améliorer les consultations entre pays, à fournir des informations sur le marché et à favoriser la Recherche-Développement. L'Organisation Internationale des bois tropicaux (OIBT) avait été créée pour gérer l'Accord, avec pour siège Yokohama, Japon. 23 pays en développement producteurs et 27 pays consommateurs, dont la Suisse, sont membres de l'OlBT. Ces pays représentent $89 \%$ de la superficie mondiale de forêt tropicale et 80 \% des importations. L'OlBT ne s'occupe pas de toute la gestion des forêts tropicales, mais uniquement du commerce international des bois tropicaux (seuls $6 \%$ des bois coupés entrent dans ce commerce).

Le Plan d'action de l'Organisation internationale des bois tropicaux (OIBT) comprend une série de directives visant à promouvoir une gestion durable des forêts tropicales. D'ici l'an 2000, toutes les exportations de bois tropicaux et de ses produits dérivés devraient, selon une recommandation non contraignante du Plan, provenir de forêts aménagées selon le principe du développement durable (actuellement le cas pour $1 \%$ des forêts seulement). La majorité des pays acceptent les objectifs de ce plan 2000, mais certains posent le problème du financement nécessaire. La Suisse finance ou cofinance des projets de Recherche-Développement, d'exploitation durable des forêts, de reboisement et de formation notamment en Malaisie, en Bolivie, en Indonésie, au Brésil et en Papouasie Nouvelle-Guinée.

Marché international du bois tropical et préoccupations écologiques

L'image du bois tropical est depuis une décennie très dévalorisée dans une partie de l'opinion publique de la plupart des pays industrialisés. Les mouvements écologiques reprochent à l'OlBT, chargée d'administrer l'Accord, de ne pas avoir su, ou pu, éviter les destructions massives de forêts tropicales. Certains mouvements écologiques ou ONG de développement réclament un boycott sur les importations de bois tropicaux. Cette position est défendue notamment par Greenpeace, ou par l'ethnologue bâlois Bruno Manser, qui dénonce la destruction effrénée de la forêt tropicale du Sarawak, Malaisie, avec ses conséquences dramatiques sur la vie des communautés indigènes (indigènes pénans).

141 La Communauté européenne et la Suisse étudient la possibilité de décerner des labels de qualité, sur une base volontaire et privée (le système suisse pourrait se rapprocherde celui du café Max Havelaar). Cet éco-label permettrait au consommateur de savoir que le bois acheté provient de forêts exploitées selon les principes d'une gestion durable des ressources forestières. Resterait alors à définir ce que l'on entend par développement durable de la forêts, la tendance des pays producteurs, même de la Malaisie, étant de déclarer que l'ensemble de leur production répond à ce critère. Une 
partie de l'industrie privée pourrait être en faveur d'un éco-label introduit sur une base volontaire (avis favorables en Suisse d'Ikea, Pfister et Interio, selon le TagesAnzeiger du 2.10.1993).

Dans les Chambres fédérales, plusieurs parlementaires soutenaient les motions de la conseillère aux Etats Rosemarie Simmen (PDC, Soleure) et du conseiller national Hugo Wick (PDC, Bâle-Ville). Ces motions demandent l'introduction d'une obligation de déclarer l'origine et l'essence des bois importés, d'introduire donc un éco-label obligatoire. Le Conseil des Etats a accepté la motion en septembre 1993 et le Conseil national doit encore se prononcer, au printemps 1994. La Confédération refuse d'interdire complètement l'importation de bois tropicaux et reste réticente à l'idée d'un éco-label obligatoire. L'Autriche a en septembre 1992 rendu obligatoire la mention "bois tropicaux" sur l'ensemble des bois en provenance du Sud, avant de reculer devant les pressions de l'industrie nationale du bois, de la Malaisie et de l'Indonésie.

tositions relatives à un nouvel Accord international ont été examinées lors réunions préparatoires organisées par l'OIBT en novembre 1992 et janvier 1993. La négociation proprement dite a débuté, sous les auspices de la CNUCED, lors de trois conférences des Nations Unies sur les bois tropicaux qui ont eu lieu en avril, en juin et octobre 1993. Plusieurs divergences fondamentales séparent encore les pays producteurs des pays consommateurs, notamment sur la portée et les objectifs du nouvel Accord, la discrimination commerciale, les ressources financières et le fonctionnement de l'Organisation internationale des bois tropicaux.

Le champ d'application même d'un nouvel Accord reste controversée. L'Accord de 1983 concernait le bois tropical non conifère à usage industriel (grumes, sciages, placages et contre-plaqués). Les pays producteurs de ces bois veulent étendre l'Accord à la totalité du commerce du bois, donc y compris ceux provenant des forêts tempérées et boréales, qui sont souvent aussi exploitées très intensivement (au Canada, aux USA ou dans les pays nordiques européens par exemple). L'attention de l'opinion publique a été focalisée sur la situation des forêts tropicales. Les pays en développement ne veulent pas que le commerce des bois tropicaux soit l'objet d'un traitement discriminatoire, au profit d'autres types de bois. Pour les pays consommateurs, la négociation d'une convention globale des forêts n'est pas du ressort de la CNUCED. Elle devrait se faire dans le cadre du suivi de la Conférence de Rio.

L'aspect financier constitue une autre pierre d'achoppement. Les pays producteurs réclament une aide financière et technologique accrue pour être en mesure d'assurer une exploitation rationnelle et durable de leurs forêts. Certains pays comme les Philippines ou la Malaisie ont de sérieux doutes quant aux possibilités de financer une gestion durable des forêts d'ici l'an 2000. Un compte pourrait être créé pour financer des projets dans ce but.

\subsection{GATT. Clôture des négociations de l'Uruguay Round}

La conclusion des négociations de l'Uruguay Round, en décembre 1993, constitue sans doute l'événement majeur des dernières années dans les relations commerciales internationales. La crise dans les négociations du domaine agricole entre les États-Unis et la Communauté européenne, ainsi que les divergences qui subsistaient sur de nombreuses questions, ont 
contribué à retarder l'issue de l'Uruguay Round. La Suisse accordait une très grande importance à un résultat favorable de ces négociations.

Plusieurs thèmes ont été examinés dans les Annuaires précédents : agriculture (Annuaires 1991, 1992 et 1993), services (Annuaire 92), propriété intellectuelle (1991, 1992 et 1993), textiles (92 et 93), pratiques commerciales restrictives (93). Nous reviendrons sur les résultats et les implications de l'Uruguay Round dans le prochain Annuaire.

Le 8ème cycle de négociations du GATT (Accord général sur les tarifs douaniers et le commerce) visant une libéralisation du commerce international se déroule depuis 1986, avec la participation de 116 pays, dont la Suisse. La conclusion de l'Uruguay Round, prévue fin 1990, a été retardée par des divergences profondes sur certains thèmes de négociation, agriculture surtout, mais aussi propriété intellectuelle, services (dont l'audiovisuel et les services financiers), le code antidumping, la question de la création d'une organisation multilatérale du commerce, et certains secteurs particuliers (textiles, acier...). Certains conflits occupant le devant de la scène concernaient surtout les États-Unis et la Communauté européenne sur les points suivants : agriculture, subventions aéronautiques européennes (construction d'avions), libéralisation des services financiers, avec des réticences nord-américaines dans ce domaine, mesures antidumping, secteur de l'audiovisuel.

Depuis le début de l'année 1992, les négociations s'opéraient sur la base du "Projet d'Acte final reprenant les résultats des négociations commerciales multilatérales", qui avait été présenté par l'ancien Directeur général du GATT, le Suisse Arthur Dunkel, le 20 décembre 1991. Une partie de ce texte était le fruit d'un consensus entre les négociateurs, alors que d'autres points restaient des propositions de compromis. (Voir les Annuaires Suisse-Tiers Monde des années précédentes). La tension dans les négociations a été particulièrement forte en automne 1993, à l'approche de la datebutoir du 15 décembre. L'ouverture des marchés et l'établissement de règles claires et prévisibles sur le plan multilatéral ont été présentés de plus en plus comme étant un moyen essentiel de relancer la croissance économique mondiale. Un échec aurait, selon le GATT, entraîné un retour en force du protectionnisme et des conflits commerciaux entre pays.

151 La levée du différend agricole entre les États-Unis et la Communauté européenne, ainsi que l'exclusion du secteur audiovisuel du champ d'application de l'Uruguay Round ont été les facteurs qui ont débloqué le processus de négociation, qui s'est terminé à midécembre 1993. Le texte final de l'Uruguay Round sera ouvert à la signature lors d'une Conférence ministérielle (prévue au Maroc au printemps 1994). Le texte est constitué d'une part d'un ensemble des 26 accords adoptés en décembre 1993, et d'autre part des engagements contraignants présentés par chaque pays. Ces engagements comprennent l'abaissement de certains obstacles au commerce des marchandises, ainsi que des réformes initiales de certaines réglementations intérieures qui restreignent le commerce des services.

Accès au marché

153 Les négociations sur l'accès au marché ont été beaucoup plus longues et laborieuses que prévues. Chaque pays devait proposer des engagements nationaux pour baisser les obstacles tarifaires et non tarifaires. Ces propositions ont ensuite fait l'objet d'une sorte de marchandage entre pays, produit par produit, afin de trouver des compromis. L'objectif global était une réduction de $33 \%$ en moyenne sur 5 ans des droits de douane, 
ainsi qu'une suppression de certaines mesures non tarifaires. Une attention devait être accordée à l'élimination de certaines crêtes tarifaires (taux de douanes nettement plus élevés que la moyenne dans certains secteurs). La progressivité des droits en fonction du degré de transformation d'un produit reste en revanche toléré. Fin août 1993, seuls 54 des 116 pays participants à l'Uruguay Round avaient présenté des offres détaillées pour les marchandises. Une décision stipule que les PMA ne sont pas tenus de contracter des engagements incompatibles avec les besoins du développement. Leurs listes de concessions et d'engagements devront être présentées d'ici avril 1995 (et non au 15 décembre 1993).

\section{Accord relatif à l'agriculture}

L'acte final prévoit une transformation en droits de douane de toutes les mesures non tarifaires (à quelques exceptions près), puis une baisse des tarifs douaniers de $36 \%$ en moyenne en 6 ans ( $24 \%$ en 10 ans pour les pays en développement). Les PMA ne doivent pas abaisser leurs droits de douane. Les subventions à l'exportation devraient être réduites de $36 \%$ en 6 ans et le volume des exportations subventionnées de $21 \%$, sur la base des exportations des années 1986-1990. Les pays en développement devront appliquer en 10 ans une réduction de deux tiers de celle qui s'applique aux pays développés, et ils n'auront pas besoin de réduire les subventions destinées à baisser les coûts de commercialisation ou de transports. "Les mesures de soutien interne à l'agriculture qui ont au plus un impact minime sur les échanges (mesures dites de la "catégorie verte") sont exclues des engagements de réduction. Elles englobent les services publics de caractère général, par exemple dans les domaines de la recherche, de la lutte contre les maladies, de l'infrastructure et de la sécurité alimentaire. Il faut y ajouter les versements directs aux producteurs, par exemple certaines formes de soutien du revenu "découplé" de la production, l'aide à l'ajustement des structures, les versementsdirectsau titre de programmes de protection de l'environnement ou d'aide régionale" (résumé de l'Acte final, NUR 80, p.10).

La Suisse était au début réticente à l'idée de la tarification de toutes les mesures non tarifaires (car ceci bouleverse, entre autres, le système des trois phases, restrictions quantitatives à l'importation, en fonction de la production nationale de fruits et légumes). Elle s'est battue pour obtenir que les soutiens internes aux paysans qui n'entraînent pas de distorsions du commerce international soient autorisés, en faisant accepter aussi le principe de multifonctionnalité de l'agriculture. Elle souhaitait une période transitoire de 10 ans pour appliquer les baisses de subventions et demandait des exceptions limitées dans le temps à la tarification pour le lait, les produits laitiers (sans fromage), certaines catégories de viande, les fruits et les légumes.

Un bilan global des avantages et des inconvénients de l'Uruguay Round est difficile à faire, de par la grande complexité des dossiers et de l'hétérogénéité des intérêts des pays en développement. Si l'Accord peut entraîner une augmentation des exportations des pays en développement les plus avancés vers les pays industrialisés, les pays qui dépendent en grande partie d'importations agricoles pourront souffrir d'une augmentation des prix mondiaux des produits alimentaires qui bénéficiaient dans le passé de subventions à l'exportation. Les pays d'Afrique-Caraïbes-Pacifique (ACP) auront des parts préférentielles de marché réduites (avantages actuels avec l'Accord multifibres, le Système généralisé des préférences et les Accords de Lomé). 
Les pays en développement accordent une grande importance à un meilleur accès pour leurs exportations dans les marchés du Nord (produits tropicaux et autres produits agricoles, textiles). Des règles négociées sur le plan multilatéral sont préférables aux mesures unilatérales arbitraires des partenaires commerciaux, au bilatéralisme commercial ou à l'établissement de blocs commerciaux. Les pays en développement sont d'ailleurs de plus en plus nombreux à participer activement au GATT et se désintéressent relativement plus des activités de la CNUCED.

La Communauté de travail des œuvres d'entraide a pris position fin octobre 1993 sur les négociations de l'Uruguay Round. Pour ces organisations, la concertation multilatérale est indispensable, mais la croissance économique axée sur les exportations et le libreéchange n'est pas suffisante en matière de développement ; le marché intérieur ne doit pas être négligé. Les considérations écologiques ont insuffisamment été prises en compte au GATT. Les relations commerciales devraient pourtant contribuer au développement durable, en tenant compte des aspects sociaux et écologiques des échanges. Les procédures de décision du GATT devraient être plus transparentes et plus démocratiques (meilleur accès à l'information, participation des $\mathrm{ONG}$ ). La négociation ne devrait plus être une épreuve de force entre les seules grandes puissances commerciales, mais garantir une pleine participation de tous les pays.

Les ONG faisaient une série de proposition pour que les intérêts des pays en développement soient mieux pris en compte dans l'acte final. Les droits de douanes sur les produits transformés au sud devraient être réduits, afin de stimuler la transformation sur place. Les pays du Sud ne devraient pas devoir ouvrir leurs marchés agricoles tant que le Nord n'aura pas réduit ses subventions agricoles. Une attention plus grande devrait être accordée aux Pays les moins avancés. Les pratiques commerciales restrictives des entreprises privées devraient être réglementées au niveau International. Le principe de préservation de la diversité biologique et le privilège des paysans (utilisation libre des semences) doivent être intégrés dans les règles commerciales, et les pays en développement devraient pouvoir choisir les produits et les délais de protection de la propriété intellectuelle. Des clauses sociales minimales sur les conditions de travail devraient permettre de combattre le dumping social (liberté des syndicats, conventions collectives, âge minimal au travail).

Certains pays en développement regrettent que l'ouverture des marchés des pays industrialisés s'opère aussi lentement. Le secteur des textiles en est un bon exemple.

Accord relatif aux textiles et vêtements

164 Le secteur du textile devra être intégré aux disciplines du GATT, ce que les pays en développement demandaient depuis longtemps. Les restrictions sur les importations de textiles provenant de ces pays devront être levées, mais progressivement, avec une période transitoire de 10 ans. Des mesures de sauvegarde pourront encore être prises si un pays importateur peut démontrer qu'une importation d'un produit particulier menace de porter un préjudice grave à la branche de production nationale. Certains pays exportateurs de textiles souhaitaient une période transitoire beaucoup plus courte, de 6 ans. Le Forum GATT des ONG suisses demandait de limiter la période transitoire à 7 ans.

\section{Accord général sur le commerce des services}

166 C'est la première fois que le GATT conclut un accord dans ce secteur. L'Accord contient des obligations fondamentales, qui concernent tous les pays membres, les listes 
d'engagements établies par les pays, ainsi qu'un certain nombre d'annexés qui portent sur la situation particulière de certaines branches (services financiers, télécommunications par exemple). Parmi les nouveautés importantes, il faut signaler la clause du traitement de la nation la plus favorisée. Cette clause stipule que tout avantage commercial octroyé par un pays membre à un autre doit automatiquement être accordé à toutes les autres parties contractantes. L'accès aux marchés doit être favorisé, en éliminant les limitations concernant le nombre de fournisseurs de services ou les limitations concernant la participation de capital étranger. La libéralisation ne touche pas les mouvements de personnes physiques.

Accord relatif aux aspects des droits de propriété intellectuelle

C'est l'un des accords qui aura beaucoup d'impact sur les pays en développement (voir les Annuaires des dernières années). La Suisse accordait une grande importance à cet accord. Une protection d'une durée de 20 ans devra être accordée pour toutes les inventions, qu'elles se rapportent à un produit ou à un procédé, dans tous les domaines technologiques. Les seules exclusions autorisées sont les suivantes: inventions qui seraient "contraires à l'ordre public ou à la moralité", les méthodes diagnostiques, thérapeutiques et chirurgicales pour le traitement des personnes ou des animaux, ainsi que les végétaux ou des animaux (autres que les micro-organismes, qui peu vent être brevetés). Les variétés végétales devront être protégées par des brevets ou par un système semblable à ce qui est prévu dans la convention internationale pour la protection des obtentions végétales (convention UPOV). Les brevets sur des procédés devront s'étendre aux produits directement obtenus par le procédé breveté. Les périodes transitoires pour l'application de l'accord s'élèvent à une année pour les pays industrialisés, 5 ans pour les pays en développement et les pays en transition, et 11 ans pour les PMA. Des demandes de dépôts de brevets devront toutefois être acceptés tout de suite pour les produits pharmaceutiques, les produits chimiques et pour l'agriculture. (Résumé de l'Acte final, NUR 80)

Pour les organisations de développement, ces règles pourront représenter un handicap pour le développement industriel des pays en développement car ils ne pourront plus imiter et adapter des produits et procédés comme ce fut le cas dans le passé lors de l'industrialisation de la Suisse ou d'autres pays aujourd'hui industrialisés. Les laboratoires des pays du Nord peuvent en outre bénéficier gratuitement de la diversité biologique conservée dans le Sud, incorporer des éléments génétiques puisés dans ces ressources biologiques dans de nouveaux produits qui seront ensuite brevetés et vendus au Sud. La question de la brevetabilité d'organismes vivants fait l'objet de discussions controversées. Une initiative opposée à la dissémination d'organismes manipulés génétiquement dans la nature et visant à interdire les brevets sur les plantes, les animaux a été déposée en Suisse.

Secteur audiovisuel

171 Les négociations de l'Uruguay Round du GATT auraient pu avoir des répercussions sur le secteur du cinéma en Suisse. Il était prévu que l'Accord du GATT sur les services soit applicable à tous les secteurs des services, dont l'audiovisuel (radio et télévision, production, projection, exploitation et diffusion d'œuvres cinématographiques, télévisuelles et vidéographiques). L'une des particularités du secteur audiovisuel est qu'il représente un support de valeurs culturelles et un élément du commerce extérieur important pour certains pays. 
Trois voies s'ouvraient au début des négociations: soustraire ce secteur aux règles du GATT, le libéraliser le plus possible ou trouver une vole médiane. Les États-Unis, premier exportateur mondial d'audiovisuel, voulaient une libéralisation complète dans ce domaine. La Communauté européenne estimait au début qu'une exclusion des services audiovisuels du champ de l'accord irait trop loin. Certains pays considéraient que la spécificité culturelle devait justifier certaines mesures commerciales restrictives, et qu'il fallait prévoir par conséquent une dérogation à l'Accord sur les services. La Suisse s'est battue, avec la Communauté européenne et les autres pays de l'AELE, en faveur d'une voie médiane, basée sur une reconnaissance formelle de la spécificité culturelle des prestations audiovisuelles, pour en tenir compte dans le processus de libéralisation. Les mesures de soutien du cinéma national, l'encouragement d'accords de coproduction entre plusieurs pays et les fonds européens d'encouragement au cinéma devaient ainsi être autorisés, selon l'avis de ces pays. Beaucoup de professionnels du cinéma craignaient qu'une libéralisation pure et simple ne se traduise par une domination encore plus grande des États-Unis dans le marché mondial, avec pour effet d'annihiler la création dans beaucoup de pays. Le débat sur la question s'est considérablement durci en automne 1993, lorsque la France a proposé une exception culturelle pour ce secteur. Le Sommet des pays francophones et des cinéastes européens renommés ont apporté leur appui à cette démarche. Le secteur a finalement été soustrait de l'Acte final de l'Uruguay Round.

Création d'une organisation multilatérale du commerce

L'Uruguay Round comprend un Accord instituant l'Organisation multilatérale du commerce (OMC). Cette organisation constituera le cadre institutionnel qui va englober l'Accord général sur les tarifs douaniers et le commerce, ainsi que tous les accords et arrangements conclus sous les auspices du GATT (donc tous les résultats de l'Uruguay Round). Une Conférence ministérielle se réunira au moins une fois tous les deux ans. Un Conseil général devra superviser le fonctionnement de l'Accord et les décisions ministérielles. Il sera l'organe de règlement des différends et le mécanisme d'examen des politiques commerciales. Il établira les organes subsidiaires: Conseil des marchandises, Conseil des services, Conseil des aspects des droits de propriété intellectuelle qui touchent au commerce (résumé de l'Acte final, NUR 80, p.5). Les pays membres de l'OMC devront accepter tous les résultats de l'Uruguay Round sans exception, donc aussi les accords sur les services, sur la propriété intellectuelle et ceux du Tokyo Round (auxquels peu de pays en développement avaient participé). La Communauté européenne et le Canada avaient proposé la création d'une OMC, mais plusieurs pays, dont la Suisse et les USA, avaient au début exprimé des réserves.

175 La Charte de la Havane de 1948 prévoyait la création de trois institutions, le FMI, la Banque mondiale et une organisation internationale du commerce. Cette dernière n'a pas vu le jour et les aspects commerciaux ont été par la suite examinés par le GATT et la CNUCED. L'Organisation internationale du commerce telle qu'elle était prévue dans la Charte de la Havane prévoyait des éléments qui ne figurent pas dans le projet 1993 de l'OMC: coopération dans les domaines du commerce et de l'emploi, assistance économique aux pays les moins développés, pratiques commerciales restrictives, accords intergouvernementaux sur les produits de base, et, thème actuel, les conditions de travail à prendre en compte. 
Certains pays en développement et des ONG souhaiteraient que certains aspects soient mieux pris en compte dans la nouvelle OMC:

- Le fonctionnement devrait être plus démocratique et transparent. La participation d'ONG devrait être favorisée.

- Le travail de l'OMC doit être coordonné avec celui d'autres organisations internationales, en particulier avec la Commission pour le développement durable, la CNUCED et l'OIT. Pour l'instant l'Accord parle surtout de coopération avec les institutions de Bretton Woods, et très peu des autres institutions qui s'occupent des mêmes thèmes (CNUCED et OMPI par exemple).

- Les règles commerciales devraient tenir compte des principes du développement durable.

Le rôle des firmes transnationales, du droit du travail et des produits de base ne devrait en outre pas être oublié.

\section{Environnement et développement}

\subsection{Rappel des résultats de la Conférence de Rio}

La Conférence des Nations Unies pour l'environnement et le développement (CNUED), qui s'est tenue en juin 1992, a débouché sur l'adoption de trois textes:

- La Déclaration de Rio

- L'Agenda 21 (plan d'Action 21 selon la terminologie officielle)

- La Déclaration de principes sur les forêts.

179 A l'origine, la Déclaration de Rio devait s'appeler la "Charte de la Terre" ; énonçant un certain nombre de principes, elle ne comporte pas d'engagements juridiques. Dans son rapport du 11 septembre 1992, la Délégation suisse à la Conférence l'estime marquée par un "esprit anthropocentrique" et regrette "l'importance donnée à la notion de souveraineté nationale (Principe 2) dans un document placé sous le signe du partenariat et de la responsabilité commune" (p. 10).

L'Agenda 21 est le produit le plus important de la Conférence. Conçu comme plan de sauvetage de la planète, il passe en revue en 40 chapitres l'ensemble des domaines de l'environnement et du développement. Pour la délégation suisse, il "pêche par manque de précision conceptionnelle" dans le domaine des instruments de l'économie de marché, de l'accès des pays du Sud aux marchés de l'OCDE et des relations entre commerce et environnement". Ses lacunes dans le domaine des technologies font de plus qu'on ne peut guère s'attendre, selon la délégation, à "un accroissement des flux de technologies écocompatibles" (p. 15).

181 Quant aux Principes cadres sur la protection des forêts, c'est tout ce qui reste après l'échec des négociations sur une convention sur les forêts. Néanmoins, ils ne retiennent pas la primauté de la souveraineté nationale dans ce domaine et affirment que la gestion forestière doit s'exercer dans le cadre du développement durable. Sur demande expresse des pays en développement, le texte se réfère explicitement à "tous les types de forêts". De l'avis de la délégation suisse, "ce texte offre une solution minimale au problème de l'usage durable des forêts, et aucun changement significatif dans ce domaine n'est à attendre à moins d'une modification importante de la situation en matière de financement international. En effet, seuls des engagements précis des pays industrialisés sur des compensations financières aux pays en développement 
dépendant de l'exploitation de leurs ressources forestières pourraient amener ces derniers à lever leur opposition massive à l'élaboration d'une convention" (p. 28-29). L'objectif fixé par l'OIBT en 1990 qu'en l'an 2000 la totalité du commerce international de bois tropicaux porte sur des grumes issues d'une gestion durable est également rejeté par les pays en développement. été créé fin 1990. Il est géré conjointement par la Banque mondiale, le Programme des Nations-Unies pour le développement et le Programme pour l'environnement. Il doit permettre de financer les coûts additionnels de projets destinés à limiter la pollution de l'environnement dans les pays en développement. Les projets concernent le climat, la biodiversité, les océans et l'ozone. A ce jour, $42 \%$ des fonds ont été accordés à des projets portant sur la biodiversité, $40 \%$ concernant le climat, et $17 \%$ les eaux internationales. En tout 113 projets ont été financés pour 727 millions de dollars. Le premier exercice, en fait une phase pilote, se termine mi-1994. Le Fonds sera aussi utilisé dans le cadre de l'application des conventions sur le climat et la biodiversité. Celles-ci comprennent explicitement des engagements à l'égard des pays en développement en matière de financement et de transfert de technologie. versements totaux, contribution prélevée sur le crédit-cadre de 700 millions de francs voté par les Chambres fédérales en 1991. Un quart a été destiné au cofinancement d'actions menées par des organismes comme le PNUE. 
Lors de la 5ème réunion des Etats membres (Pékin, mai 1993), les bailleurs de fonds étaient tombés d'accord pour que les contributions augmentent la prochaine période (presque un doublement des contributions), le Fonds étant ainsi porté à environ 2 milliards de dollars; sa thématique serait aussi élargie aux questions de la désertification, des sols et de la déforestation. Contrairement à ce qui se pratique à la Banque mondiale, les ONG ont accès à l'ensemble des projets du Fonds et des représentants d'ONG font partie de délégations officielles de négociation (la Suisse a accepté un représentant d'ONG lors de la réunion de Pékin).

S'agissant de la restructuration, la Suisse avait demandé une évaluation indépendante de la phase-pilote. A ce sujet, la 4ème réunion, tenue à Abidjan en décembre 1992, avait désigné un comité d'experts provenant de 7 pays (France, Inde, Costa-Ftica, Indonésie, Canada, Kenya, Suisse) en vue d'évaluer le fonctionnement du Fonds, l'expert suisse étant Rudolf Hôgger, président d'Helvetas. Les experts ont rendu leur rapport en novembre 1993. Ce rapport relève des dysfonctionnements importants: compétences mal définies des organes de décision, priorités et stratégie peu transparentes, projets reflétant avant tout les intérêts des organismes qui les proposent, manque de concertation et de participation à la base, conflits entre les trois gérants du Fonds. $60 \%$ des projets sont simplement ajoutés à des projets menés par la Banque mondiale.

Les pays en développement réclament que le pouvoir de décision revienne à l'assemblée des Etats membres (actuellement au nombre de 72) et que les organes exécutifs soient indépendants des 3 agences. Depuis décembre 1992, le Fonds est ouvert à tout pays ayant payé le droit d'entrée de 4 millions de dollars. Le Conseiller fédéral Flavio Cotti avait déclaré à la CNUED que la Suisse "souhaite une réforme de ses structures, dans le sens d'une amélioration de sa transparence et d'une meilleure représentation de tous les pays en son sein, en particulier les pays en développement" (discours du 10 juin 1992). La Suisse souhaitait éviter la création d'un organe de financement nouveau pour chaque nouvelle convention. Elle s'est prononcée en faveur d'un mode de décision où pays en développement et pays industrialisés seraient à égalité, et pour une plus grande indépendance de l'exécutif du Fonds à l'égard de la Banque mondiale.

191 Le réapprovisionnement du Fonds pour la période 1994-1996 et la réalisation des réformes de structure étaient à l'ordre du jour de la réunion de Carthagène, Colombie, tenue du 6 au 10 décembre 1993. Malheureusement, cette réunion s'est conclue sur un constat d'échec: aucune réforme de structure substantielle n'a pu être adoptée et, quant aux engagements financiers, on demeure dans le vague. Une nouvelle réunion est programmée au début de 1994.

\subsection{L'instrument de suivi : la Commission du développement durable (CDD)}

Du 2 au 6 novembre 1992, l'Assemblée générale des Nations Unies a débattu des suites à donner à la CNUED.

193 A l'issue de plusieurs semaines de négociations, 7 résolutions ont pu être adoptées le 22 décembre 1992, acceptant le rapport sur la CNUED, créant une commission du développement durable, mettant sur pied un comité intergouvernemental de négociation sur une convention contre la désertification, appelant à une conférence sur le développement durable des petits Etats insulaires, lançant le programme Capacity 21 
du PNUD. En entérinant le rapport de la Conférence, l'Assemblée générale donna son aval à la Déclaration de Rio, à la Déclaration sur les forêts et l'Agenda 21, et en réclama une mise en œuvre efficace. Les ONG ont pu assister aux débats. Une commission d'experts pour le développement durable comprenant 21 personnalités conseillera le secrétaire général. En 1997, cinq ans après la CNUED, une session spéciale de l'assemblée générale sera consacrée à une revue d'ensemble de la mise en œuvre de l'Agenda 21.

194 La résolution créant la CDD a rattaché cette dernière à l'ECOSOC, l'a localisée à NewYork et prévu une composition de 53 membres de niveau ministériel (13 représentants d'Etats d'Afrique, 11 d'Asie, 10 d'Amérique latine, 6 de l'Europe de l'Est et 13 autres). La Suisse avait engagé une importante offensive diplomatique pour obtenir la localisation de la CDD à Genève, mais de nombreux pays préféraient une concentration au siège. La tâche de la CDD sera de stimuler la mise en œuvre de l'Agenda 21, y compris en matière de transfert de technologie et de financement. A cet effet, elle évaluera les rapports nationaux sur la mise en œuvre de l'Agenda 21, recevra les impulsions des ONG, fera des recommandations à l'assemblée générale par l'entremise de l'ECOSOC. Elle renforcera aussi le dialogue sur l'intégration du développement durable à tous les niveaux, à l'intérieur du système des Nations Unies, y compris le GATT et la Banque mondiale. Commission de l'ECOSOC, la CDD n'a pas de compétence de décision ni la capacité de donner des directives à d'autres organes des Nations Unies (p. ex. au Fonds pour l'environnement, etc.). Elle a par contre la compétence d'inviter les instances des Nations Unies à rapporter sur leurs activités, et de commenter ces rapports; elle reste libre de ses recommandations. La CDD a aussi l'intention de développer des indicateurs du développement durable.

$\mathrm{Au}$ cours de sa première session, tenue du 14 au 25 juin 1993, à New-York, la Commission a défini ses modes de coopération avec les organisations des Nations Unies, les exigences relatives aux rapports des pays et son plan de travail pour les années à venir. La Commission est placée sous la présidence de l'ambassadeur Razali, de Malaisie. Le gouvernement suisse était représenté par Mme Ruth Dreifuss, laquelle insista sur l'importance d'exigences de qualité pour les rapports nationaux; elle souhaita un rôle actif et de stimulant pour la Commission, disant que cette dernière devait se "mêler des affaires des autres"; selon le Conseil fédéral, le transfert de technologie propre reste une clé, ainsi que la redéfinition des règles du commerce international.

Les travaux de la CDD sont ouverts aux ONG, et les règles d'accréditation sont celles, libérales, de la CNUED ; à la première réunion assistèrent environ 280 représentants d'ONG, certains présents aussi dans des délégations officielles (par exemple dans les pays suivants: Italie, Grande-Bretagne, France, Etats-Unis, Pays-Bas). Le programme de travail retenu prévoit de passer en revue chaque année les thèmes relatifs aux ressources et aux mécanismes financiers, aux transferts de technologie, à la formation et à la recherche, aux structures de décision et aux groupes sociaux concernés. Il y aura des groupes de travail intersessionels ad hoc sur les questions de financement, de transfert de technologie et sur les demandes des pays en développement (dette, prix des matières, accès aux marchés, etc.). En 1994 seront en outre passés en revue les chapitres de l'Agenda 21 relatifs à la santé, à l'habitat, aux eaux douces, aux toxiques et aux déchets toxiques (chapitres 6,7 et 18 à 22), en 1995 on parlera des sols, de la désertification, des forêts et de la diversité biologique (ch. 10-15), puis, en 1996, de 
l'atmosphère, des océans et des mers (ch. 9 et 17). La Suisse dispose pour l'instant d'un statut d'observateur au sein de la commission.

Quant aux rapports nationaux, les pays en développement souhaitaient limiter au minimum les prescriptions relatives à leur contenu. Finalement la recommandation a été retenue qu'ils fournissent des informations sur l'état d'avancement des plans d'action, ne dépassent pas 50 pages, se concentrent sur les thèmes débattus selon le programme arrêté par la CDD et soient livrés six mois à l'avance; le secrétariat de la $\mathrm{CDD}$ présentera des synthèses à partir de cette documentation.

\subsection{Aperçus sur la mise en œuvre de l'Agenda 21}

L'Agenda 21 concerne de prime abord l'ensemble des opérateurs institutionnels : les Etats, et les organisations inter-étatiques.

Trois agences ont reçu des mandats spécifiques : le PNUD est chargé du renforcement des capacités nationales, le PNUE doit promouvoir une meilleure coordination internationale des politiques environnementales, la CNUCED de l'étude des relations entre commerce et environnement. Le programme Capacity 21 du PNUD a été doté de 100 millions de dollars pour sa phase pilote.

Le chapitre 38 de l'Agenda 21 assigne au PNUE le rôle de leader dans le développement du droit international de l'environnement. Le 17ème Conseil biennal d'administration, qui s'est tenu du 10 au 21 mai 1993, a manifesté un certain flottement de l'organisation quant à ses orientations, d'autant plus qu'elle fait face à des réductions de budget. Lors de cette réunion, la Suisse a apporté son soutien au Centre d'assistance environnementale d'urgence, en demandant qu'il reçoive un mandat plus précis, et en appuyant une nouvelle phase-pilote de 12 mois, devant se terminer par une évaluation. "La Suisse, déclare le Conseil fédéral dans son rapport sur la politique extérieure de la Suisse dans les années 1990, fait partie de la douzaine de pays qui apportent les plus importantes contributions au PNUE" (p. 36).

Au niveau des Etats, plusieurs pays ont d'ores et déjà institué des commissions du développement durable nationales, chargées de promouvoir la mise en œuvre des objectifs définis à Rio, et établi des plans d'action nationaux (Australie, Danemark, Canada, Pays-Bas, etc). Dans divers pays les ONG sont associées. Du 13 au 15 octobre 1993 s'est tenue à Ottawa une rencontre organisée par l'OCDE sur la manière de concevoir les plans nationaux de développement durable, s'agissant des définitions, de la quantification des objectifs, des critères d'évaluation ou encore des méthodologies. Lors de cette réunion, la crainte a été exprimée que les plans ne soient par trop vagues et demeurent au stade de déclarations d'intention sans poids réel sur la politique économique et sociale des Etats.

\subsection{Convention sur les changements climatiques}

202 Parmi les premiers Etats ayant ratifié la Convention, on note d'importants émetteurs de gaz à effet de serre comme le Canada, les Etats-Unis, la Chine, l'Australie ou le Japon, mais aussi des Etats insulaires, comme les Seychelles, les îles Fidji ou la Barbade.

La Convention oblige les parties à fournir un inventaire national tenu régulièrement à jour sur les émissions de gaz à effet de serre, et les capacités d'absorption existantes (dites "puits"), et à mettre en place un programme national de mesures portant sur 
l'ensemble des émissions. La Convention comporte des mécanismes qui lui permettront, au même titre que la Convention de Genève sur la pollution atmosphérique transfrontière ou la Convention de Vienne sur la protection de la couche d'ozone, des développements ultérieurs (protocoles, amendements, annexes).

L'entrée en vigueur de la Convention est agendée pour fin mars 1994, la première conférence des parties étant prévue du 28 mars au 17 avril 1995 à Berlin. Divers Etats ayant signé mais non encore ratifié la Convention commencent d'ores et déjà à développer les éléments de la mise en œuvre, et trois réunions du comité de négociation (CIN) ont eu lieu à Genève et à New-York entre décembre 1992 et août 1993. Les problèmes actuellement en suspens concernent la définition de méthodologies comparables pour les inventaires nationaux d'émissions et le financement des transferts de technologie, mais aussi la relation Convention-FEM, le rôle des organes subsidiaires, l'adéquation des engagements. Les Etats-Unis, en particulier, ont mis à disposition de l'expertise et des moyens pour l'élaboration des plans nationaux par des pays en développement.

Sur le plan scientifique, le GIEC, Groupe d'experts intergouvernemental sur l'évolution du climat (en anglais : IPCC), poursuit ses travaux; il s'est fixé un programme de travail de 3 ans en vue d'être prêt pour la conférence des parties. Enfin, la Suisse a contribué à la création, au sein du PNUE, d'un Bureau d'information sur les changements climatiques destiné aux pays en voie de développement, établi, comme les secrétariats du CIN et du GIEC, à Genève, et dont elle a assuré dans la phase initiale la presque totalité du financement. Plus de $20 \%$ des émissions mondiales des gaz à effet de serre proviennent d'Asie, et cette proportion atteindra $35 \%$ d'ici l'an 2025. Le PNUD aidera les pays de cette région à formuler des plans afin de limiter leurs émissions de gaz à effet de serre.

Les pays de l'OCDE, et d'Europe centrale et orientale, se sont en principe engagés à stabiliser leurs émissions de C02 d'ici l'an 2000. La Suisse a ratifié la Convention en novembre 1993. Dans son message à ce sujet, le Conseil fédéral expose que $37 \%$ des émissions nationales de $\mathrm{C0} 2$ sont dues aux transports, $29 \%$ au chauffage, $13 \%$ à l'industrie et $15 \%$ aux services, le gaz carbonique représentant entre 74 et $90 \%$ de l'ensemble des émissions de gaz à effet de serre de la Suisse. En 1989 a été institué un Groupe de travail interdépartemental sur l'évolution du système climatique (GIESC), sur la base des travaux duquel le plan national suisse sera établi.

207 Pour la Suisse, l'objectif de stabilisation se trouve déjà dans le programme Energie 2000 défini par le Conseil fédéral en novembre 1990. Ce programme est cependant considéré comme trop dispersé et pas assez volontariste par les ONG, et en septembre 1993 deux initiatives populaires ont été lancées. La première demande une redevance de 0,1 à 0,5 centime par kWh d'énergie non renouvelable durant 20 ans en vue de constituer un fonds pour l'énergie solaire, la seconde une redevance sur les énergies non renouvelables en vue de rendre rentable une politique de conservation de l'énergie, ainsi qu'une réduction de la consommation de ces énergies de $1 \%$ par an sur 25 ans. Précédemment, en avril 1993, les ONG avaient rendu publics leurs propres objectifs sous forme d'un programme appelé Energie Demain, comprenant une stabilisation des émissions de $\mathrm{C} 02$ dès maintenant, et une réduction de $50 \%$ d'ici 2025 par rapport à 1990. Présentant le 3ème rapport d'activités d'Energie 2000, le conseiller fédéral Ogi déclara le 16 septembre 1993 que "l'énergie coûte moins cher aujourd'hui, en termes réels, qu'avant la première crise du pétrole, en 1973 (...) : l'électricité dans le ménage a 
baissé de $16 \%$, l'essence de $29 \%$ et le mazout de $34 \%$ ". L'idée d'une taxation énergétique, compensée fiscalement, est par ailleurs toujours poursuivie dans les instances européennes.

\subsection{Convention sur la biodiversité}

208 A l'instar de la Convention précitée, le texte de la Convention sur la biodiversité est d'une grande complexité, traitant à la fois de la question de la protection des milieux de vie des espèces, et de l'exploitation économique de leur potentiel génétique.

Lors de la signature, le 11 juin 1992, la Suisse avait insisté, dans une "déclaration interprétative" sur le "respect des principes et des règles sur la propriété intellectuelle (...), essentiels pour la recherche et les investissements privés, en particulier dans les technologies de pointe, comme la biotechnologie moderne qui demande de grands efforts financiers." La Communauté européenne avait pris une position analogue. Ces déclarations - puisque la Convention ne permet pas les réserves au sens juridique soulignent l'ampleur des enjeux économiques. Les entreprises du Nord ont déjà puisé gratuitement des éléments génétiques dans le patrimoine biologique diversifié des pays du Sud. La Convention constitue à cet égard une transaction d'ampleur planétaire, dans laquelle le Sud tente de monnayer une exploitation qui a déjà bien commencé, et où les enjeux économiques s'appellent accès aux ressources génétiques d'une part, et accès aux technologies de l'autre.

La Convention est entrée en vigueur au 29 décembre 1993. D'ores et déjà, des plans d'action nationaux sont en préparation, par exemple en Indonésie, au Brésil, au Canada ou encore en Chine. En mai 1993 le PNUE instituait un comité intergouvernemental sur la Convention, dans le but de préparer la première conférence des parties. La première réunion de ce comité se tint à Genève en octobre 1993, avec 120 représentants de gouvernements et 80 d'ONG; elle se solda par un relatif constat d'échec, un des points d'achoppement étant les exigences de sécurité en matière d'organismes génétiquement manipulés.

211 Les Etats-Unis, qui avaient combattu la Convention à leurs yeux trop favorable aux intérêts du Sud l'ont finalement signée en juin 1993, mais faisant diverses restrictions quant à la définition du transfert de technologie, notamment. En Suisse, des questions demeurent en suspens. Lors d'une conférence de presse en octobre 1993, le WWF Suisse, Swissaid et l'organisation agricole Union des Producteurs suisses reprochèrent au Conseil fédéral la lenteur des préparatifs de la procédure de ratification. Dans sa réponse du 23 juin 1993 à une motion de la commission de l'environnement du Conseil national, le Conseil fédéral explique qu'il envisage que la ratification ait lieu au cours de la première moitié de 1994. Pour répondre aux exigences de la Convention, il faudra compléter les instruments pour inventorier le patrimoine naturel, dans lesquels entreront les informations et concepts existants ou encore à créer, notamment en matière de paysage.

212 Le principe de l'accord préalable des pays en développement pour l'accès à leurs ressources génétiques pose également des problèmes d'ajustement, selon le Conseil fédéral. Les ONG suisses sont fortement opposées au brevetage d'organismes vivants et défendent la diversité génétique ainsi que la prise en compte des effets économiques et sociaux de l'exploitation du potentiel génétique. Des positions restrictives sur la 
technologie génétique sont articulées par voie d'initiative populaire (initiative "protection génétique" déposée en octobre 1993).

\subsection{La négociation sur la désertification}

213 A Rio, la Suisse avait apporté son soutien à la proposition du Groupe africain demandant une Convention contre la désertification. Institué par l'assemblée générale des Nations-Unies, le comité intergouvernemental de négociation sur la désertification (CIN-D), présidé par l'ambassadeur suédois Kjellen, doit terminer ses travaux en juin 1994. Cinq sessions de négociation sont prévues entre mai 1993 et juin 1994. Un groupe international de 15 experts de la désertification accompagne les travaux du CIN, qui se sont ouverts sur une première séance d'auditions. Le projet de Convention prévoit des plans d'action nationaux, des dispositions sur la recherche et la formation, le transfert de technologies, la participation de la population locale, et l'évaluation continue de la situation. Un protocole sur l'Afrique sera négocié et présenté simultanément à la Convention; d'autres protocoles régionaux devront être établis pour la fin 1994. Plus de 230 ONG sont accréditées auprès du CIN-D. La Suisse, qui abrite le secrétariat du CIN, souhaite que le financement des mesures prévues dans la Convention se fasse prioritairement à travers le Fonds pour l'environnement.

\subsection{Le suivi de Rio en Suisse}

Le Conseiller fédéral Flavio Cotti avait exposé devant la CNUED que le gouvernement suisse s'est engagé à accroître substantiellement le volume de son aide publique au développement" (discours du 10 juin 1992), et que "la Suisse s'engage à assumer pleinement sa part de l'effort demandé“ (13 juin). Cette position a été réaffirmée lors d'une conférence de presse tenue le 22 juin 1992, où ont été annoncées l'augmentation de l'aide publique à $0,4 \%$ du PNB et la présentation prochaine d'une taxe sur le C02. Après les réductions budgétaires linéaires opérées par le parlement, on a passé de 0,39\% en 1992 (chiffre comprenant les coûts de l'entrée à la Banque mondiale et au FMI) à 0,34 en 1993.

Le programme de législature 1992-1995 prévoit l'introduction d'une taxe sur le C02, coordonnée "dans la mesure du possible" avec les mesures similaires prises par d'autres pays industrialisés, et dont le taux "tiendra compte de la charge fiscale existante" (Message sur la Convention sur le climat, p. 9). Une étude faite sur mandat de l'OFEFP par le bureau Ecoplan souligne que la Suisse connaît, pour les huiles de chauffage, les taxes fiscales parmi les plus basses d'Europe; pour l'essence, malgré l'augmentation de 20 centimes par litre décidée en mars 1993, elle reste dans la partie inférieure de la moyenne européenne.

216 Le mode d'organisation pour assurer la traduction nationale des engagements contenus dans l'Agenda 21 et de participation des ONG a fait l'objet de longues tractations. L'idée de départ des ONG était de partir de la délégation suisse à la CNUED. Malgré plusieurs échanges de lettres et diverses interventions, il a fallu attendre le mois de mars 1993 pour que le Conseil fédéral décide d'un mode d'organisation. Le 1 er mars 1993, le Conseil fédéral créa "un Comité interdépartemental chargé de coordonner les politiques sectorielles dans les domaines impliqués dans le suivi de la CNUED", ce suivi exigeant "l'amélioration de la cohérence des politiques sectorielles et leur ajustement 
de façon à ce que le mode de développement pratiqué par la Suisse soit finalement durable pour ses habitants autant que pour les autres occupants de la planète" (communiqué de presse DFAE). Le comité interdépartemental (appelé Cl-Rio) est "chargé de la concertation et de la coordination des politiques sectorielles dans des domaines tels que les politiques agricoles et forestières, la gestion urbaine, la protection de la diversité biologique, le commerce international." Il est présidé chaque année à tour de rôle par le directeur de la DDA, de l'OFEFP ou de l'OFAEE. En mars les secteurs non gouvernementaux étaient conviés à une séance d'information, puis, en mai fut constitué un Groupe de liaison réunissant les administrations concernées et 9 représentants non gouvernementaux. Sept groupes de travail interdépartementaux comptant des représentants de milieux externes ont commencé leurs travaux.

Un Plan d'action doit, pour chaque problématique traitée dans l'Agenda 21, exprimer les intentions du Conseil fédéral quant aux mesures particulières adoptées ou à adopter pour la Suisse jusqu'en l'an 2000 et au-delà. Les moyens qu'il entend mettre en œuvre doivent être mentionnés. Chaque chapitre exposera l'objectif poursuivi par la Suisse, avec mention des délais, des conséquences financières, et les actions prévues sur le plan interne suisse, sur le plan de la politique internationale et sur le plan de la coopération. Les difficultés majeures de ce processus proviennent du manque de moyens (le Conseil fédéral n'a affecté aucun poste supplémentaire au suivi de Rio, ni moyens financiers spécifiques) et des complexités propres à l'harmonisation interdépartementale. Par contre l'association de milieux externes est bien acceptée. Dans son rapport sur la politique extérieure, le Conseil fédéral accorde une place importante aux enjeux du développement durable : "La Suisse œuvrera en faveur d'une utilisation judicieuse des ressources naturelles, d'une croissance qualitative et d'un développement durable" (p. 45); une des tâches reconnues prioritaires par l'administration et les milieux non gouvernementaux est de parvenir à une définition opérationnelle du développement durable, et qui puisse servir de référence à tous les secteurs de la société.

218 Signalons également l'établissement d'une Stratégie environnementale de la DDA en juin 1993, et d'une stratégie suisse pour l'encouragement de la recherche dans les pays en développement, et sur le développement, "partenaires dans la recherche avec les pays en développement, dans l'esprit de Rio", proposée en août 1993 par la Conférence des Académies scientifiques suisses et la DDA. Rappelant que sur 441 Prix Nobel seuls 7 proviennent du Sud, M. J.-F. Giovannini, directeur adjoint de la DDA, soulignait que la dimension du Sud doit prendre davantage de poids dans la politique de la recherche suisse.

\subsection{La Conférence de Lucerne "Un environnement pour l'Europe"}

Enfin, la Suisse a abrité et présidé à Lucerne en avril 1993 la Conférence des ministres de l'environnement de 46 Etats européens, du Canada, des Etats-Unis, de l'Australie et du Japon, “Un environnement pour l'Europe". La conférence a adopté un programme d'action pour l'Europe centrale et orientale, fondé sur trois principes : intégration des facteurs environnementaux dans les plans de développement économique ; création de capacités ; assistance immédiate d'urgence. A cet égard, la Suisse s'est engagée pour une meilleure valorisation des diverses Conventions internationales existantes. 
220 Le programme d'action comporte une liste de projets, à réaliser sous l'égide d'un comité de préparation des projets ; aucun financement supplémentaire n'est prévu, et la Suisse affectera 30 millions de francs pris sur les crédits d'aide à l'Europe de l'Est. Les ONG suisses ont regretté la faiblesse des engagements concrets et insisté sur la nécessité de valoriser des technologies propres, de redéfinir la politique de l'énergie et des transports, et de mettre en œuvre des instruments économiques. Par contre elles se sont réjouies des acquis en matière d'accès à l'information et de possibilités d'intervention. En 1995 se tiendra une nouvelle conférence, à Sofia. La Suisse apportera son concours pour qu'à cette occasion une décision paneuropéenne pour une taxe sur le $\mathrm{C} 02$ puisse être prise. Le groupe de travail international chargé de préparer cette conférence comprend des représentants d'ONG.

221 Un chapitre particulier de la situation à l'Est est la question nucléaire. 64 centrales nucléaires sont situées en Europe centrale et de l'Est, et dans les Etats de la CEI, et présentent des défaillances importantes dans les systèmes de sécurité, de surveillance et d'entretien. L'Académie russe des sciences a demandé en 1992 l'arrêt des réacteurs du type Tchernobyl, au nombre de 16. En effet, après la catastrophe de 1986, les incidents et accidents n'ont pas cessé dans ce type d'installation. A ce sujet, l'industrie suisse a présenté 27 projets de réhabilitation de centrales nucléaires, pour un volume d'investissements de 200 millions de francs suisses. Les ONG demandèrent que ces centrales soient fermées et que ces fonds aillent dans les alternatives énergétiques, position que la Banque mondiale n'est pas loin de partager.

La Conseillère fédérale Ruth Dreifuss, qui présidait la conférence, a insisté sur le fait que notre coopération politique et économique avec l'Est ne nous délie pas de notre responsabilité à l'égard du Sud.

\subsection{Autres activités environnementales}

223 - Commission baleinière internationale

224 La Suisse avait rejoint la Convention dans le but de pouvoir soutenir une politique restrictive de pêche à la baleine. Lors de la 45éme assemblée de la CBI, tenue en mai 1993 à Kyoto, la proposition de créer une réserve dans les eaux antarctiques en-dessous du 40 ème parallèle Sud a été faite. La délégation suisse, craignant que cette proposition soit purement et simplement rejetée (une majorité des $3 / 4$ est exigée), a préféré s'abstenir, et présenta une proposition alternative laissant ouverte la délimitation de la réserve. La Suisse assume la présidence du groupe de travail chargé d'étudier cette question.

225 - Convention de Bàie sur les mouvements transfrontières des déchets dangereux

Cette Convention, dont la Suisse est dépositaire, est entrée en force en mai 1992. Pratiquement aucun pays de l'Union Européenne, hormis la France, ni les Etats-Unis ni le Japon, n'ont encore ratifié ce texte; ces pays produisent plus de $90 \%$ des déchets toxiques dans le monde

- Protocole de Montréal sur la protection de la couche d'ozone

Lors de la 4ème Conférence des parties contractantes, tenue en novembre 1992, à Copenhague, le plan de réduction des substances dommageables pour la couche d'ozone a été avancé dans le temps. Le Fonds multilatéral destiné à aider les pays en développement à promouvoir des produits de substitution comprenait pour 1993113 
millions de dollars. L'OMM signalait en octobre 1993 des teneurs particulièrement basses en ozone au-dessus de l'Antarctique, où, entre 14 et $19 \mathrm{~km}$ d'altitude, l'ozone a complètement disparu. Dans cette question se révèle à nouveau l'importance centrale du transfert de technologie: selon une étude du PNUE, la consommation de produits dommageables pour la couche d'ozone a augmenté dans le Sud de $50 \%$ entre 1986 et 1991. Sans promotion planétaire de technologies propres, les efforts de substitution opérés (à grand peine) dans le Nord se verraient assez rapidement compensés par le développement des émissions en provenance du reste du monde. La 5ème Conférence des parties qui s'est tenue en novembre 1993 à Bangkok a été consacrée à ce thème, et a chiffré les besoins financiers du transfert de technologies à 510 millions de dollars pour les trois prochaines années.

- Réglementation de la pêche en haute mer

En novembre 1993, la FAO a mis sur pied une convention sur la pêche en haute mer, destinée à la régulation de la pêche et à la protection des effectifs de poisson. Depuis 1950, le produit de la pêche mondiale s'est multiplié par quatre, et en maints endroits des signes d'épuisement se manifestent. La situation actuelle se caractérise par un suréquipement de l'industrie de la pêche et une concurrence renforcée.

- Interdiction du déversement de déchets radioactifs en mer

232 En 1983 les 71 Etats signataires de la Convention de Londres sur les déversements en mer avaient convenu d'un moratoire de 10 ans sur le déversement de déchets radioactifs en mer. La Suisse a renoncé en 1992 au déversement de déchets moyennement et faiblement radioactifs, et a soutenu lors de la conférence des parties tenue début novembre 1993 à Londres la proposition du Danemark de transformer le moratoire en interdiction définitive. La France et la Grande-Bretagne se sont abstenues, préférant la reconduction du moratoire. 29 Etats membres de la Convention n'avaient pas participé à la réunion; les Etats qui se sont abstenus ou qui étaient absents disposaient d'un délai de 100 jours pour se prononcer définitivement, les pays refusant d'endosser l'interdiction de déversement se retirant de la Convention.

- Organisations privées

Le 19 juin 1993 a été présentée à Genève la Croix verte internationale. Cette nouvelle organisation a pour buts la prévention, la réduction et la maîtrise des catastrophes écologiques, la diffusion des connaissances sur les risques écologiques et les moyens de les contenir, la promotion du développement durable et le dialogue entre les décideurs. Le siège principal se trouve à La Haye.

De son côté, le Business Council for Sustainable Development (BCSD), qui regroupe aujourd'hui 52 chefs d'entreprise de niveau mondial, poursuit ses travaux dans trois directions : l'internalisation des coûts environnementaux dans les prix des biens et des services ; le marché des capitaux et les pays en développement ; le partenariat pour des projets écologiques dans les pays en développement. En novembre 1993 un ancien premier ministre de Thaïlande, A. Panyarachun, a été élu pour 2 ans président du BCSD, en remplacement du Suisse Stefan Schmidheiny ; un Américain du Nord doit prendre le relais dans 2 ans. Trois chefs d'entreprises basées en Suisse font partie du BCSD: Elisabeth Salina Amorini (Société Générale de Surveillance), Alex Krauer (Ciba-Geigy) et Percy Barnevik (ABB). 


\subsection{Perspectives}

Si la notion du développement durable se révèle effectivement extrêmement adéquate, le passage à l'acte nécessite un certain nombre de conditions :

1. Au plan international, l'intégration effective des problèmes de la crise des pays industrialisés dans la notion de développement durable, faute de quoi les causes communes aux différentes manifestations de dysfonctionnement économique mondial ne seront pas perçues comme telles et les préoccupations d'environnement et de développement pourront passer de plus en plus en seconde priorité.

2. Au plan international toujours, l'intégration des exigences du développement durable dans les politiques économiques, en cherchant à éliminer au niveau géographique le plus large les distorsions en défaveur du développement durable; c'est toute la problématique du commerce et de l'environnement. Après la fin du Cycle de l'Uruguay, cette question centrale doit être impérativement reprise; la Convention sur le climat contient également une disposition visant la coopération internationale en matière d'instruments économiques.

3. Au plan des pays, un vaste débat impliquant tous les acteurs sociaux sur la définition et la mise en œuvre du développement durable comme diagnostic des besoins du monde et issue à la crise.

4. Ces conditions feront que le développement durable ne sera pas une formule creuse de plus peuplant le cimetière des bonnes intentions mais agissant à l'interface des politiques économiques et des politiques extérieures des nations comme clé de cette "Weltinnenpolitik" qui semble bien le seul mode d'appréhension sensé de nos problèmes.

\section{Développement humain}

\subsection{Conférence mondiale sur les droits de l'homme}

La Conférence a permis de réaffirmer la valeur universelle des droits de l'homme et l'importance des instruments multilatéraux adoptés dans ce domaine. Aucune percée décisive n'a par contre été trouvée pour l'instauration d'un poste de haut Commissaire, ni pour un renforcement de la prévention ou la répression des violations des droits de l'homme.

Plusieurs controverses ont jalonné la préparation du projet d'acte final de la Conférence, avec notamment la remise en question par certains pays de la valeur universelle des droits de l'homme, ainsi que le débat sur l'importance du droit au développement.

La Suisse a plaidé en faveur d'un renforcement des institutions des Nations Unies qui travaillent dans ce domaine, afin de permettre notamment une meilleure prévention des violations graves de ces droits.

Plusieurs organes des Nations Unies travaillent dans le domaine de la protection et de la promotion des droits de l'homme. Une série d'instruments ont été adoptés sur le plan multilatéral, sous les auspices des Nations Unies, ou, plus contraignants, par le Conseil de l'Europe (voir encadré). Les atteintes aux droits de l'homme continuent pourtant à être perpétré dans la majorité des pays, cela malgré le renforcement des dispositions internationales.

\section{Enjeux et résultats de la Conférence de Vienne}

241 La Conférence mondiale avait pour objet de dresser le bilan des progrès accomplis et des obstacles à lever en matière de protection des droits de l'homme. Elle devait 
formuler des recommandations destinées au renforcement de l'action menée par les Nations Unies. Près de 4000 délégués de 165 pays ou de 800 ONG se sont réunis pour cela à Vienne, du 14 au 25 juin 1993.

Des divergences sur des questions de fond entre pays du Nord et certains pays en développement sont rapidement apparues lors des réunions préparatoires, notamment en raison d'une conception différente des droits de l'homme dans les régions du monde. Dans sa déclaration devant la Conférence, le Secrétaire général des Nations Unies Boutros Boutros-Ghali a réaffirmé l'universalité des droits de l'homme. Une action internationale est pour lui justifiée lorsque les Etats ne garantissent pas les droits humains, car ces droits abolissent, par leur nature, la distinction traditionnelle entre l'ordre interne et l'ordre international. Le processus de démocratisation est aussi indissociable de la protection des droits de l'homme.

La Conférence s'est terminée par l'adoption d'une Déclaration et d'un Programme d'action dans le domaine.

\section{La Suisse face à la politique multilatérale de protection des droits de l'homme}

L'action des Nations Unies est basée sur sa charte constitutive et la Déclaration universelle des droits de l'homme de 1948.

- La Suisse a ratifié les pactes des Nations Unies en 1992 : Pacte sur les droits économiques, sociaux et culturels, Pacte sur les droits civils et politiques. Ces pactes de 1966 ont permis d'établir un catalogue de droits fondamentaux qui doivent être garantis par des règles juridiques. Les Etats doivent se justifier devant les Comités des pactes et devant la Commission des droits de l'homme lors de violations. Cette dernière commission siège à Genève, ainsi que la sous-commission de la lutte contre les mesures discriminatoires et celle de la protection des minorités, le Groupe de travail sur les peuples autochtones et le Centre des droits de l'homme des Nations Unies. La Suisse participe aux travaux de la Commission des droits de l'homme depuis 1987 (sans droit de vote).

- La Suisse a adopté la Convention de 1984 contre la torture, dont le comité est présidé par un Suisse.

- La Convention des droits de l'enfant a été ratifiée par plus de 120 pays. Les États-Unis, le Japon et certains pays européens ne l'ont pas encore ratifiée : Bosnie, Croatie, Grèce, Irlande, Pays-Bas, Suisse et Turquie. Le parlement examinera la question de l'adhésion de la Suisse en 1994.

- La procédure de ratification par la Suisse est en cours pour la Convention sur l'élimination de toutes formes de discrimination raciale, le Protocole visant l'abolition de la peine de mort.

- La Suisse n'a pas ratifié la Convention des Nations Unies contre la discrimination à l'égard des femmes, ni la Convention sur la protection des droits des travailleurs migrants, ni celle sur l'élimination du crime d'apartheid ou celle réprimant le génocide.

- Elle a ratifié la Convention européenne des droits de l'homme, qui prévoit des mécanismes de contrôle plus efficaces qu'au niveau mondial, mais pas encore tous les protocoles qui s'y réfèrent.

\section{Universalité des droits de l'homme}

La question de l'universalité des droits a été remise en question d'une part par ceux qui voulaient faire reconnaître les particularismes nationaux et régionaux, face à une 
conception des droits héritée surtout de la France et des États-Unis. Certains pays asiatiques et du monde arabe ont insisté sur les contextes historiques, politiques, culturels et religieux qui pourraient justifier, selon eux, une conception différente des droits de l'homme. Beaucoup de pays du Sud craignaient aussi une trop grande ingérence étrangère dans les affaires intérieures. Ces positions ont été défendues notamment par la Birmanie, la Chine, la Malaisie, Singapour, le Soudan, le Viêtnam, mais aussi Cuba.

D'autres part, les droits de l'homme peuvent être perçus par certains pays comme un "luxe des pays riches", alors que les pays du Sud doivent lutter avant tout contre la pauvreté et pour le droit au développement. Les pays latino-américains, dont certains sont sortis de régimes dictatoriaux, ont insisté sur les liens entre les droits humains, la démocratie et le développement. Les ONG du continent sud américain ont relevé que les nouvelles démocraties néolibérales laissent une large place à l'autoritarisme, à la corruption et à la violence.

Le processus de démocratisation reste pour beaucoup indissociable de la protection des droits de l'homme. Certains pays industrialisés (États-Unis par exemple) auraient souhaité conditionner l'aide au développement à des progrès dans le domaine du respect de ces droits. Les pays industrialisés et les ONG ont fermement défendu le concept d'universalité des droits de l'homme, concept repris dans la Déclaration finale, avec toutefois des références aux particularismes nationaux et traditions culturelles différentes.

Question des garanties liées au respect des droits humains

Les positions des pays étaient partagées entre ceux qui souhaitaient une simple consolidation des structures et mécanismes qui existent et ceux qui prônaient la création de nouveaux organes et de nouvelles procédures pour mieux prévenir et sanctionner les violations des droits humains. Les Etats-Unis, soutenus entre autre par la Suisse et Amnesty International, préconisaient la création d'un poste de Hautcommissaire des Nations Unies. Ils reprenaient une idée qui avait été lancée par le Costa Rica. Ce Haut-commissaire pourrait coordonner l'action des commissions et groupes dej'ONU, ainsi que pour établir un système d'alerte destiné à la prévention des violations graves de ces droits. Cette proposition n'a été soutenue que par un peu moins de la moitié des pays, beaucoup craignaient une trop grande ingérence dans leurs affaires intérieures. Le Programme d'action adopté finalement mandate l'Assemblée générale des N. U. pour étudier la création du poste de Haut-commissaire. L'Assemblée a accepté la création de ce poste en décembre 1993.

Le projet de création d'une cour internationale de justice pour réprimer les graves violations des droits de l'homme n'a pas pu être concrétisé lors de la Conférence. Le Programme d'action final se borne à recommander une coordination accrue au sein du système des Nations Unies. Il recommande un renforcement des moyens financiers pour le Centre des droits de l'homme. Seul $1 \%$ des ressources des N.U. est pour l'instant affecté à ce domaine. L'instauration d'une cour internationale de justice est renvoyée à l'appréciation de la Commission du droit international.

Droits des femmes et droits des minorités

252 La Conférence a souligné l'importance de la lutte contre les discriminations à l'égard des femmes. Leurs droits ont été pour la première fois explicitement intégrés aux mécanismes des N.U. relatifs aux droits fondamentaux de l'Homme. 
Les Etats devraient, selon le texte final, garantir les droits des handicapés ou des minorités, en particulier ceux des populations autochtones.

La Conférence encourage les pays qui ne l'ont pas encore fait à ratifier rapidement les traités internationaux relatifs aux droits humains et les protocoles s'y rapportant.

\section{Position des ONG de défense des droits de l'homme}

Les recommandations des ONG ont été élaborées notamment lors d'un vaste Forum des ONG qui s'est tenu à Vienne juste avant la Conférence. Contrairement à ce qui se passe souvent lors de conférences internationales, les positions des ONG des pays industrialisés étaient très proches de celles défendues par leurs gouvernements. Les revendications portaient sur un renforcement du contrôle, une meilleure prévention des violations des droits de l'homme et l'établissement d'un système de sanctions. Amnesty International préconisait la création d'un poste de Commissaire spécial et d'une cour internationale de justice. A la fin de la rencontre de Vienne, l'organisation, déçue des résultats, a qualifié celle-ci de "sommet des occasions manquées".

\section{Position de la Suisse}

La Suisse a été déçue des trop maigres résultats de la Conférence. Lors de son intervention devant la Conférence, le Conseiller fédéral Flavio Cotti a demandé un renforcement des institutions de l'ONU qui travaillent dans ce domaine, dont le Centre pour les droits de l'homme. Il a accordé son soutien au projet de création d'un poste de Haut-commissaire de l'ONU. La prévention des violations devrait être renforcée selon lui, notamment par le projet d'origine suisse de Protocole facultatif à la Convention contre la torture, qui prévoit de soumettre toute menace potentielle contre les droits de l'homme à l'examen d'une commission d'enquête ad hoc. La mise en œuvre du droit international humanitaire devrait être renforcée (voir point II.4.2. de la partie Revue). Une femme devrait être nommée "Rapporteur spécial" de la Commission des droits humains, sur la question des droits fondamentaux des femmes (proposition reprise dans le texte final).

Flavio Cotti a réaffirmé l'universalité des droits humains. Aucun Etat ne saurait donc se soustraire aux obligations sous prétexte de moindre développement ou de particularismes culturels, même s'il reconnaît que le droit au développement fait partie intégrante des droits humains. Pour lui, "les pays industrialisés ont, dans le cadre du droit au développement, un devoir moral de solidarité". La réalisation des droits économiques et sociaux passe nécessairement par un processus de démocratisation favorable au développement. L'aide au développement doit donc s'orienter vers les principes de bonne gestion des affaires publiques, soit transparence de l'action de l'Etat, parlement librement élu, intégration de l'armée dans la société civile, protection des libertés, justice sociale, administration compétente fonctionnant sans corruption, etc.

La Suisse veut soutenir cette orientation par le dialogue politique, la concertation, le soutien de projets de coopération en faveur de la démocratisation, mais sans conditionner toute aide au développement au respect des droits de l'homme. Il serait, selon l'avis du Conseil Fédéral, illusoire pour un petit pays comme la Suisse, de vouloir faire insérer, dans un traité bilatéral de nature économique, une clause sur les droits de l'homme. Les ONG suisses de développement ou de défense des droits de l'homme ont 
pourtant à plusieurs reprises fait pression sur le Conseil Fédéral pour que celui-ci tienne mieux compte de la situation politique de certains pays (lors d'exportations d'armes, de renvois de réfugiés ou lors d'adoption d'accords bilatéraux par exemple).

La politique suisse dans ce domaine est menée par la Section des droits de l'homme du Département fédéral des affaires étrangères, sur le plan bilatéral ou multilatéral. Cette section gère le crédit destiné à financer des actions concrètes en faveur des droits de l'homme et du droit humanitaire. D'un demi-million en 1989, ces contributions ont passé à un million en 1992, pour baisser à 900000 francs en 1993, suite aux coupures budgétaires. Les contributions sont notamment destinées à des ONG de défense des droits humains et à des fonds spéciaux de l'ONU.

\subsection{Conférence internationale pour la protection des victimes de la guerre 1993}

La "Conférence internationale pour la protection des victimes de la guerre" s'est déroulée à Genève du 30 août au 1er septembre 1993. Convoquée par la Suisse, à l'initiative du Comité international de la Croix-Rouge (CICR), elle a réuni 159 pays (sauf l'ex-Yougoslavie). En organisant cette conférence, la Suisse souhaitait lancer un débat en vue de renforcer le respect du droit international humanitaire et inciter les gouvernements à se préoccuper plus activement des nombreuses victimes de la guerre. Une déclaration finale adoptée par les Etats est venue confirmer leur volonté de respecter et de faire respecter les obligations du droit international humanitaire. Une cour pénale internationale devrait être créé pour sanctionner les violations de ce droit. La "purification ethnique", la violence sexuelle dirigée contre les femmes et les enfants, la famine utilisée comme arme contre les civils ont été condamnées comme étant des infractions graves au droit international humanitaire.

La Suisse est le pays dépositaire des conventions de Genève qui règlent la protection des victimes de la guerre et qui ont été adoptées en 1949 sous l'effet du choc provoqué par la deuxième guerre mondiale. Après la décolonisation sanglante des années 60 et du début des années 70, deux protocoles additionnels sont venus s'ajouter aux conventions de Genève (voir l'encadré). Aujourd'hui, après la fin de la guerre froide et la dissolution du bloc de l'Est, le monde traverse à nouveau une période de bouleversement qui se traduit par des conflits régionaux et des guerres civiles, dans lesquels les principes éthiques et moraux du droit international humanitaire sont de moins en moins respectés.

Le Comité international de la Croix-Rouge doit veiller à l'application des Conventions de Genève et des Protocoles additionnels. En tant qu'organisation impartiale, neutre et indépendante, il peut exiger de prendre librement contact avec les personnes qui ont besoin de son aide. La Conférence internationale des Sociétés de la Croix-Rouge et du Croissant Rouge, qui réunit tous les quatre à cinq ans les délégués de 150 pays, offre un forum aux débats sur le respect du droit international humanitaire qui est contenu dans les Conventions de Genève. La 26ème Conférence internationale de la CroixRouge, qui devait se dérouler à Budapest en novembre 1991, a dû être annulée peu avant sa tenue (en raison entre autres du désaccord qui a régné au sujet du statut de la délégation de l'OLP). La prochaine Conférence internationale des Sociétés de la CroixRouge et du Croissant-Rouge ne devrait pas se tenir avant 1995.

Sollicitée par le Comité international de la Croix-Rouge, la Suisse, considérant la recrudescence des violations du droit international de la guerre sur tous les continents, 
a jugé opportun de rappeler le respect des Conventions de Genève au niveau international et d'inviter la communauté des Etats à réaffirmer le respect du droit International humanitaire à l'occasion d'une conférence. Dans son allocution d'ouverture, le Conseiller fédéral Flavio Cotti - qui a présidé la Conférence - a constaté que le droit International de la guerre fait partie des normes de droit international parmi les moins respectées. Les travaux de la Conférence se sont fondés sur un rapport du CICR sur les violations du droit international humanitaire, que tous les Etats ont reçu avec l'invitation à la Conférence. Celle-ci ne devait ni servir de tribune politique ni fonctionner comme un tribunal. Elle n'avait pas pour objectif de condamner certains Etats, mais de réaffirmer les principes du droit international humanitaire et de confirmer que l'aide humanitaire aux victimes de la guerre ne tient pas compte des frontières politiques.

L'intervention armée des forces de l'ONU pour assurer l'acheminement de l'aide humanitaire en Somalie, mais aussi dans le conflit qui agite le territoire de l'exYougoslavie, illustre les difficultés que rencontre cette aide. Selon le CICR, les acteurs des conflits, surtout lorsqu'il s'agit de conflits régionaux et de guerres civiles, tendent à violer avec de moins en moins de scrupules le droit international humanitaire. D'aucuns n'hésitent pas à livrer des attaques armées contre la population civile et contre les organisations humanitaires ou à prendre des otages, pour obliger leur adversaire militaire à consentir des concessions. On bafoue le droit des organisations humanitaires de s'occuper des victimes et de la population touchée dans les zones de conflit. Nombre d'œuvres d'entraide gouvernementales et non gouvernementales mues parfois par des motifs politiques - travaillent sur le terrain, ce qui rend difficile la situation particulière $\mathrm{du}$ CICR et du droit international humanitaire reposant sur les Conventions de Genève. La Conférence de Genève avait pour but de rappeler la place spécifique du CICR et du droit international humanitaire et de réaffirmer le caractère universel du droit de toutes les victimes de la guerre d'obtenir de l'aide.

Déclaration sur la protection des victimes de la guerre

La Conférence a adopté par consensus la "Déclaration sur la protection des victimes de la guerre". Dans une première partie, cette déclaration dénonce l'accroissement de la cruauté dans les zones de conflit, une cruauté qui touche de plus en plus la population civile: "Nous refusons d'accepter que, partout dans le monde, la guerre, la violence et la haine s'étendent, que les droits fondamentaux de la personne humaine soient bafoués de plus en plus gravement et de plus en plus systématiquement. Nous refusons d'accepter que des blessés soient achevés, des enfants massacrés, des femmes violées, des prisonniers torturés, des victimes privées d'assistance humanitaire élémentaire, que la famine soit utilisée comme méthode de guerre contre les civils..." La "purification ethnique" et la violence dirigée contre les femmes et les enfants ont été condamnées comme des pratiques particulièrement odieuses ${ }^{(13)}$.

La seconde partie de la déclaration appelle instamment les Etats à respecter et à faire respecter le droit international humanitaire, à diffuser systématiquement le contenu des Conventions de Genève et de leurs Protocoles additionnels, à enseigner le droit international humanitaire aux membres de l'administration et de l'armée, à faire participer les médias à une large information de la population sur ce droit et d'inclure ses dispositions dans la législation nationale. Le maximum d'Etats doivent ratifier dans les meilleurs délais les Protocoles additionnels des Conventions de Genève. 
Le droit international comprend les normes de droit qui ont été fixées par les accords et les conventions conclues au niveau des Etats ou des organisations internationales. Le droit international de la guerre (droit humanitaire international) concerne toutes les règles que doivent respecter toutes les parties d'un conflit armé présentes sur le terrain des hostilités. Il comprend l'interdiction de certains engins et méthodes de combat. Le droit de Genève fait partie du droit international de la guerre et comprend les dispositions destinées à protéger les victimes de la guerre. Comme le démontrent la plupart des conflits armés, le grand défaut du droit international de la guerre réside dans la faiblesse de ses instruments d'application. On envisage depuis des années de créer une cour pénale internationale permanente qui serait chargée de punir les violations de ce droit et la Commission de l'ONU pour le droit international public prépare un projet. La majeure partie du droit international humanitaire est inscrite dans les quatre Conventions de Genève de 1949 sur la protection des victimes de la guerre. Celles-ci sont venues remplacer la Convention de Genève de 1864. Les deux premières conventions visent à améliorer le sort des soldats blessés, malades ou victimes d'un naufrage, la troisième convention régit le traitement des prisonniers de guerre et la quatrième convention la protection des personnes civiles. Les deux protocoles additionnels de 1977 visent à assurer une protection accrue à la population civile en cas de conflits internationaux (protocole) et non internationaux (protocole II). Pratiquement tous les Etats ont adhéré aux Conventions de Genève, y compris les nouveaux pays nés dans les années 90 (181 signataires au total). Toutefois, nombre de pays n'ont pas ratifié les protocoles additionnels.

La déclaration invite également les gouvernements à sanctionner et à punir les crimes de guerre. Cette procédure est d'ailleurs prévue par les Convention de Genève. La déclaration demande aussi que la communauté internationale soutienne la création d'une cour pénale internationale et permanente.

Des divergences sont apparues quant à l'application du droit international humanitaire dans le cadre de conflits armés internes. Quelques pays ont demandé que l'on supprime la formule qui prévoit expressément que le droit international humanitaire s'applique également aux conflits internes et aux guerres civiles ("conflits à caractère non international"). Sur demande de certains pays, la déclaration comprend un passage selon lequel les "forces de maintien de la paix de l'ONU sont également tenues d'agir conformément au droit international humanitaire".

Les participants à la Conférence ont ajouté un paragraphe à la déclaration dans lequel ils demandent à la Suisse de réunir un groupe d'experts sur le droit international humanitaire chargé de rechercher des moyens pratiques de promouvoir le plein respect de ce droit et l'application de ses règles. Ce groupe devra rédiger un rapport à l'intention de la prochaine Conférence internationale de la Croix-Rouge et du Croissant-Rouge (prévue pour 1995).

Campagne d'information de la Croix-Rouge

272 A l'occasion de la Conférence de Genève pour la protection des victimes de la guerre, le CICR a lancé une vaste campagne d'Information qui s'adresse à tous les citoyens et citoyennes. Son message est le suivant: "181 Etats ont signé les Conventions de Genève. 
Engagez-vous, vous aussi pour le respect de ce droit." Les sociétés nationales de la Croix-Rouge et du Croissant-Rouge sont chargées de transmettre ce message à toute la population au travers des médias et de diverses actions, afin d'accroître la reconnaissance du droit international humanitaire.

\subsection{OIT : Conférence internationale du travail 1993}

L'Organisation internationale du travail (OIT) a tenu en juin (du 2 au 22) 1993 la 80ème session de la Conférence internationale du travail à Genève. Elle a adopté une convention sur la prévention des accidents industriels majeurs et examiné en première lecture une convention sur le travail à temps partiel. La sécurité sociale a constitué le thème principal des débats et du rapport que le directeur Michel Hansenne a adressé aux représentants de 155 pays réunis à la conférence. M. Hansenne a été réélu à son poste de directeur pour une nouvelle période de cinq ans. Diverses voix suggèrent à l'OIT de se restructurer pour mieux faire face à ses nouvelles tâches (accroissement du chômage, dimension sociale des programmes d'ajustement structurel). La Conférence a adopté une résolution sur la coopération technique de l'OIT et une autre sur la protection sociale en période de transition et d'ajustements structurels.

L'Organisation internationale du travail a été fondée en 1919 avec l'objectif suivant : atténuer la pauvreté et le chômage dans le monde entier, couvrir les besoins essentiels des groupes les plus défavorisés, rendre plus humain le monde du travail ${ }^{(14)}$. Elle compte aujourd'hui parmi les institutions spécialisées des Nations Unies et elle est la seule à fonctionner selon le système tripartite : des représentantes et des représentants des gouvernements ( 2 voix), des associations d'employeurs et des syndicats (une voix respectivement) prennent part au processus de décision. L'Organisation compte aujourd'hui 164 Etats membres et son organe permanent, le Bureau International du travail, a son siège à Genève. Elle a créé un code international du travail complet qui comprend 1973 accords (conventions/normes). Les gouvernements sont tenus de faire régulièrement rapport sur l'application des normes ratifiées.

On demande des réformes

La tâche centrale de l'OIT consiste à mettre en place des normes pour protéger les travailleurs et à veiller à leur application. Elle fournit également une aide technique pour l'application des normes. Depuis quelques années, les employeurs proposent des réformes selon lesquelles la tâche normative de l'OIT devrait être placée au second plan au profit d'une aide technique en faveur de la croissance. Selon eux, les conventions de l'OIT représentent des obstacles à la croissance qui finissent par porter préjudice aux investissements et à l'emploi. Ils remettent notamment en question le droit de grève. Les employeurs exigent qu'à l'avenir l'OIT s'attache plus à soutenir l'économie. Ce soutien devrait profiter aux divers pays indépendamment du respect des conventions de l'OIT.

Les syndicats se sont violemment opposés à cette proposition visant à faire de l'OIT un instrument en faveur de la croissance économique. Ils proposent de leur côté des réformes pour rendre l'Organisation plus efficace : au vu du taux élevé de chômage qui s'accompagne d'une détérioration des conditions de travail, elle devrait renforcer ses activités. A l'avenir, l'OIT devrait s'attacher à représenter et à défendre la dimension sociale des programmes d'ajustement du FMI et de la Banque mondiale. De plus, l'Organisation devrait organiser plus efficacement sa campagne en faveur de l'adoption d'une clause sociale au sein du GATT. 
La mauvaise conjoncture et la récession ont a nouveau remis à l'ordre du jour la divergence entre travailleurs et employeurs. Depuis la disparition des blocs idéologiques, qui s'opposaient dans le conflit Est-Ouest, cette divergence prend de plus en plus de place dans les débats de l'OIT. Dans son rapport annuel, l'Organisation note que le développement qui a le plus marqué le monde du travail ces dernières années réside dans la montée du chômage et dans l'affaiblissement de la position des travailleurs.

Prévention des accidents industriels majeurs

Lors de sa session de 1993, la Conférence a adopté une convention et une recommandation concernant la prévention des accidents industriels majeurs et sur les mesures à prendre dans une telle situation pour protéger les travailleurs, la population et l'environnement. La nouvelle convention exige des gouvernements qui la ratifient qu'ils élaborent une politique de sécurité nationale pour prévenir les accidents industriels de grande envergure. Cette politique doit prévoir entre autres les mesures de prévention et de protection pour les installations à risques et encourager le développement et la mise en place des meilleures techniques de sécurité disponibles.

Les entrepreneurs sont tenus de notifier à l'autorité compétente toute installation à risque d'accident majeur; ils doivent aussi présenter un système de prévention. La convention ne s'applique pas aux installations nucléaires, ni aux usines traitant des substances radioactives, ni aux installations militaires, ni au transport (hormis les pipelines). La recommandation comprend des indications plus détaillées dans ce domaine, mais demeure vague pour ce qui est des dédommagements; elle appelle simplement les Etats à mettre en place des systèmes destinés à dédommager les travailleurs dès que possible après un accident industriel et à faire face aux effets de cet accident sur la population et l'environnement. La question centrale relative à la responsabilité et à l'obligation de dédommager reste ouverte. Les représentants syndicaux ont particulièrement critiqué cette absence de réglementation. Ils regrettent également que la convention ne prévoie pas une participation active des employés dans l'entreprise, car ceux-ci sont simplement consultés lors de l'élaboration d'un dispositif de sécurité.

282 Le représentant du gouvernement suisse s'est prononcé en faveur de la convention, mais a présenté deux réserves à son adoption :

1. La consultation des travailleurs prévue dans la convention va nettement plus loin que ne le prévoit l'ordonnance suisse en la matière.

2. L'obligation incombant aux pays exportateurs d'informer tout pays importateur sur les motifs qui l'ont amené à interdire l'utilisation d'un produit à risque, appartient au domaine de la politique économique et d'exportation et non à la politique sociale et du travail. La délégation syndicale s'est prononcée en faveur de la convention et les représentants des employeurs ont fait de même.

Après l'incendie de Sandoz à Schweizerhalle en 1986, la Suisse a élaboré une ordonnance sur les accidents majeurs dans le cadre de la loi sur la protection de l'environnement; cette ordonnance ne prévoit pas non plus la participation des travailleurs et de la population. Contrairement à la norme de l'OIT, elle s'applique toutefois aussi aux entreprises utilisant des procédés biologiques ou génétiques.

Travail à temps partiel 
L'OIT applique le principe de la double lecture, c'est-à-dire qu'une convention est débattue au cours d'une première conférence annuelle, pour être mise au point et adoptée l'année suivante. Ce système laisse suffisamment de temps aux membres pour consulter les milieux intéressés et prendre une décision.

En 1993, la Conférence a ainsi accepté en première lecture une convention sur le travail à temps partiel. Celle-ci doit couvrir les aspects suivants : le droit des travailleurs et des travailleuses à choisir librement leur poste de travail (à temps partiel), l'importance et la nécessité économique du travail à temps partiel, la protection et la sécurité sociale des personnes travaillant à temps partiel. politique de l'organisation en matière de coopération technique. Ce thème a à nouveau fait l'objet de discussions en 1993 et une résolution a été adoptée. Le programme de coopération technique de l'OIT devra à l'avenir mettre l'accent sur les domaines suivants : appui à la démocratisation, atténuation de la pauvreté, dont la création d'emplois est l'un des instruments, protection des travailleurs. Pour améliorer les conditions dans le monde du travail, l'élaboration de normes et le soutien technique dans l'application de ces normes doivent aller de pair. Les employeurs ont en majorité soutenu cette résolution, mais ils n'acceptent pas le lien étroit qu'elle prévoit entre l'aide technique d'une part et la création et l'application des normes d'autre part. Ils souhaitent distinguer la coopération technique de la position qu'un pays adopte face aux normes de l'OIT. Selon eux, un tel lien pourrait même nuire à la population des pays en développement; on priverait en effet cette population de toute coopération technique si le gouvernement du pays omet d'appliquer les normes de l'OIT. Les syndicats sont favorables au lien créé entre coopération technique et respect des normes, car la création de postes de travail ne doit pas négliger la protection des travailleurs, faute de quoi on favorise l'exploitation des demandeurs d'emploi - en particulier des plus faibles d'entre eux, c'est-à-dire des femmes et des enfants - surtout dans le Tiers Monde et dans les pays de l'Est qui sont en plein bouleversement. Le débat portant sur l'orientation des activités de l'OIT en matière de coopération technique a seulement permis aux membres d'exprimer leur opinion et n'a pas donné lieu à une décision.

utre résolution a été adoptée qui concerne la protection sociale et l'atténuation du chômage et de la pauvreté, ainsi que la dimension sociale de l'ajustement structurel et de la transition vers une économie de marché. Selon cette résolution, la protection sociale est un droit que devrait pouvoir exercer chaque membre de la société. En période de récession et de changement économique et politique, le dialogue social, c'est-à-dire la participation de toutes les couches concernées de la population à la formulation de réformes économiques et structurelles, revêt une importance particulière. L'OIT a été Invitée à renforcer sa collaboration avec le FMI et la Banque mondiale, afin d'assurer que la sécurité sociale soit inscrite dans les programmes d'ajustement structurel et de réforme économique dans les pays en développement et dans les pays de l'Est. L'OIT a 
été appelée à mettre son expérience au service de la préparation et de la tenue du "Sommet mondial pour le développement social" prévu pour 1995.

\section{Budget et programme pour 1994 à 1995}

La Conférence a adopté le plan de travail pour la période de 1994 à 1995, ainsi qu'un budget de 466,5 millions de dollars pour cette même période. Outre la poursuite des activités “classiques" de l'OIT, le plan de travail prévoit également des réformes structurelles dans le domaine de la coopération technique. Celle-ci devra à l'avenir appliquer plus systématiquement le principe du "partenariat actif", ce qui signifie que le gouvernement du pays bénéficiaire de l'aide collaborera plus étroitement à la réalisation du programme de l'OIT.

Des groupes dits multidisciplinaires seront créés à cet effet dans toutes les régions du monde, qui seront chargés d'assurer le suivi des activités sur place. Les représentants du gouvernement suisse se sont opposés à cette politique de partenariat actif. Selon eux, elle gonfle l'appareil administratif et risque de politiser les activités de l'OIT. Le gouvernement suisse souhaite que l'OIT concentre ses activités sur la politique de l'emploi, et plus spécialement sur la protection des travailleurs. Elle devrait se faire le pendant social des négociations multilatérales purement économiques pour défendre la protection des travailleurs ;elle pourrait ainsi devenir une sorte de "GATT social (15).

Autres thèmes abordés par la Conférence

- L'application de la Convention de l'OIT sur les droits de l'homme au cours de l'année écoulée.

- Une séance extraordinaire a été consacrée à la situation des travailleurs des territoires arabes occupés. C'est la quatrième année de suite que l'OIT soulève cette question. Les délégués suisses soutiennent les recommandations de l'OIT et souhaitent plus particulièrement que les travailleurs palestiniens aient accès au marché du travail en Israël.

- L'apartheid en Afrique du Sud constitue toujours un thème spécial de la Conférence du travail. Au vu des réformes engagées et des élections prévues en Afrique du Sud, la session de 1993 a fait part de son espoir de voir bientôt l'égalité des droits établie entre les races. Souhaitant continuer à soutenir le processus de démocratisation, elle a demandé aux gouvernements de maintenir leurs pressions sur l'Etat sud-africain (y compris l'embargo sur les armes et l'embargo sur les produits pétroliers de l'ONU). Pendant toutes ces années, le gouvernement suisse a refusé de prendre des sanctions économiques contre l'Afrique du Sud tout en condamnant la discrimination raciale. En 1993, il a accepté les conclusions du rapport de l'OIT sur l'Afrique du Sud. La Suisse estime qu'il convient de suivre de près la politique appliquée en Afrique du Sud et de revoir le cas échéant les "actions de l'OIT contre l'apartheid" (levée de l'embargo).

- Le président argentin Carlos Menem a été l'hôte de la Conférence. Il a expliqué aux participants les efforts entrepris par son gouvernement pour créer des emplois dans le respect des normes de l'OIT.

\subsection{OMS : Assemblée mondiale de la santé 1993}

Les délégués des Etats membres de l'Organisation Mondiale de la Santé ont en mai 1993 examiné les questions liées à la lutte contre certaines maladies (SIDA, paludisme, tuberculose...). Le nouveau budget-programme pour les années 1994/ 95 a été adopté, avec une croissance réelle zéro par rapport au budget précédent. La réélection du japonais Hiroshi Nakajima pour un second mandat à la tête de l'organisation ne s'est pas déroulée sans problèmes, compte tenu des 
critiques adressées envers sa gestion des dernières années. Plusieurs décisions adoptées par l'Assemblée visent un meilleur contrôle et une meilleure transparence dans les activités de l'OMS. (Voir aussi le dossier de la partie Analyses et positions sur la politique de la santé vis à vis des pays en développement).

L'OMS dirige et coordonne depuis 1948 les activités internationales en matière de santé. Les axes de travail sont l'information sur la situation sanitaire dans le monde, l'encouragement de la coopération technique, la recherche et la formation du personnel de santé. La 46ème Assemblée mondiale de la santé s'est déroulée à Genève du 3 au 14 mai 1993, en présence de quelque 1200 délégués de la plupart des 186 Etats membres, dont la Suisse.

Situation sanitaire mondiale

La fréquence de certaines maladies diminue et les campagnes de vaccination ont permis de faire reculer certaines maladies de l'enfance. Près de 13 millions d'enfants de moins de 5 ans meurent pourtant encore chaque année, soit 35000 . Selon l'OMS et l'UNICEF près des deux tiers de ces décès pourraient être évités grâce à des mesures assez simples et peu onéreuses: antibiotiques, vaccination, réhydratation orale lors de maladies diarrhéiques. 3 millions d'enfants meurent chaque année suite aux diarrhées, 3,6 millions de la pneumonie, 880000 de la rougeole (en régression), $800000 \mathrm{du}$ paludisme, 560000 du tétanos du nouveau-né et 360000 de la coqueluche (chiffres Rapport 1993 de l'UNICEF). Certaines maladies tropicales reprennent de l'ampleur: paludisme, choléra, fièvre jaune, dengue (transmis par des moustiques, maladie touchant des dizaines de millions de personnes). 
Une résolution présentée par un groupe de pays africains demande l'élimination des pratiques traditionnelles nocives et des obstacles sociaux préjudiciables à la santé des femmes, des enfants et des adolescentes : mariages d'enfants, restrictions alimentaires durant la grossesse (aggravant l'anémie), mutilations sexuelles pratiquées sur les femmes (concernant plus de 80 millions de femmes dans plus de 30 pays, africains surtout). Ces pratiques provoquent des complications de santé, augmentent la mortalité maternelle ou des bébés à la naissance, et constituent donc des freins à la réalisation des objectifs de santé fixés par l'OMS. Plus d'un demi-million de femmes meurent chaque année lors de la grossesse et de l'accouchement. élevées en 1992 à 2,8 millions de francs pour le Programme de lutte contre le SIDA, 2 millions pour le programme de recherche sur les maladies tropicales, 550000 francs pour le Programme sur la santé maternelle, 525000 pour lutter contre les maladies diarrhéiques, 350000 pour le Programme des médicaments et vaccins essentiels et 325000 francs pour la recherche sur la reproduction humaine. 
La Suisse soutient fortement le Programme d'action de l'OMS pour les médicaments essentiels. En Suisse, la Déclaration de Berne poursuit depuis dix ans une campagne sur l'utilisation rationnelle des médicaments. Elle publie depuis 1987 la lettre d'information "Med in Switzerland". Certaines pratiques publicitaires ont été dénoncées et certains produits diffusés jugés non rationnels (médicaments obsolètes, vitamines contre la stérilité des femmes, stimulant de l'appétit diffusés dans des pays où règne la malnutrition, etc.). Une étude publiée en 1989 recensait 515 médicaments exportés par la Suisse jugés inadéquats (médicaments non enregistrés en Suisse, interdits en Suisse mais exportés, préparations avec des associations jugées irrationnelles de produits, information incomplète et notices d'emplois différentes selon les pays, compositions de médicaments différentes entre pays...). En novembre 1993 et d'après les Informations fournies par les entreprises concernées, seuls 46 des 515 préparations jugées inadéquates auraient été retirées du marché ( 7 autres ont été modifiées). La Déclaration de Berne et Medicus Mundi déplorent que la Suisse, troisième exportateur mondial de produits pharmaceutiques, n'ait encore aucune loi sur le contrôle des exportations de médicaments. $15 \%$ des produits suisses sont exportés dans les pays en développement. Une firme suisse peut donc fabriquer des médicaments et les exporter sans que ces produits aient été soumis à un contrôle par les autorités. Les médicaments dont la vente est interdite en Suisse, ou qui ont été retirés du marché, peuvent être exportés. Deux motions ont été déposées aux Chambres fédérales pour demander un contrôle à l'exportation (Motions Dormann et Jaggi). Les motions ont été transformées en postulat par le Conseil national et le Conseil des Etats et transmises au Conseil fédéral en 1990. Pour le Conseil fédéral, il n'est pas possible d'interdire l'exportation de tous les médicaments non enregistrés en Suisse, car une partie des médicaments non enregistrés en Suisse ne sont utilisés que dans les pays en développement (contre les maladies tropicales par exemple). D'une façon générale, les médicaments exportés devraient satisfaire aux critères de qualité en vigueur en Suisse et des groupes de travail ont été mis sur pied par le Conseil fédéral pour élaborer une loi fédérale pour la surveillance du commerce transfrontalier des médicaments. La situation est rendue plus complexe par le fait qu'en Suisse, la réglementation pour les médicaments reste intercantonale : concordat intercantonal sur le contrôle des médicaments.

\section{Agriculture - nutrition}

\subsection{FAO, OMS : Conférence internationale sur la nutrition}

La première Conférence internationale surla nutrition d'envergure planétaire s'est tenue à Rome en décembre 1992. Elle a réuni plus de 1400 représentantes et représentants de gouvernements ainsi que d'organisations gouvernementales et privées de plus de 150 pays, dont la Suisse. La Conférence avait pour but de réunir les pays participants dans un consensus sur un Plan d'action contre la faim, la sous-alimentation et la malnutrition etd'adopter une "Déclaration mondialesurla nutrition".

319 La Conférence s'est tenue du 5 au 11 décembre 1992 à Rome, où se trouve le siège de la FAO. C'est la première fois qu'une conférence d'une telle Importance s'est penchée sur les relations existant entre la faim, la sous-alimentation et la malnutrition et les problèmes qui en résultent pour la santé et le développement des populations. Elle a de 
plus élaboré des stratégies en vue de garantir à tous, au même titre qu'un droit fondamental, une alimentation suffisante et saine. La Conférence a été présidée par Simone Veil, Ministre français de la santé. Elle a été précédée de huit réunions préparatoires régionales.

La Déclaration mondiale sur la nutrition constate que puisque nous disposons des moyens et des connaissances pour lutter contre les liens qui existent entre malnutrition et sous-alimentation, d'une part, et le développement des hommes et des pays, d'autre part, il est d'autant plus inadmissible que tant de personnes continuent de souffrir de faim et de malnutrition. Le Plan d'action adopté comprend les stratégies nécessaires pour venir à bout de ces problèmes.

La FAO et l'OMS ont élaboré le document de base de la Conférence, Intitulé Nutrition et développement - un défi mondial, qui brosse un tableau exhaustif des principales difficultés et connaissances en matière de faim et de santé(16) $:$ La production vivrière mondiale est largement suffisante pour satisfaire les besoins nutritionnels de toute l'humanité, mais c'est l'accès à la nourriture qui pose problème, c'est-à-dire sa répartition. On constate ainsi d'une part que $20 \%$ de la population des pays en développement (soit 786 millions de personnes) souffrent de malnutrition chronique (en 1970 elles étaient 941 millions, soit $36 \%$ ). Plus de 40000 enfants de moins de cinq ans meurent chaque jour et la malnutrition est la principale responsable de leur décès. Plus de deux milliards de personnes souffrent de carences en micronutriments (vitamines, oligo-éléments). D'autre part, les excès alimentaires (sucre, graisse) dans les pays industrialisés ont des effets néfastes sur la santé, puisqu'ils provoquent des problèmes d'obésité et des troubles cardio-vasculaires. Cette remarque vaut également pour les nouvelles formes de malnutrition des populations urbaines dans nombre de pays en développement.

L'élaboration des stratégies s'est basée sur huit propositions spécifiques ayant les thèmes suivants :

- améliorer la sécurité alimentaire des ménages ;

- prévenir et traiter les maladies infectieuses ;

- prendre en charge les personnes défavorisées et vulnérables (nourrissons, enfants, femmes, personnes âgées) ;

- promouvoir des régimes alimentaires appropriés et des modes de vie sains;

- protéger le consommateur en améliorant la qualité et la sécurité des produits alimentaires ;

- prévenir les carences en micronutriments ;

- évaluer, analyser et surveiller la situation nutritionnelle;

- inclure les objectifs nutritionnels dans les politiques de développement.

\section{Plan d'action}

Chaque pays doit définir des priorités en fonction de sa propre situation et spécifier des objectifs quantitatifs à atteindre dans un délai fixé. Pour atteindre ces objectifs, il conviendra de faire appel à la coopération entre fournisseurs publics et privés, aussi bien au niveau local, que régional et international. Des actions s'imposent notamment dans les domaines suivants : éducation, information et formation, création de revenus, politique des prix, amélioration de l'intégration des femmes à tous les niveaux, amélioration et surveillance de la qualité des aliments, accès à l'eau potable.

Chaque pays est responsable 
La Conférence a été marquée par un débat réaliste sur le thème nutrition et développement. Les pays en développement ont renoncé à obtenir de nouvelles promesses d'aide financière de la part des pays industrialisés. Tout le monde s'est ainsi accordé pour dire que chaque pays est le premier responsable de la sécurité alimentaire de sa population et qu'il lui incombe donc d'appliquer les principes suivants pour l'assurer : produire des aliments sains, si possible sur son propre territoire; assurer l'accès à ces produits également à la population démunie; dispenser à tous une formation en faveur d'une alimentation et d'un mode de vie sains; l'Etat doit en particulier soutenir les petits agriculteurs, la population rurale et surtout les femmes, car ils jouent tous un rôle essentiel dans la production et dans la distribution des biens alimentaires.

Le débat fut beaucoup plus animé lorsqu'il s'est agi de définir les limites d'intervention d'une aide humanitaire intransigeante dans les régions en crise, telles que la Somalie. Le devoir d'Ingérence se heurte au principe de la souveraineté des Etats. Les participants à la Conférences sont toutefois parvenus à un compromis qui prévoit que l'aide humanitaire doit être acheminée dans le respect de la souveraineté nationale, sauf dans les "situations humanitaires exceptionnelles" qui restent à "apprécier" au niveau approprié des instances compétentes des Nations Unies ${ }^{(17)}$.

\section{Position des organisations non gouvernementales}

Dans la plupart des pays, les organisations non gouvernementales (ONG) ont pris part aux réunions préparatoires et, dans certains cas, elles étaient même représentées au sein des délégations nationales à Rome. Avant et pendant la Conférence, elles ont lancé des appels en faveur de manifestations d'opposition, car elles condamnaient l'orientation générale de la Conférence. Le principal désaccord résidait dans l'appréciation du libre-échange. Nombre d'organisations non gouvernementales sont sceptiques, car elles craignent que la libéralisation du commerce mondial et que l'application indifférenciée des mesures d'ajustement structurel n'aggravent encore le problème de la faim dans les pays du Tiers Monde. La commercialisation au niveau mondial de produits agricoles bon marché pousserait les agriculteurs des pays en développement à abandonner la production et pourrait menacer, voire anéantir, l'auto-approvisionnement de ces pays. Les ONG ont critiqué les déclarations faites lors de la conférence sur la responsabilité des Etats et sur l'auto-approvisionnement, car elles ne tiennent pas compte de cette réalité.

De plus, des proclamations générales telles que "le droit à la nutrition pour tous" demeurent lettre morte tant que des bases légales contraignantes n'obligent pas les Etats à tout mettre en œuvre pour améliorer l'approvisionnement alimentaire. Les ONG regrettent aussi que l'on ne consulte pas assez la base lors de l'élaboration de programmes et de projets alimentaires. Dans une plate-forme commune présentée avant la Conférence, elles ont invité les participants à prévoir expressément dans le Plan d'action que les programmes alimentaires soient conçus de façon à ce que leurs résultats puissent être mesurés et vérifiés et que l'amélioration de la situation nutritionnelle fasse partie de tout programme de développement ${ }^{(18)}$.

Position de la Suisse

La délégation suisse était emmenée par Jean-François Giovannini, Directeur adjoint de la Direction de la coopération au développement et de l'aide humanitaire. Comprenant des délégués du gouvernement, de la science, de la protection des consommateurs, de 
l'industrie et des cantons, elle était très représentative de la société suisse. Aussi bien pendant la Conférence qu'au cours des réunions préparatoires, la Suisse a toujours voulu souligner le rôle essentiel que joue la situation politique et économique dans la lutte contre la faim et la malnutrition. La faim étant une conséquence de la pauvreté, les stratégies visant à combattre la faim doivent être menées de concert avec la lutte contre la pauvreté. Il convient donc de mettre en place une collaboration entre tous les secteurs sociaux, de la famille au gouvernement, et entre les secteurs public et privé.

La Suisse n'a promis aucune aide financière dépassant les engagements pris jusqu'ici. La délégation suisse a toutefois joué un rôle actif lors de la réunion préparatoire de Genève (du 18 au 24 août 1992) et pendant la Conférence à Rome. Elle a en effet présenté plusieurs propositions qui ont été acceptées. Celles-ci concernaient notamment les thèmes suivants :

- mettre l'accent sur le rôle de l'agriculture et sur sa polyvalence :

- Inclure dans la politique démographique le droit des parents de décider librement du nombre de leurs enfants ;

- reconnaître que l'allaitement est la meilleure alimentation qui soit pour un nourrisson ;

- promouvoir la recherche en matière de nutrition ;

- améliorer la formation et l'information sur les interdépendances en matière de nutrition ;

- souligner que les pratiques agricoles doivent être écologiquement sûres.

\section{BIBLIOGRAPHIE}

\section{Sources de la partie 1.2}

Voir les sources du chapitre 1 auxquelles s'ajoutent : epd-Entwicklungspolitik 18/19/72 (septembre), fin de la crise de l'endettement; $12 / 93$ (juin), la dette en chiffres

Alfred Gugler, Am Ende des Tunnels ? - Internationale Verschuldung und globale Finanzflüsse, dans : Finanzplatz-Informationen 1/1993 NZZ, 12/2/1993 (l'endettement de l'Europe de l'Est) NZZ, 28.4.1993 (assemblée annuelle de la BERD) Tages-Anzeiger, 26.4.1993 et 9.7.1993 (critiques à la BERD)

\section{Source de la partie 1.3}

IMF-Survey, octobre 1992 et 1993 (Annual meetings) IMF-Survey, novembre 1992 (IMF-Facilities) epd-Entwicklungspolitik 18/19/1992 (septembre) (session annuelle/prolongation des FASR) epd-Entwicklungspolitik 14/1993 (juillet) (sommet économique du G-7) Nations Unies, communiqué de presse ECOSOC/1407 (29.6.1993) (programmes d'ajustement structurel et mesures sociales)

Communauté de travail Swissaid/Action de Carême/Pain pour le Prochain/Helvetas/ Caritas, Artikel-IV'-Konsultationen des IWF mit der Schweiz, 20.-28. Oktober 1993 -Strukturreformen für die Schweiz in globaler Perspektive (Memorandum) et communiqué de presse du 26.10.1993 (Expertenteam 
des IWF berät die Schweiz) NZZ, 11.11 et 12.11.1993 (augmentation des quota du FMI) NZZ, 12.3.1993 (allocation de DTS à la Russie ?)

NZZ, 19.3 et 20/21.3.1993 (crédit du FMI au Pérou/droits de l'homme contre aide financière du FMI)

NZZ, 16.4, 21.4, 30.6 et 2.7.1993 (aide du FMI à la Russie) NZZ, 15/16.5.1993 (crédit au Kirghizistan) NZZ, 13.7.1993 (Gerster - réforme du droit de vote au FMI) NZZ, 15.7.93 (crédit du FMI au Viêtnam ?)

Tages-Anzeiger, 26.9.1992 (session annuelle/entretien avec Otto Stich) Tages-Anzeiger, 17.4 et 19.4.1993 (voyage en Asie centrale/délégation Stich) NZZ et Tages-Anzeiger, 16.9.1993 (propositions de réforme du FMI et de la Banque mondiale par les œuvres d'entraide )

\section{Source de la partie 1.4}

Banque mondiale, Rapport sur le développement 1992, Washington, 1993 epd-

Entwicklungspolitik 14/1993 Quillet) (rapport sur le développement dans le monde) NZZ, 15/16.5.1993 (crédit de l'AID au Kirghizistan) NZZ, 8.7.1993 (octroi des crédits)

NZZ, 31.3 et 2.4.1993 (l'Inde renonce à l'aide de la Banque mondiale dans son projet du Narmada) NZZ, 20.11.1993 (rapport Wapenhans)

Tages-Anzeiger et NZZ, 13.7.1993 (propositions de réforme)

Tages-Anzeiger et NZZ, 7.7.1993 (rapport de la Banque mondiale sur le développement) NZZ, 16.12.1993 (augmentation du capital de l'AID) NZZ, 20.4.1993 (nouvelles tâches pour la SFI) NZZ, 24.12.1993 (augmentation du capital de la SFI)

Inside-Out, IWF, Weltbank und die Schweiz, éditions 1992 et 1993 (publié par la Déclaration de Berne/Suisse alémanique et Greenpeace Suisse) i3w-Dokument, Die Weltbank unter Reformdruck, Berne, mars 1993 NZZ, 16.9.1993 (rapport d'activités de la SF11993)

\section{Source de la partie 1.5}

IMF-Survey, septembre et octobre 1993 (Annual Meetings)

Documentation sur la politique suisse du développement et service de presse, 23.9.93 : Die Schweizer Politik in IWF und Weltbank : eine Zwischenbilanz der Arbeitsgemeinschaft, par Richard Gerster, Bruno Gurtner, Thomas Bürge

Office fédéral des affaires économiques extérieures

NZZ, 24.9,28.9,29.9,30.9 et 1.10.1993 (session annuelle du FMI et de la Banque mondiale) TagesAnzeiger, 4.10.1993

\section{Source de la partie 1.6}

Office fédéral des affaires économiques extérieures Rapport des affaires économiques extérieures 1992

Francesco Abbate, Le Club de Paris : un groupe d'agents de recouvrement des créances ou une institution au service du développement? dans : CNUCED-Bulletin $n^{\circ} 19$ (mars/avril 1993) 


\section{Source de la partie 1.7}

Office fédéral des affaires économiques extérieures, Mesures de désendettement officiellement prises par la Suisse en faveur des pays en développement les plus pauvres et lourdement endettés, Berne, 24.5.1993, ainsi que Mesures de désendettement officiellement prises par la Suisse, Berne, 6.2.1992.

i3w-Dokument, 31.3.1993, Schweizerische Entschuldungsmassnahmen : Wo stehen wir heute? de Richard Gerster, directeur de la Communauté de travail Swissaid/Action de Carême/Pain pour le Prochain/Helvetas/Caritas, et Alfred Gugler, Bureau du désendettement

NZZ, 18.6.1993 (accord de désendettement Suisse-Nicaragua)

Gerhard Pfister, Alfred Gugler (Bureau du désendettement), Gegenwertfonds im Kontext des Entschuldung - Erfahrungen und neue Perspektiven, Rapport à l'Office fédérale des affaires économiques extérieures, Berne, février 1992

Office fédéral des affaires économiques extérieures, Mesures de désendettement officiellement prises par la Suisse, Berne, 6 février 1991 Rapport sur la politique économique extérieure, 1992

\section{Source de la partie 2.1}

Rapport du Conseil fédéral sur la politique économique extérieure 92/1+2, Berne, 20 janvier 1993 CNUCED, Politiques commerciales, ajustement structurel et réforme économique : Réformes de politique commerciale dans les pays en développement et appui international requis, Rapport du secrétariat de la CNUCED, 8.1.1993, TD/B/39(2)/3 CNUCED, Le développement durable, y compris la contribution de la CNUCED à la mise en œuvre des conclusions et recommandations de la CNUED, Rapport du secrétariat de la CNUCED, 25 août 1992, TD/B/39(1)/7

CNUCED, La mise en valeur des ressources humaines pour le commerce, Rapport du Secrétaire général, 1er février 1993, TD/B/39(2)/14

CNUCED, Rapport de la Commission permanente des produits de base sur sa 1ère session, 19-23 octobre 1992, TD/B/39(2)/4

CNUCED, Rapport du Groupe de travail spécial sur l'efficacité commerciale sur sa 1ère session, 16-20 novembre 1992, TD/B/39(2)/9

CNUCED, Aperçu général du Rapport 1992 sur les pays les moins avancés, 1993. CNUCED Bulletins, mai-juin 1993

Communiqués de presse de la CNUCED, TAD/INF/ 2248, 2253, 2258 à 2267, 2274, 2279, année 1992 ; TAD/INF2305 à 2316, 2317, 2319, 2320, 2321, 2336, 2337, 2340, 2347 à 2351, 2357 à 2373 , 2382, 2383, année 1993

Marchés tropicaux et méditerranéens, chronique hebdomadaire sur les produits tropicaux, du 27 novembre 1992 au 30 juillet 1993 ; numéro spécial Produits tropicaux, 9 juillet 1993 NZZ, 17/18.4,21.4, 19.8.1993 Tages-Anzeiger, 24.3., 8.7, 2.10.1993 Jeune Afrique, 25-31 mars 1993

Journal de Genève/Gazette de Lausanne, 4.12.1992 ; 29.4, 8.5.1993 Le Monde, 21.9, 14.3, 24.5.1993

\section{Source de la partie 2.2}

Rapport sur la politique économique extérieure 92/1+2, du 20 janvier 1993, 93.008, Berne.

Nouvelles de l'Uruguay Round (NUR), Le projet d'Acte final de l'Uruguay Round, Résumé pour la presse, NUR 55, 3 décembre 1992 
Nouvelles de l'Uruguay Round, L'Acte final de l'Uruguay Round, Résumé pour la presse, NUR 80, 14 décembre 1993

GATT, Nouvelles de l'Uruguay Round, NUR 58 Quillet 1993) à 78 (1.12.1993) Nadine Keim, Les pays en développement et l'Uruguay Round du GATT, Lausanne Communauté de travail Swissaid/ Action de carême/Pain pour le prochain/Helvetas/ Caritas, dossier de presse, novembre 1993

OXFAM, Christian Aid et CAFOD, Leelananda de Silva A curate's Egg. An assessment of the Mulilateral Trade Organisation, Oktober 1993 NZZ, 8.12.1993

Tages-Anzeiger, 22.10, 30.10, 15.12 und 16.12.1993

\section{Source de la partie 3.11}

Rapport sur la politique économique extérieure 92/1+2, du 20 janvier 1993, 93.008, Berne Rapport sur la politique extérieure de la Suisse dans les années 1990, Berne, décembre 1993

Message du Conseil Fédéral sur la Convention sur le climat, Berne, 31.3.1993

DDA, La Suisse et la Conférence de Rio sur l'environnement et le développement, Berne,

DDA, 1993

OFEFP, Dossiers de presse, diverses fiches d'informations, Berne, Office fédéral de

l'environnement, des forêts et du paysage, 1992 et 1993

Service de presse du Conseil de l'Europe, PAN-European Conférence "An Environment for Europe" (Lucerne, avril 1993), Strasbourg, 1993

Pressemitteilungen und Presserohstoff "Umwelt fur Europa", Luzern, Aprii 1993 Action 21, Nations Unies, New York, Genève, 1992

Keating, Michael, Sommet de la Terre 1992, Un programme d'action, Genève, Centre pour notre avenir à tous, avril 1993 Epd-Entwicklungspolitik 14/1993

NZZ, 1.4, 16.4, 21.4, 23.4, 27.4, 3.5, 23/24.5, 26/27.6.1993 Tages-Anzeiger, 29.4, 8.5.1993

\section{Source de la partie 4.1}

epd Entwicklungspolitik Nr 5/6,13,1993

Département fédéral des affaires étrangères. Documentation pour la presse, juin 1993 Amnesty International, Media Pack on the World Conference on Human Rights ; nouvelles hebdomadaires, Londres, mai, juin et juillet 1993.

VIGNY, Jean-Daniel, Politique des Nations Unies pour les droits de l'homme, Suisse et politique multilatérale pour les droits de l'homme, in Manuel de la politique extérieure de la Suisse. Ouvrage collectif, Berne, Haupt, 1992 Le Courrier, 11.6,17.6.1993

NZZ, 15/16.5, 11.6, 12/13.6, 15.6, 22.6, 26/27.6.1993 Tages-Anzeiger, 11.6,15.6,17.6,9.7.1993

\section{Source de la partie 4.2}

Documents de la Conférence internationale pour la protection des victimes de la guerre, Genève, du 30 août au 1 er septembre 1993.

Nations Unies, Service d'information, communiqué de presse SG/SM/1471/30.8.1993 : Allocution prononcée par le Secrétaire général des Nations Unies Tages-Anzeiger, 26.8., 2.9.1993 NZZ, 27.8., 30.8., 31.8. et 2.9.1993 DFAE, documents de presse 


\section{Source de la partie 4.3}

BIT, Conférence internationale du Travail, Compte rendu provisoire, 80ème session, Genève, 1993

BIT-Presse, Communiqués 4-16/1993

Office fédéral de l'industrie, des arts et métiers et du travail

Service de presse de l'USS, 15.7.1993 (Convention sur la prévention des accidents industriels majeurs)

Service de presse de l'USS, 20.7.1993 (OIT : l'offensive est patronale) NZZ, 24.3.1993 (Jahresbericht der Internationalen Arbeitsorganisation) NZZ, 3.6.1993 (80. Tagung IAO/Reformen)

\section{Source de la partie 4.4}

OMS Presse, Communiqués de presse, janvier et mai 1993.

UNICEF, La situation des enfants dans le Monde 1993, New York, Genève.

Vers un développement solidaire, $\mathrm{n}^{\circ}$ 119, octobre 1993

Le Courrier, 30/31.10.1993.

\section{Source de la partie 5.1}

FAO/OMS, Conférence internationale sur la nutrition, Documents de la Conférence,

Communiqués de presse, Rome, novembre et décembre 1992

Direction de la coopération au développement et de l'aide humanitaire, Berne

Secrétariat de la FAO, OFAG/DFEP, Berne

NZZ, 14.12.1992 (Clôture de la Conférence de la FAO)

Tages-Anzeiger, 19.8.1992 (Plan d'action de l'ONU Alimentation pour tous)

\section{NOTES}

1. epd-Entwicklungspolitik 18/19/92 (septembre), Preston feiert Ende der Schulden-krise, p. 9.

2. Les cinq républiques asiatiques Kazakhstan, Kirghizistan, Ouzbékistan, Tadjikistan et Turkménistan sont considérées pays en développement depuis 1993. Les chiffres se fondent sur une étude de l'endettement de l'Europe de l'Est par l'Institut autrichien de recherche économique (Wifo), présentée dans : NZZ, 12.2.1993.

3. Certains cercles politiques et du monde du développement ont lancé un référendum contre l'adhésion de la Suisse au FMI. La votation, organisée en mai 1992, a clairement avalisé l'adhésion de la Suisse. Les arguments pour et contre cette adhésion ont été présentés en détail dans les éditions 1992 et 1993 de l'Annuaire Suisse-Tiers Monde.

4. Richard Gerster, Notwendige Stimmrechtsreform im IMF - Vorschläge der Hilfswerke, dans : NZZ, 13.7.1993.

5. Le rapport d'Oxfam Africa, make or break, juge qu'en Afrique, les programmes d'adaptation structurelle sont inconciliables avec les efforts de démocratisation. En effet, la compétence économique et politique des projets est confiée à la Banque mondiale et au FMI, lesquels ne doivent pas répondre de leurs actes devant les populations concernées. Cité dans: epdEntwicklungspolitik 12/1993 Quin). 
6. Office fédéral des affaires économiques extérieures, Mesures de désendettement officiellement prises par la Suisse, Berne, 6.2.1992.

7. Richard Gerster, Innenpolitische Aspekte der Entschuldungsmassnahmen, dans : i3w-Dokument, 31.3.1993, Schweizerische Entschuldungsmassnahmen : Wo stehen wir heute ?, p.4.

8. Petite question de Gadient du 19 juin 1992 : Insolvenzrecht zur Entschuldung reformwilliger Entwicklungsländer und Antwort des Bundesrates vom 11.11.1992 (Conseil des Etats 92.1072).

9. Petite question de Gadient du 19 juin 1992 : Insolvenzrecht zur Entschuldung reformwilliger Entwicklungsländer und Antwort des Bundesrates vom 11.11.1992 (Conseil des Etats 92.1072).

10. Communiqué de presse de la CNUCED TAD/INF/2311, 23.3.1993.

11. Rapport de la Commission permanente des produits de base sur sa 1 ère session, 19- 23 octobre 1992, TD/B/39(2)/4.

12. UNCTAD, A Survey of Commodity Risk Management Instruments, Report by the UNCTAD secrétariat, UNCTAD/COM/15,15 March 1993

13. Citation tirée de la "Déclaration de la Conférence internationale pour la protection des victimes de la guerre" adoptée par la séance plénière du 1er septembre 1993.

14. Cité à partir des documents de l'OIT dans: Service de presse de l'USS du 20.7.1993, OIT: l'offensive est patronale.

15. Jean-Jacques Elmiger, OFIAMT, 80. Session der Internationalen Arbeitskonferenz-Uebersicht über die verabschiedeten Beschlüsse, in : Volkswirtschaft 9/93.

16. Nous nous référons ici à la version abrégée de ce rapport, Nutrition et développement - un défi mondial, Conférence internationale sur la nutrition, Rome, 1992.

17. "Les vivres et les fournitures médicales doivent être acheminés sans délai vers ceux qui en ont besoin dans le respect de la souveraineté nationale, hormis les situations humanitaires exceptionnelles qui restent à apprécier au niveau approprié des instances compétentes des Nations Unies“(paragraphe 9 de la Déclaration).

18. Ces exigences sont tirées de: epd-Entwicklungspolitik 22/92 (November), FAO-Konferenz: NRO fordern "Food-first"-Politik.

\section{AUTEUR}

\section{RENÉ LONGET}

Directeur romand de la Société suisse pour la protection de l'environnement, Saint-Ours 6,1205

Genève 